\title{
CLARKE:
}

CAD PARA SIMULAÇÃO DE SISTEMAS VIA SATÉLITE.

JOSÉ EMANUEL DE LIMA SOUSA BARBOSA

ORIENTADOR: PAULO HENRIQUE PORTELA DE CARVALHO.

Brasília- DF 


\section{Clarke: CAD para Simulação de Sistemas Via Satélite}

\section{José Emanuel de Lima Sousa Barbosa}

Monografia apresentada ao Departamento de Engenharia Elétrica da Universidade de Brasília, como requisito para a obtenção do grau de Engenheiro Eletricista.

Banca Examinadora:

Paulo Henrique Portela de Carvalho - Dr. (UnB)

(Orientador)

Antonio José Martins Soares - Dr. (UnB)

(Examinador Interno)

Ismar do Vale Junior - Eng. (Embratel)

(Examinador Externo)

Brasília, fevereiro de 2002 


\section{Agradecimentos,}

Agradeço aos meus pais Olívio e Maria José, aos meus irmãos, que mesmo estando longe, me deram total apoio e condições para que este trabalho fosse concluído. Agradeço também a minha namorada, Lilhan, que soube me dar todo apoio nos momentos mais tensos e difíceis deste trabalho. Agradeço também ao Sr. Eng. Ismar, gerente técnico de redes de transporte que tornou possível uma parte do desenvolvimento do programa. Em especial ao Professor Paulo Carvalho, cuja orientação foi paciente e dedicada. A Deus que me conduziu e cuidou da minha saúde, para que fossem superadas as dificuldades durante a minha caminhada. 


\section{Sumário}

Capítulo

Página

AGRADECIMENTOS

iii

SUMÁRIO

iv

ÍNDICE DE FIGURAS

vi

ÍNDICE DE TABELAS

viii

RESUMO

ix

ABSTRACT

$\mathrm{x}$

1.0 INTRODUÇÃO 1

1.1 OBJETIVOS 4

1.1.1 Objetivo Geral 4

1.1.2 Objetivos Específicos 4

2.0 FUNDAMENTOS DE SISTEMAS DE SATÉLITE 5

2.1 CARACTERÍSTICAS BÁSICAS DOS SATÉLITES 5

2.2 ELEMENTOS DO SISTEMA

2.2.1 Segmento Espacial $\quad 8$

2.2.2 Segmento Terrestre 9

2.3 ALOCAÇÃO DE ESPECTRO DE FREQÜÊNCIAS 10

2.3.1 Regiões e Alocação de Espectro feita pelo ITU 11

2.4 VANTAGENS DA COMUNICAÇÃO POR SATÉLITES 13

2.4.1 Comunicação Móvel Independente da localização 14

2.4.2 Cobertura de Vastas Áreas: Países, Continentes ou Globo 14

2.4.3 Grande Largura de Banda Disponível o Tempo Todo 14

2.4.4 Independente da Infra Estrutura Terrestre 15

2.4.5 Rápida Instalação de Redes Terrestres 15

2.4.6 Baixo Custo por Local Adicionado $\quad 15$

2.4.7 Características Uniformes do Serviço 16

2.4.8 Serviço Total a Partir de Único Servidor $\quad 16$

3.0 CÁLCULO DE ENLACE

3.1 GEOMETRIA SATÉLITE - ESTAÇÃO TERRENA 19

3.1.1 Determinação dos Ângulos de Apontamento 19

3.1.1.1 Cálculo da Elevação 20

3.1.1.2 Cálculo do Azimute $\quad 21$ 
3.2 TEORIA BÁSICA DE TRANSMISSÃO 23

3.3 TEMPERATURA DE RUÍDO E FIGURA DE RUÍDO DO SISTEMA 26

3.4 ENLACE DE SUBIDA 30

3.5 ENLACE DE DESCIDA 32

3.6 PROPAGAÇÃO E SUAS INFLUÊNCIAS NO ENLACE 34

3.6.1 Atenuação por Gases Atmosféricos $\quad 35$

3.6.2 Atenuação por Chuva 38

3.6.3 Atenuação por Nuvens 43

3.6.4 Atenuação por Cintilação Atmosférica e Múltiplo Percurso $\quad 44$

3.6.5 Atenuação Atmosférica Total 48

3.7 POLARIZAÇÃO CRUZADA 48

3.8 ANÁLISE DA INTERFERÊNCIA 51

4.0 PROGRAMA CLARKE $\quad \mathbf{5 4}$

4.1 ENTRADA DE DADOS

4.2 FERRAMENTAS DE ANÁLISE $\quad 57$

4.3 PROJETO DE SISTEMAS VIA SATÉLITE $\quad 59$

$\begin{array}{ll}5.0 \text { CONCLUSÃO } & 68\end{array}$

6.0 REFERÊNCIAS BIBLIOGRÁFICAS 
Figura

Página

1: As três órbitas mais populares nos satélites de comunicação.

2: Segmento terrestre de uma rede de comunicação por satélite provendo serviços interativos two-way para uma grande variedade de lugares.

3: Espectro de rádio freqüência identificando as faixas de freqüências mais utilizadas e as suas designações.

4: Regiões definidas pelo ITU

5: Representação geométrica do Azimute e da Elevação.

6: Geometria utilizada para determinação da elevação da antena presente Ana estação terrena.

7: Trigonometria do calculo do azimute, onde $E$ é a estação, $S$ o ponto subsatélite e $\mathbf{G}$ o ponto de interseção da longitude da estação com a linha do equador.

8: Densidade de fluxo produzida por uma fonte de radiação isotrópica.

9: Resultado da análise da perda para o espaço livre para uma distancia entre a estaco terrena e o satélite de $37.749,26 \mathrm{~km}$.

10: Modelo do sistema linear ruidoso ideal.

11: Esquema simplificado do receptor de uma estação terrena. 28

12: Enlace de subida básico. 30

13: Enlace básico de descida.

14: Modelo equivalente do ruído no enlace. 33

15: Atenuação existente num enlace de satélite devida aos gases atmosféricos.

16: : Atenuação que o enlace sofre devido à chuva.

17: Representação esquemática do enlace Terra-Satélite dando os parâmetros que serão empregues no calculo da atenuação por chuva.

18: Atenuação por nuvens e nevoeiro.

19: O múltiplo-percurso provoca o enriquecimento ou o cancelamento do sinal direto quando recebido por uma antena tal como mostrado pelos diagramas dos vetores.

20: Atenuação por cintilação ionosférica.

21: Atenuação atmosférica total.

22: Explicação simplificada da despolarização por chuva. Uma onda eletromagnética com vetor campo elétrico Ei atinge uma gota de chuva. 
Ele é decomposto em dois componentes; um vertical EiV e um horizontal EiH. O componente horizontal sofre uma atenuação maior do que o componente vertical uma vez que atravessa mais água. Portanto quando são recombinados os componentes vertical, ErV, e horizontal, ErH, que chegam ao receptor, notamos que o campo recebido, Er, teve uma rotação na polarização ao longo do eixo vertical por um ângulo.$\theta$.

23: Efeito da polarização cruzada em função da freqüência.

24: Tela inicial.

25: Campo de editoração dos dados que se encontram no banco de dados. No caso os dados que serão editados serão os dados de satélite.

26: Visualização dos limites de visibilidade do satélite e informação dos ângulos de elevação e azimute das antenas das estações terrenas, utilizando a informação fornecida.

27: Menu Analysis do programa. Ele permite acessar as diferentes calculadoras existentes no programa.

28: Aparência de um das calculadoras que permitem a análise individual de cada um dos fatores que afetam o enlace.

29: Tipos de saída que temos depois de definidos os parâmetros de análise e as faixas de variação.

30: Saída para o caso de mais de termos mais de um evento para se fazer à análise e assim escolher o melhor caso.

31: Caixa de dialogo informando uma situação de calculo que foi violada.

32: Curva característica do transponder.

33: Entrada e/ou escolha de informações sobre as estações terrenas.

34: Escolha do satélite que será utilizado.

35: Localização das estações e do satélite. Verificação de visibilidade das estações. Determinação dos ângulos de elevação e azimute.

36: Curva de back-off e escolha do ponto ideal.

37: Escolha dos pontos de operação do transponder escolhido.

38: Escolha das porcentagens em que o fenômeno ira exceder um valor e calculo automático da disponibilidade dos enlaces de subida e descida.

39: Curvas de BER fornecidas pelo programa para auxiliar na escolha da razão $\mathrm{C} / \mathrm{N}$ total do sistema.

40: Etapa final do projeto em que é apresentado o relatório detalhado do que ocorreu durante o processo. 
Índice de Tabelas

Tabela

Página

1 - Conversão das unidades típicas de potência.

2 - Equações para calcular o azimute a partir do triangulo esférico de angulo $\alpha$ usando a figura 7 como referência.

3 - Característica do transponder do satélite. 


\section{Resumo}

Barbosa, José Emanuel de Lima Sousa, Clarke: CAD para Simulação de Sistemas Via Satélite. Universidade de Brasília. Professor Orientador: Paulo Carvalho. Fevereiro de 2003

A pesquisa centraliza seus estudos num dos sistemas de comunicação amplamente utilizado e difundido pelo mundo: o sistema de comunicação por satélites. No estudo realizado procurou-se compilar e aplicar as recomendações e normas que regem esse setor das comunicações para que fosse possível desenvolver uma ferramenta de projeto. As informações aqui apresentadas foram analisadas com base nas publicações dos órgãos que monitoram e controlam este segmento emitem e na bibliografia de especialistas que atuam na área. 


\begin{abstract}
The research centers its studies in one of the systems of communication widely used and spread out by the world: the system of communication for satellites. . In the carried through study it was looked to compile and to apply the recommendations and norms that conduct this sector of the communications so that it was possible to develop a project tool. The information presented here had been analyzed on the basis of publications of the agencies that monitor and control this segment emit and in the bibliography of specialists who act in the area.
\end{abstract}




\section{0 - INTRODUÇÃO.}

Com o desenvolvimento da ciência, da tecnologia e da globalização, o mundo foi se tornando cada vez menor, organizações, empresas e indivíduos começaram a deslocar-se para regiões cada vez mais remotas alimentando assim a necessidade de se estabelecerem comunicações e de se aumentar troca de informações. Com isso começaram a ser estabelecidas conexões e a serem ligadas regiões que se encontravam muito distantes umas das outras e as quais não se tinha nenhum acesso. No entanto, os meios que existiam e que possibilitavam a comunicação e a troca de informação entre esses pontos e regiões eram caros, ineficientes e necessitavam uma grande as infra-estruturas para que pudessem ser implantados, tornando assim esse processo de expansão e de comunicação muitas vezes inviável.

Entretanto, com o surgimento da era espacial, e como conseqüência disso dos sistemas de satélite, uma nova possibilidade surgiu, passou a ser possível ligar estes pontos antes remotos e inalcançáveis com o mínimo de custo de instalação e implantação de redes e sistemas, permitindo assim que essas organizações e empresas pudessem partilhar da informação que dispunham num ponto remoto e permitindo também ao homem que se comunicasse, localizasse e transmitisse informações a partir de qualquer parte do globo independentemente de fronteira e de situações políticas.

Pode-se dizer que foi a partir de 1945, ano em que Arthur C. Clarke demonstrou que era possível com apenas três satélites com arcos orbitais de $120^{\circ}$ seria possível cobrir o globo por completo, que o homem começou a sonhar com um mundo onde as distancia não seriam mais um problema para um sistema de transmissão de informações globalizado e sem fronteiras.

Com o avanço tecnológico e com o advento da Segunda Guerra Mundial e logo em seguida a Guerra Fria, onde foi possível construir com sucesso foguetes lançadores que em 1957 permitiram o lançamento do Sputnik-1, primeiro satélite artificial da Terra, o qual pela primeira vez transmitiu sinais vindos do espaço que foram detectados por uma estação terrena.

Só a partir dos anos 60 é que se começaram a verificar progressos para as comunicações via satélite quando a NASA lançou em 1960 o ECHO-1, que foi o primeiro satélite de comunicação e que consistia de um refletor passivo que recebia um sinal de 2,5 $\mathrm{GHz}$ de um ponto da Terra e o retransmitia por reflexão a outro ponto. Ainda neste mesmo ano foi lançado o Courier-1B o qual foi o primeiro satélite de comunicação a utilizar um amplificador. Já em 1962 a AT\&T enviou o TELSTAR-1 que era um satélite de órbita 
inclinada e se encontrava a $5632 \mathrm{~km}$ de altitude, e a NASA enviou o RELAY-1 que se encontrava a $1000 \mathrm{~km}$ de altitude, os quais foram os primeiros a empregar as técnicas de diferentes freqüências para a subida e para a descida.

Em 1965 foi lançado o INTELSAT-1, primeiro satélite geoestacionário de comunicações para uso comercial que tinha uma capacidade de 240 canais de telefonia e 1 de TV, e que em 1965 foi usado para assumir o serviço de um cabo submarino que estava em manutenção. Essa pratica se tornou rotineira e marcou a importância dos sistemas via satélite. A partir desse momento a tecnologia evoluiu rapidamente e com isso houve um aumento de capacidade dos satélites.

A partir de 1974 o Brasil passou a fazer parte do mundo das telecomunicações via satélite alugando transponders ao INTELSAT e construindo 4 estações terrenas. No entanto só foi em 1985 que houve o lançamento do primeiro satélite doméstico brasileiro denominado de BRASILSAT série A. Já em 1994, o Brasil lançou o BRASILSAT-B que é composto por 28 transponders em banda $\mathrm{C}(6 / 4 \mathrm{GHz})$ e um transponder em banda $\mathrm{X}(8 / 7$ $\mathrm{GHz}$ ) para aplicações militares.

Hoje no mundo existem mais de 200 satélites geoestacionários a $36000 \mathrm{~km}$ de altitude e na mesma velocidade de rotação da Terra. Porém eles sofreram um grande aumento de tamanho, de vida útil e de capacidade e ganharam sistemas de comunicação mais eficientes e seguros.

Devido ao grande congestionamento que a órbita geoestacionária vem sofrendo com o constante aumento do numero de satélites que vem sendo adicionados a sua órbita os órgãos responsáveis pelo controle começaram a elaborar normas mais restritivas e que consideram cada vez mais os fatores que afetam a boa comunicação entre a Terra e os seus satélites.

Portanto, neste trabalho irão ser abordados os conceitos básicos que regem esse segmento de comunicações, a mostrar o estudo que é necessário fazer para que se possa planejar com sucesso um enlace de comunicações por satélite. Finalmente, irá ser desenvolvida uma ferramenta de simulação CAD, que considerando as normas e recomendações editadas pela União Internacional de Telecomunicações, que é uma organização internacional reguladora das comunicações existentes no mundo e das comunicações por satélite, nos permite planejar um enlace de comunicação entre uma estação terrena e um satélite.

Assim sendo, dividiu-se o trabalho em três capítulos. No capítulo 1 foi feita uma breve introdução aos fundamentos dos sistemas de comunicações via satélites apresentando-se as suas características, as suas configurações básicas, os elementos que 
compõem o sistema, as vantagens que o sistema apresenta, a alocação de freqüências que é feita para ele e a definição de regiões que teve que ser feita a fim de se permitir um aumento de capacidade do sistema e uma redução de interferência. Já no capítulo 2 , mostram-se os estudo que é necessário fazer, para que se possa dimensionar e projetar um enlace de satélite, dos fatores que se deve levar em consideração e que afetam o enlace, como eles são tratados para que no final se tenha um sinal de qualidade. Nele é vista a geometria que é utilizada, a teoria básica de transmissão, os efeitos das atenuações sobre essa teoria e a forma de se determinar à temperatura e figura de ruído que existem no sistema e permitem a extração de parâmetros necessários ao projeto do sistema de comunicação por satélite. No capítulo 3 apresentaremos a ferramenta computacional desenvolvida que implementa as expressões desenvolvidas no capítulo 2. 


\section{1 - OBJETIVOS}

\subsection{1 - OBJETIVO GERAL.}

O trabalho tem por objetivo geral o desenvolvimento de um programa computacional que auxilia o planejamento e otimização de um enlace de microondas via satélite.

\subsection{2 - OBJETIVOS ESPECÍFICOS.}

1. Montar um banco de dados das estações terrenas, das estações de satélites e das condições ambientais globais;

2. Com base em recomendações e normas internacionais de comunicações via satélite desenvolver calculadoras que nos permitam visualizar o que ocorre com a variação dos parâmetros de cada fator que compõe o enlace;

3. Unificar o banco de dados e as calculadoras e os aplicar em projetos de planejamento e otimização de enlaces de comunicação por satélite;

4. Gerar relatórios que informem como se comporta o sinal e os diferentes fatores ao longo do processo de propagação. 
2.0 - Fundamentos de Sistemas de Satélite.

Nos últimos anos a comunicação por satélite vem sendo inserida em nossas vidas e feito parte do nosso dia a dia sem que se tenha dado conta de tal fato ou ocorrência. Mesmo com o aparecimento da era de banda larga e das comunicações de alta velocidade, que vêm sendo proporcionadas pelo desenvolvimento dos sistemas de comunicações ópticas e pelos sistemas digitais de ultima geração, o sistema de comunicação por satélite continua servindo de base para muitas das necessidades de comunicação de diversos países, de várias corporações e organizações que por causa do efeito da globalização estão se difundindo pelo mundo afora e como conseqüência disso precisam manter contacto com suas filiais, fornecedoras e acionistas que por vezes se encontram em locais remotos, onde não existe uma infra-estrutura que permita a comunicação e transmissão de informações.

É principalmente em casos de emergência e de catástrofes que a comunicação por satélites tem se revelado como sendo um instrumento de muita importância uma vez que os demais sistemas devido ao tipo de estrutura que possuem, acabam não cobrindo a região de interesse ou então tendo suas infra-estruturas danificadas pelo evento tornando-se assim falhos, ineficientes e inúteis.

Neste capítulo abordaremos os sistemas de comunicação por satélites apresentando as suas características básicas onde serão abordados: a definição de satélites, os diferentes tipos de satélites artificiais que existem, como são classificados segundo a órbita que ocupam e as subclassificações que eles recebem dentro dessas órbitas. Logo em seguida serão abordados os elementos que compõem os sistemas e em que segmento eles se encontra cada um dos elementos que constituem um sistema de comunicação por satélite. Feito isso falaremos rapidamente da alocação de freqüências que os órgãos reguladores internacionais e nacionais estabelecem para esse setor de comunicações, para finalmente terminarmos abordando as vantagens que este sistema apresenta.

\section{1 - CARACTERÍSTICAS BÁSICAS DOS SATÉLITES.}

Um satélite é um corpo celeste que gravita em torno de outro, sendo que este outro é chamado de corpo principal.[12]

Existem vários tipos de satélites, dentre eles os mais conhecidos são:

- Satélite natural: todo satélite que não foi criado pelo homem;

- Satélite artificial: veículo colocado em órbita em volta do planeta ou astro; 
- Satélite de comunicações: satélite artificial para comunicação entre vários pontos da Terra. Esse satélite pode transmitir desde uma conversa telefônica a dados de Internet. Ele é definido como sendo uma estação repetidora de microondas que permite ligar por meio de enlaces de radio freqüência dois pontos quaisquer na superfície da Terra e que permite a troca de informações entre dois ou mais usuários empregando-se para tal as mais variadas técnicas de comunicação. Este tipo de satélite possui uma carga útil composta basicamente por transponders que é o termo usado para identificar um canal de transmissão de microondas completo.[1];

- Satélite geoestacionário: satélite que completa sua translação em 24 horas, ficando assim parado em relação a um ponto da Terra;

- Satélite meteorológico: obtém informações meteorológicas, como posição de nuvens, massas de ar, etc.

Como eles são corpos celestes que estão posicionados a diferentes altitudes, em relação à superfície da Terra percorrendo as mais variadas órbitas então podem segundo estas duas características ser classificados, em:

- Satélites de órbita geoestacionária (GEO). Foram os primeiros tipos de satélites de comunicação a orbitarem a Terra. O que os diferencia dos demais tipos de satélites existentes é a órbita que eles descrevem, a qual se encontra no plano do equador, a uma altitude, em relação à superfície da Terra, superior a $36.000 \mathrm{~km}$ (figura 1 b) e cujo período de rotação é de 24 horas período este que é o mesmo que o planeta Terra apresenta em torno do seu eixo. Por esse motivo ele se encontra parado em relação à superfície terrestre e quando projetado sobre esta fica representado apenas por um ponto fixo, ponto este que é definido como ponto subsatélite. Esta classe de satélite pode apresentar uma pequena oscilação em sua órbita, que não pode exceder os $0,1^{\circ}$ uma vez que acima desse valor irá existir a necessidade de se fazer o rastreamento do satélite pela antena. Por causa da altitude em que se encontram, é um sistema em que com apenas três satélites, separados por um ângulo de $120^{\circ}$, pode-se ter uma cobertura quase global do planeta com exceção de uma pequena região ao redor dos pólos, região esta que está acima dos paralelos 80. Esta região não é iluminada pelo feixe do satélite porque como a Terra apresenta uma forma oblata, achatada nos pólos e esticada no equador, então os feixes de ondas eletromagnéticas não conseguem chegar à superfície. Por causa da altitude em que se encontram 
eles apresentam severas restrições no planejamento do enlace que estão relacionadas à potência do sinal recebido que é bastante atenuado e têm que conviver com um atraso de propagação de cerca de 1/4 de segundo para cada salto ou ligação entre duas estações terrenas.

- Satélites de órbita não geoestacionária (não-GEO). São aqueles satélites que se encontram a altitudes de órbitas inferiores a da órbita dos satélites geoestacionários a da órbita dos satélites geoestacionários possuindo assim um período de revolução menor do que o período da Terra. Como conseqüência dessa diminuição do período de revolução estes têm uma velocidade maior o que faz com que quando projetados sobre o plano terrestre desenhem um tipo de trajetória característica que varia com a altitude a que o mesmo se encontra e com o tipo de órbita que o satélite descreve. Por serem mais rápidos e por não apresentarem uma posição fixa então para se garantir uma cobertura constante de uma determinada região são necessários mais de três satélites por órbita. Para garantir uma cobertura global é preciso utilizar mais de uma órbita. Por se apresentarem mais próximos da superfície do planeta, a potência de radiação necessária para o fechamento do enlace é bem menor. $\mathrm{O}$ atraso que existe nos satélites nãogeoestacionários é considerado desprezível e pode em alguns casos ser desconsiderado.

Por sua vez os satélites não-geoestacionários são classificados nas seguintes categorias:

- Satélites de órbita baixa (LEO): são aqueles que se encontram a altitudes que vão dos 500 aos $1000 \mathrm{~km}$ de altitude e apresentam um período que varia de 1,6 a 1,8 horas (figura 1 a);

- Satélites de órbita média (MEO): são aqueles cuja altitude está por volta dos $10000 \mathrm{~km}$ e apresentam um período de aproximadamente 6 horas (figura 1 a);

- Molniya: são os satélites que apresentam uma órbita elíptica e inclinada em relação ao plano do equador. Este tipo de órbita é característica dos satélites russos (figura $1 \mathrm{a}$ );

- Polares: são aqueles cujas altitudes variam entre os 700 e $900 \mathrm{~km}$ e sua característica básica está na órbita que é perpendicular ao plano do equador 
e que passa sobre os pólos vindo daí a designação de órbita polar (figura 1 c).
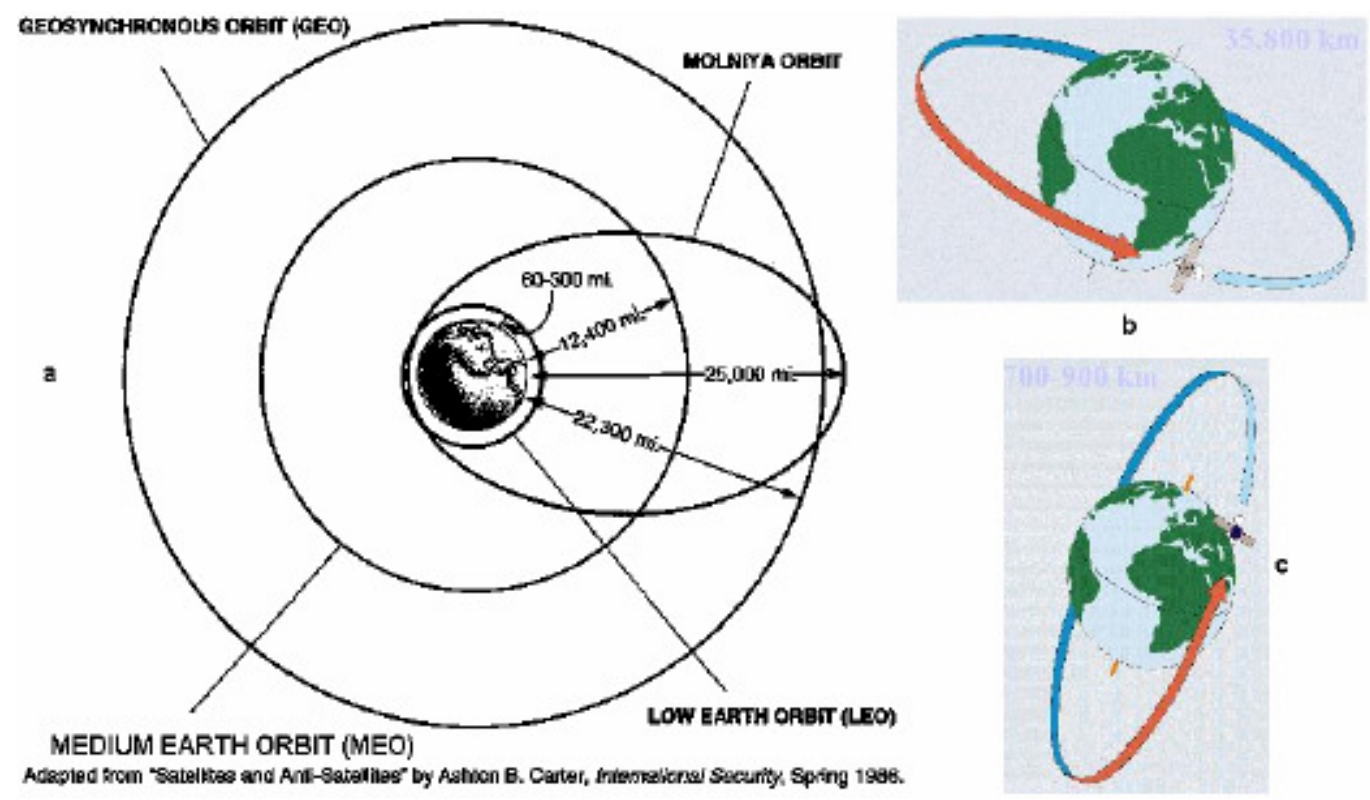

Figura 1: As três órbitas mais populares nos satélites de comunicação.

Entre os 2000 e $8000 \mathrm{~km}$, tem-se uma faixa de altitude que não é utilizada por nenhum satélite o que é devido à existência do cinturão de radiação de Van Allen que é uma região de bastante interferência eletromagnética e conseqüentemente não amigável para componentes eletrônicos.

\section{2 - ELEMENTOS DO SISTEMA.}

\subsection{1 - SEGMENTO ESPACIAL.}

É no segmento espacial onde se definem as características do satélite, onde estão envolvidos o planejamento, projeto e o posicionamento em órbita. Nele são definidos os parâmetros dos transponders, os níveis de potência radiados, a razão entre o ganho e a temperatura de ruído, a parte eletrônica dos componentes de comunicação, os circuitos de redundância e outros parâmetros que serão necessários para o bom funcionamento do satélite a quando da sua colocação em órbita. Este segmento é composto por várias fases e etapas que só irão culminar com o posicionamento do satélite em órbita e com a entrada em operação.

Dentre as diferentes fases existentes podemos salientar: a fase de lançamento, que é a etapa em que ocorre a contratação de uma empresa que será responsável pela construção 
do veículo de lançamento e a contratação de uma agência de lançamento responsável pelo lançamento e posicionamento do satélite na posição a qual ele se destina.

Depois de posto em órbita passa-se para a fase em que o operador do satélite assume o controle e monitoramento do mesmo até que o tempo de vida útil seja alcançado. O controle e monitoramento do satélite é um processo que é realizado constantemente de forma a garantir não só o apontamento contínuo das antenas da estação, como também o funcionamento contínuo do enlace, e a posição do satélite em sua órbita. Ele é feito pela estação de rastreamento, telemetria e comando (TT\&C).

Este segmento é composto também pelo centro de controle do satélite (SCC) que contém os equipamentos de operação e de processamento de dados que serão usados pelos operadores do sistema. Geralmente a SCC se encontra localizada nas instalações do operador de satélite podendo também estar localizada na estação de TT\&C

\subsection{2 - SEGMENTO TERRESTRE.}

O segmento terrestre é o segmento que permite o acesso ao satélite a partir de estações terrenas, temo utilizado internacionalmente que inclui as estações de comunicação com o satélite, que se encontram localizadas na superfície da Terra e que oferecem uma grande variedade de serviços. Na figura 2 podemos ver um exemplo de um segmento terrestre típico onde está representado apenas um satélite.

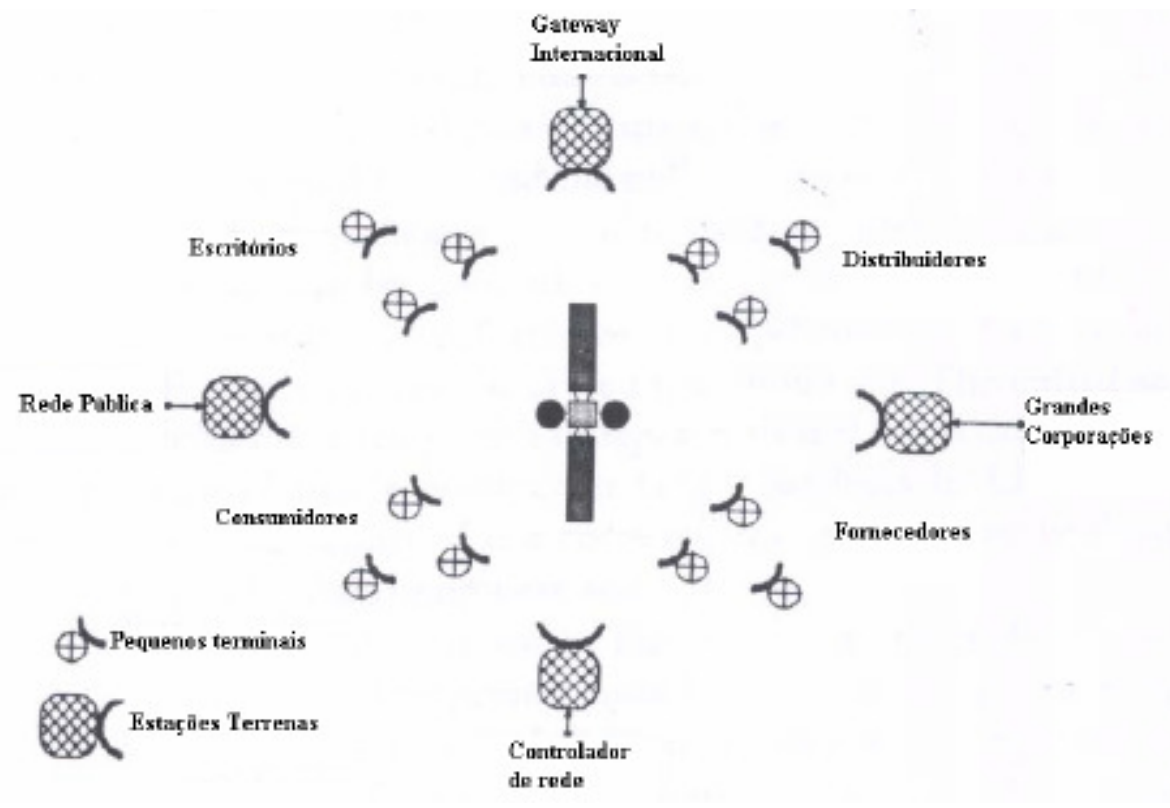

Figura 2: Segmento terrestre de uma rede de comunicação por satélite provendo serviços interativos two-way para uma grande variedade de lugares. Fonte: Bruce R. Elbert,. 
Os serviços oferecidos pelas estações terrenas são classificados em:

- Serviço fixo por satélite (FSS): que é o serviço prestado entre satélites e estações fixas na Terra (estações terrenas);

- Serviço de radiodifusão por satélite (BSS): que é o serviço de difusão de rádio e televisão diretos do satélite aos usuários;

- Serviço móvel por satélite (MSS): que é o serviço que existe entre o satélite e estações moveis.

Com a evolução da tecnologia e o aparecimento das comunicações digitais, este segmento tem passado por: uma diminuição do tamanho das estações, um aumento de capacidade das mesmas que têm proporcionado o aparecimento de novos serviços tais como o serviço direto de radio difusão em massa (DBS) ou serviço direto para casa (DTH), que são ramificações dos serviços do tipo BSS.

\section{3 - ALOCAÇÃO DO ESPECTRO DE FREQÜÊNCIAS.}

O espectro de freqüência é toda a faixa de freqüências que vai do zero até o infinito. Esta grande faixa de freqüências está por sua vez subdividida em outras faixas de freqüência menores e que possuem diversas aplicações.

Para os sistemas de comunicações a faixa de freqüências que é utilizada e que permite uma geração e transmissão eficiente do sinal de radio é denominada de faixa de ondas de rádio (Figura 3). Essa faixa de freqüências vai de $3 \mathrm{kHz}$ a $3000 \mathrm{GHz}$ e por sua vez está subdividida em pequenas subfaixas de freqüência denominadas de banda de freqüência.

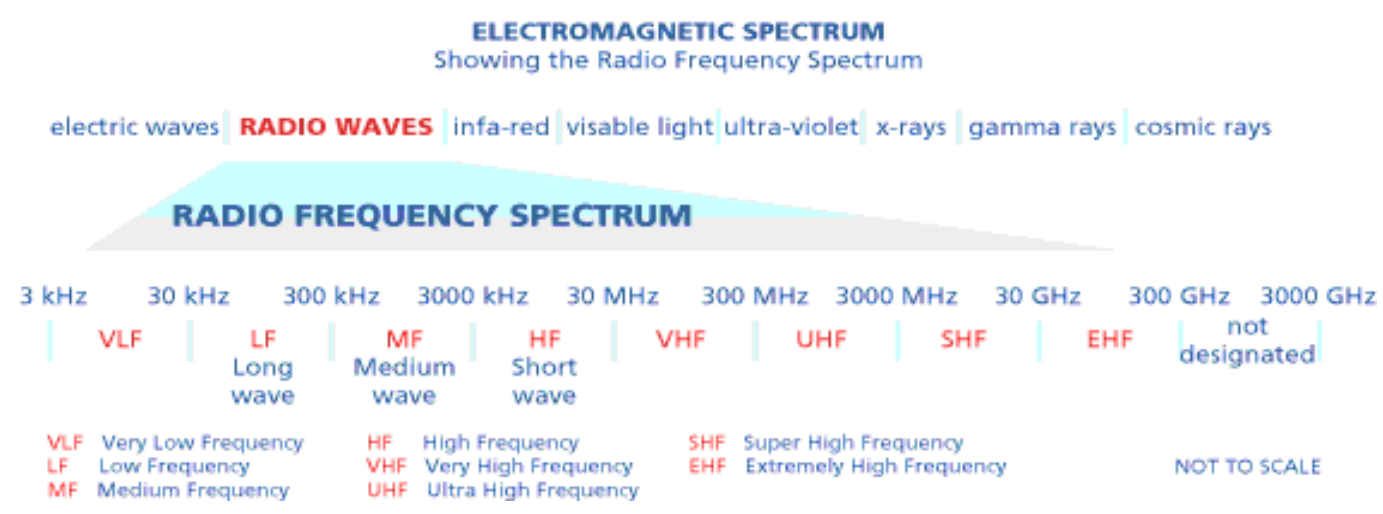

Figura 3: Espectro de rádio freqüência identificando as faixas de freqüências mais utilizadas e as suas designações. Fonte: http://www.radio.gov.uk/publication/ra_info/ra354/ra354.gif

A subdivisão do espectro de rádio freqüência em bandas de freqüência permite que cada sinal de rádio seja centrado em uma dada freqüência chamada de portadora, a qual 
transporta o sinal modulado. A modulação do sinal faz com que o mesmo apresente uma determinada largura de banda que quando não é bem filtrada provoca a interferência em outras portadoras e outros sinais modulados que se encontram dentro da mesma faixa de freqüências ou numa banda de freqüência próxima.

As faixas de freqüência que são interessantes para a comunicação por satélite estão acima dos $100 \mathrm{MHz}$. É nela onde encontramos as bandas VHF, UHF e SHF. A faixa SHF por sua vez foi subdividida em sub-bandas com as seguintes designações: L, S, C, X, Ku e $\mathrm{Ka}$, sendo que as que são mais utilizadas são as faixas de freqüência que se encontram abaixo da banda $\mathrm{Ku}$, por causa do preço relativamente barato dos equipamentos, e pelas características de propagação favoráveis que existem nestas freqüências.

Para um sistema de comunicações via satélite a melhor faixa de freqüência se encontra entre $1 \mathrm{GHz}$ e $4 \mathrm{GHz}$, faixa essa denominada de janela de ruído para transmissões em microondas uma vez que nessa faixa o ruído tem muito pouco efeito sobre os sinais que são transmitidos. No entanto, também são utilizadas faixas de freqüência superiores, onde em algumas delas se verifica a existência de uma grande absorção do sinal pela atmosfera, freqüência de $12 \mathrm{GHz}$, chegando a existir pontos de absorção quase total, freqüências de 22 e $60 \mathrm{GHz}$. Essa absorção é provocada pela freqüência de ressonância das moléculas de oxigênio e vapor de água.

\subsection{1 - REGIÕES E ALOCAÇÃO DE ESPECTRO FEITA PELO ITU.}

Como o espectro de rádio freqüência é muito limitado e existe um numero crescente de aplicações que fazem uso do mesmo, sendo que cada uma delas procura ocupar a faixa de freqüência e a banda que mais as convém, então houve a necessidade de se criar um órgão que fosse responsável pela regulamentação, alocação e coordenação dos diversos serviços existentes pelas diferentes faixas de freqüência que compõem o espectro de radio freqüência. O órgão que foi criado e que ficou responsável por essa alocação de freqüências é a União Internacional de Telecomunicações (ITU), que é uma agencia das Nações Unidas especializada em telecomunicações. O ITU é composto por membros que são os governos de todos os países que são os responsáveis pela atribuição de freqüências de rádio para bandas alocadas aos usuários domésticos.

Tendo em vista que existia um grande numero de aplicações funcionando na mesma freqüência, a necessidade de se aumentar à capacidade dos sistemas, dado que o numero de usuários estava cada vez maior, que este aumento não só de capacidade como 
de uso de freqüência estava provocando um aumento de interferência entre os sistemas do mesmo tipo então para minimizar essa interferência entre sistemas o ITU dividiu o globo em três regiões, permitindo assim que houvesse um reuso de freqüências, um aumento do tráfico de informação, e que o sistema que estivesse funcionando em uma dada região não acabasse interferindo no que se encontrava em outra.

A banda típica para satélites está por sua vez dividida em duas partes separadas. Uma para os enlaces terra-espaço (enlace de subida ou uplink) e outra para o enlace espaço-terra (enlace de descida ou downlink). As bandas de enlace de subida são relativamente mais altas que as de enlace de descida porque é mais fácil gerar a potência necessária para a comunicação na estação terrena do que no satélite.

Como resultado da alocação e reutilização de espectro, as regiões que o ITU definiu e que se encontram representadas na figura 4, foram:

- Região I : Composta pela Europa e África;

- Região II : Composta pelas Américas do Norte e Sul;

- Região III : Composta pela Ásia e Pacífico.

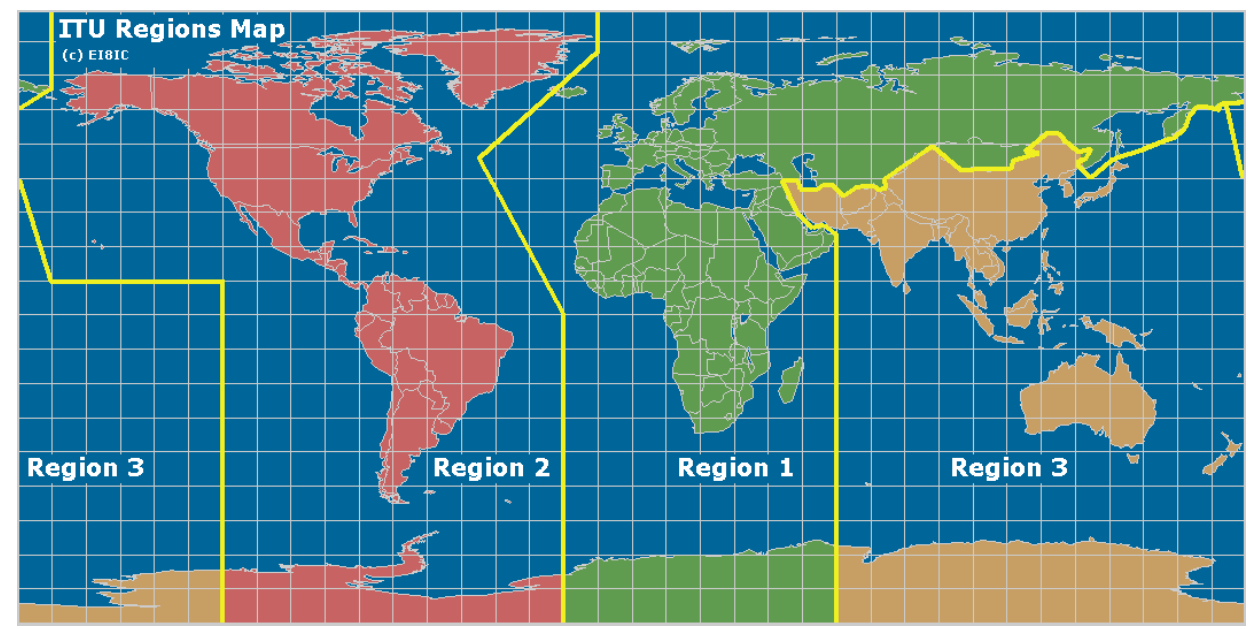

Figura 4: Regiões definidas pelo ITU. Fonte: www.itu.int.

Das bandas de freqüência disponíveis para satélite as mais exploradas são as bandas $\mathrm{C}, \mathrm{X}$ e $\mathrm{Ku}$. Dentre elas a mais popular é a banda $\mathrm{C}$ também designada de $6 / 4 \mathrm{GHz}$, que representa a identificação das freqüências centrais de enlace de subida $(5,925$ a 6,425$)$ e enlace de descida $(3,700$ a 4,200) que é utilizada tanto por serviços de telefonia quanto pro transmissões de TV a cabo e sistemas DTH. Isto ocorre porque ela é bem mais imune a ruídos naturais e a atenuação por chuva. Ela garante uma boa qualidade na comunicação com um nível de sinal baixo. Outro fator que atualmente joga a favor da banda $\mathrm{C}$ é a disponibilidade e tecnologia dos equipamentos que fez com que os seus preços sejam baixos e que sua qualidade seja muito boa. 
A banda $\mathrm{X}$ é de uso exclusivo dos militares e do governo se encontra numa faixa de 7,90 a 8,40 GHz no enlace de subida e 7,25 a 7,75 $\mathrm{GHz}$ no enlace de descida. Os terminais terrestres para este tipo de aplicações e banda são projetados para operar em qualquer situação.

Já a banda $\mathrm{Ku}$ é mais utilizada para enlaces de alta capacidade e atualmente está sendo utilizada também para a distribuição de sinais de TV. Ela também funciona como uma segunda opção para sistemas DTH e VSATs. A faixa de freqüências da banda $\mathrm{Ku}$ varia de região para região e a mesma foi subdividida em três segmentos. O primeiro segmento se encontra nas faixas de 14,00 a $15,50 \mathrm{GHz}$ para o enlace de subida e 10,95 a $11,70 \mathrm{GHz}$ para o enlace de descida e é conhecido como $14 / 11 \mathrm{GHz}$ e é utilizado pelos serviços FSS.

O segundo segmento conhecido por $14 / 12 \mathrm{GHz}$ cujas faixas são 14,00 a 14,50 GHz no enlace de subida e 11,70 a 12,20 GHz no enlace de descida é limitado para a região II e pode ser usado apenas para serviços de comunicação doméstica.

O terceiro segmento, designado de $18 / 12 \mathrm{GHz}$ é apenas para os serviços BSS e tem como objetivo permitir a transmissão de sinais de TV e outras transmissões DTH.

As vantagens do 14/12 e do 18/12 GHz esta na facilidade de localização da estação e de se terem níveis de potência altos no enlace de descida, para além de se terem antenas menores.

\section{4 - VANTAGENS DA COMUNICAÇÃO POR SATÉLITES.}

Os satélites são usados extensivamente por uma ampla variedade de aplicações de comunicações, e por um numero muito grande de paises, organizações e empresas por causa das vantagens que eles possuem em relação aos demais sistemas. As que serão abordadas nesse ponto estão baseadas na física básica do sistema, e na capacidade de enxergar uma vasta área geográfica de uma só vez.

Do ponto de vista desses benefícios, a comunicação por satélite pode se apresentar como sendo um poderoso meio, quando o operador olha para a sua robustez. Para alguns tipos de transmissões e de negócios ele é de extrema importância e geralmente é visto como uma opção estratégica de negócios, pois permite a implantação do empreendimento, em qualquer região que esteja dentro da área de cobertura independentemente de existir infra-estrutura ou não, a um custo relativamente baixo. 


\subsection{1 - COMUNICAÇÃO MÓVEL INDEPENDENTE DA LOCALIZAÇÃO.}

Como ele é um sistema que possui como sua grande característica a grande área de cobertura então é um serviço que pode ser usado por qualquer usuário que tenha acesso aos seus sistemas desde que se encontre dentro da região de cobertura e que tenha visibilidade do céu. Esta comunicação que pode ser estabelecida entre o usuário e os sistemas de comunicação do satélite são independentes do fato do usuário ser fixo ou móvel, desde que no fechamento do enlace o sinal se mantenha satisfatório para o propósito a que ele se propõe a obedecer no momento em que é requerido.

\subsection{2 - COBERTURA DE VASTAS ÁREAS: PAÍSES, CONTINENTES OU GLOBO.}

A cobertura que é oferecida é independente de fronteiras, situações políticas e adversidades naturais e ambientais. Com ele pode-se servir qualquer região de qualquer tamanho, sendo que no caso geoestacionário por conseguir cobrir $1 / 3$ da superfície, então com vários satélites pode-se oferecer uma grande quantidade de canais de comunicação.

Outra grande vantagem dos satélites GEO é a sua habilidade de fornecer cobertura de um único hemisfério com um só feixe, o que permite que todas as antenas que estejam dentro da área de cobertura do mesmo recebam a mesma transmissão e sejam configuradas igualmente.

\subsection{3 - GRANDE LARGURA DE BANDA DISPONÍVEL O TEMPO TODO.}

A disponibilidade do espectro de freqüências a ele destinado é considerada boa e com uma grande amplitude de faixa. Para as bandas $\mathrm{C}$ e $\mathrm{Ku}$ o espectro é de cerca de $1 \mathrm{GHz}$ para cada uma e ela se torna disponível dentro da cobertura podendo ser multiplicada empregando-se técnicas de reuso de freqüência e mudança de polarização do feixe de comunicação. 


\subsection{4 - INDEPENDENTE DA INFRA-ESTRUTURA TERRESTRE.}

Como o repetidor se encontra no espaço então o seu enlace é independente de outras estruturas além das estações.Se a instalação da estação é feita diretamente no ponto de aplicação tornam-se desnecessárias as conexões externas, o que o torna vantajoso para locais onde existe uma infra-estrutura pobre ou que a implantação desta a torne economicamente inviável. Quando utilizados no modo duplex bastam apenas duas estações para transmissão, de sinais a longas distâncias, sendo que geralmente elas têm um custo de implantação baixo, o que permite que o sistema tenha uma difusão maior. Isto já não acontece com os enlaces terrestres e outros sistemas de comunicação visto que necessitam de várias estações repetidoras ao longo do percurso para que se possa manter o contato.

\subsection{5 - RÁPIDA INSTALAÇÃO DE REDES TERRESTRES.}

Uma vez operacional as estações terrenas individuais podem ser rapidamente ativadas em função da demanda do serviço. Cada uma delas pode ser instalada e testada num curto período de tempo dependendo muitas vezes do grau de complexidade que esta associada ao local. A manutenção dessas estações comparada com a manutenção da infraestrutura dos outros tipos de sistemas é relativamente mais econômica e menos complexa uma vez que se utilizam poucos elementos.

\subsection{6 - BAIXO CUSTO POR LOCAL ADICIONADO.}

As redes comunicação baseadas em satélite do ponto de vista de flexibilidade, manutenção e operação são mais baratas do que as redes de comunicação terrestres, uma vez que essas exigem o emprego de uma grande infra-estrutura, a qual se torna cara à medida que vai precisando ser expandida, o que já não ocorre num desses sistemas que à medida que vai sendo expandido e ganhando mais usuários vai diminuindo o custo da implantação do satélite. Para além da facilidade de instalação a construção de sites apresenta um custo relativamente baixo. Os novos receptores DTH e VSAT possuem elementos que permitem que qualquer um os instale. Já as estações de comunicação twoway podem necessitar de uma montagem mais cuidadosa por questões de segurança e por motivos de seleção de local adequado. 


\subsection{7 - CARACTERÍSTICAS UNIFORMES DO SERVIÇO.}

Como a área de cobertura padrão define a área de serviço e dentro dele o serviço é o mesmo então, isso permite que se fragmente e espalhe a rede terrestre e que em todos os pontos dessa rede se tenha acesso a todos os dados transmitidos.

\subsection{8 - SERVIÇO TOTAL A PARTIR DE UM ÚNICO SERVIDOR.}

A rede de satélites pode ser administrada tanto por uma companhia quanto por uma agencia governamental, permitindo assim que os seus clientes, que podem ser uma ou várias organizações governamentais ou não governamentais, negociem apenas com um único individuo para poderem ter acesso ao serviço.

O serviço dos sistemas baseados em satélite pode apresentar coberturas internacionais, nacionais ou regionais e é independente da situação imposta pela fragmentação dos mercados e das situações políticas e econômicas da região. 


\section{0 - CÁLCULO DO ENLACE.}

Para realização do projeto de um sistema de comunicações deve-se obedecer a padrões mínimos de performance, a parâmetros de interferência e atenuação, trabalhar dentro dos limites de potência de transmissão e dentro da banda de rádio freqüência para qual o sistema é destinado. O critério mais importante para performance é a razão sinal ruído $(S / N)$ existente no canal de informação.

Uma boa razão sinal ruído depende da qualidade do sinal no enlace de subida, que por sua vez depende da intensidade do sinal quando deixa a estação terrena em que se originou e do nível em que este é recebido pelo satélite. Já no enlace de descida a qualidade do sinal depende do nível de potência em que o satélite pode retransmitir o sinal recebido e de como a estação receptora o irá capturar.

A razão sinal ruído no canal de banda básica depende de vários fatores, sendo os mais importantes os seguintes:

- Razão portadora ruído $(C / N)$ na entrada do receptor;

- Tipo de modulação usada para modular o sinal de banda base em uma portadora;

- Freqüência intermediária e banda dos canais de banda base no receptor.

Por causa das grandes distancias envolvidas entre um satélite geoestacionário e a estação terrestre, e uma vez que a potência do sinal irradiado diminui com o quadrado da distancia, o sinal recebido pelo satélite no enlace de subida e o sinal recebido pela estação receptora no enlace de descida são muito fracos e podem ser facilmente distorcidos pelo sempre presente ruído branco aditivo gaussiano. Para além desse o sinal no enlace de subida pode ser interferido pelo sinal de outras estações destinados aos satélites adjacentes e pelo sinal de satélites adjacentes no enlace de descida. Ele pode também ser severamente atenuado pela chuva, a qual fará com que num sistema que opere com reuso de freqüência ocorra uma redução do isolamento que existe entre as duas ondas polarizadas ortogonalmente.

Nestes sistemas se lida basicamente com potência do sinal, medida em watts, sendo que os seus efeitos, que a podem tanto reduzir quanto aumentar de nível do sinal, são expressos em decibel $(\mathrm{dB})$, que é um valor definido em relação a uma razão de potências ou de tensões, portanto converter um valor em decibéis significa apenas achar o logaritmo decimal e multiplicar o seu valor por dez, ou seja: 


$$
d B=10 \log \left(\frac{P_{\text {out }}}{P_{\text {in }}}\right)=20 \log \left(\frac{V_{\text {out }}}{V_{\text {in }}}\right)
$$

O inverso do decibel é um valor que nos dá a razão, ou seja:

$$
\begin{aligned}
& \frac{P_{\text {out }}}{P_{\text {in }}}=10^{\left(\frac{d B}{10}\right)} \\
& \frac{V_{\text {out }}}{V_{\text {in }}}=10^{\left(\frac{d B}{20}\right)}
\end{aligned}
$$

O desvanecimento ou descaimento é expresso por um valor de decibel negativo, em que a redução de potência pela metade do seu valor corresponde a uma diminuição de $3 \mathrm{~dB}$ e a diminuição de $1 \mathrm{~dB}$ representa uma queda de $25 \%$.

Num sistema de comunicações é comum o uso da expressão dBW (decibel-Watt) para sistemas com elevados níveis de potência. O valor de $1 \mathrm{~W}$ é selecionado como referência e é definido como $0 \mathrm{dBW}$, ou seja:

$$
d B W=10 \log \left(\frac{P[W]}{1[W]}\right)
$$

Quando esse valor de potência é referenciado em relação a $1 \mathrm{~mW}$, o que geralmente ocorre para sistemas com baixos níveis potência, então é empregue o dBm, ou seja:

$$
d B m=10 \log \left(\frac{P[m W]}{1[m W]}\right)
$$

A conversão das unidades típicas de potência para $\mathrm{W}, \mathrm{mW}$ e $\mathrm{dBm}$ é fornecida pela tabela 1 .

Tabela 1: Conversão das unidades típicas de potência.

\begin{tabular}{c|ccccccc}
\hline $\begin{array}{c}\text { Unidades de } \\
\text { Potência }\end{array}$ & $\mathbf{1} \boldsymbol{M W}$ & $\mathbf{1} \boldsymbol{k W}$ & $\mathbf{1} \boldsymbol{W}$ & $\mathbf{1} \boldsymbol{m} \boldsymbol{W}$ & $\boldsymbol{1} \boldsymbol{\mu} \boldsymbol{W}$ & $\mathbf{1} \boldsymbol{n W}$ & $\boldsymbol{1} \boldsymbol{p} \boldsymbol{W}$ \\
\hline $\mathbf{W}$ & $10^{6}$ & $10^{3}$ & 1 & $10^{-3}$ & $10^{-6}$ & $10^{-9}$ & $10^{12}$ \\
$\mathbf{d B W}$ & 60 & 30 & 0 & -30 & -60 & -90 & -120 \\
$\mathbf{m W}$ & $10^{9}$ & $10^{6}$ & $10^{3}$ & 1 & $10^{-3}$ & $10^{-6}$ & $10^{-9}$ \\
$\mathbf{d B m}$ & 90 & 60 & 30 & 0 & -30 & -60 & -90 \\
\hline
\end{tabular}

Fonte: Carvalho, Paulo H.

Muitos dos fatores naturais que afetam o enlace apresentam um comportamento probabilístico que segue uma distribuição padrão, onde os piores casos são tipicamente três vezes maiores do que o valor médio que às vezes é representado pelo valor quadrático médio (RMS). Quando existem múltiplos fatores contribuindo ou afetando o processo a 
especificação é obtida pela raiz quadrada da soma dos quadrados dos fatores individuais, ou seja:

$$
\text { System }=\sqrt{u n i t_{1}^{2}+u n i t_{2}^{2}+\ldots+u n i t_{N}^{2}}=\sqrt{\sum_{i=1}^{N} u n i t_{i}^{2}}
$$

Nesse capítulo iremos abordar o calculo da razão portadora ruído com base na potência e no nível de ruído de sinal presente no receptor realizando um tratamento de forma individual. Iremos também tratar dos diferentes efeitos que ocorrem no enlace.

\section{1 - GEOMETRIA SATÉLITE - ESTAÇÃO TERRENA.}

Para que o satélite e a estação terrena possam fechar o enlace de comunicação é necessário que a antena da estação esteja corretamente direcionada para o mesmo. Esse direcionamento é feito a partir do calculo da distancia entre os dois pontos (estação terrena - satélite) e dos ângulos de apontamento.

\subsection{1 - DETERMINAÇÃO DOS ÂNGULOS DE APONTAMENTO.}

Chamamos de ângulos de apontamento as coordenadas para as quais a antena de uma estação terrena deve ser direcionada permitindo assim que se estabeleça um enlace de comunicação entre um e outro. Os ângulos que permitem esse apontamento da antena são o azimute, ângulo tomado, no sentido horário, a partir do norte geográfico da estação terrestre, e a elevação, ângulo vertical tomado em relação ao plano base da antena (figura $5)$.

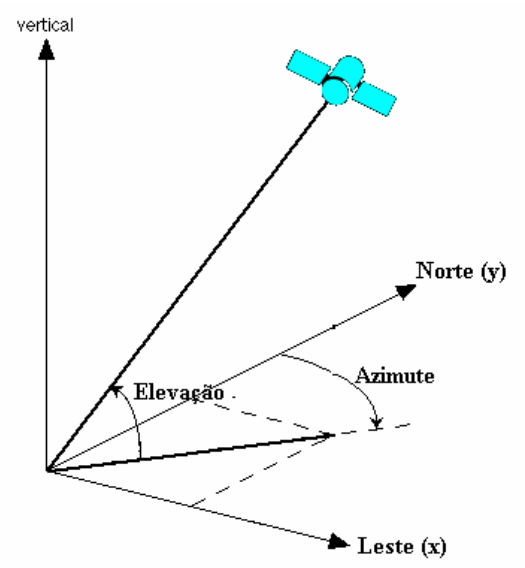

Figura 5: Representação geométrica do Azimute e da Elevação. 


\subsubsection{1 - CALCULO DA ELEVAÇÃO.}

Considerando a figura 6 , onde:

$r_{S}$ - é o vetor que vai do centro da terra até o satélite;

$r_{e}$ - o vetor que liga o centro da Terra a estação terrena;

$d$ - o vetor que liga a estação ao satélite.

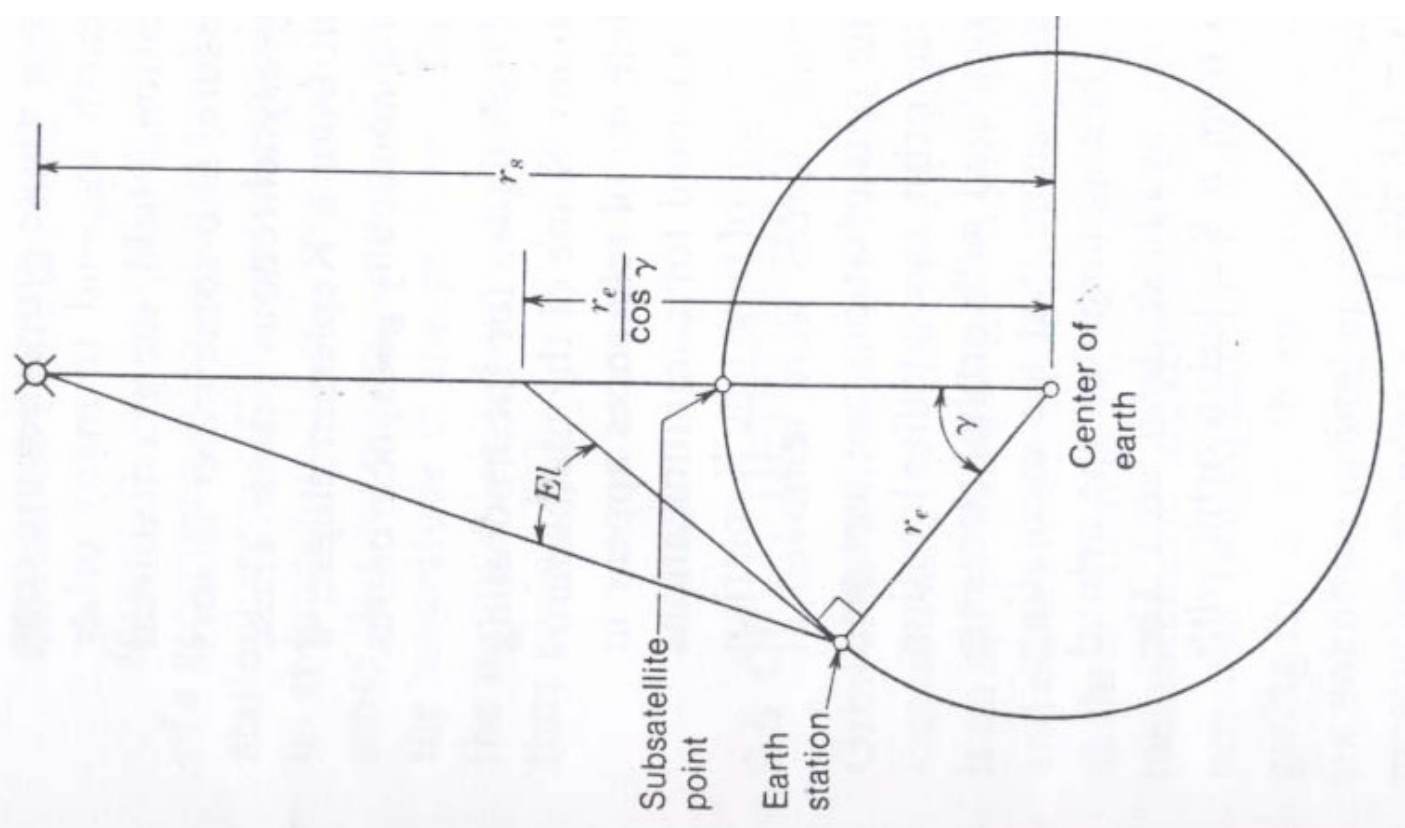

Figura 6: Geometria utilizada para determinação da elevação da antena presente Ana estação terrena.

Fonte: Pratt, Thimoty.

Estes três vetores se encontram num mesmo plano, onde o ângulo $\gamma$, medido entre $r_{e}$ e $r_{s}$, é o ângulo central e é medido de forma a que o seu valor seja sempre positivo. Já o ângulo entre $d$ e $r_{e}$ é designado de $\psi$. $\gamma$ ? está relacionado com a latitude norte $\left(L_{e}\right)$, a longitude oeste $\left(l_{e}\right)$ da estação e com a latitude norte $\left(L_{s}\right)$, a longitude oeste $\left(l_{s}\right)$ do ponto sub-satélite (projeção do satélite sobre a superfície do globo), pela seguinte relação trigonométrica:

$$
\cos \gamma=\cos L_{e} \cdot \cos L_{s} \cdot \cos \left(l_{s}-l_{e}\right)+\sin L_{e} \cdot \sin L_{s}
$$

Pela lei dos co-senos temos que a distancia entre a estação e o satélite é dada por:

$$
d=r_{s} \sqrt{1+\left(\frac{r_{e}}{r_{s}}\right)^{2}-2 \cdot \frac{r_{e}}{r_{s}} \cdot \cos \gamma}
$$

Como o plano horizontal na estação é perpendicular a $r_{e}$ então o ângulo de elevação esta relacionado ao ângulo central por:

$$
\theta=\Psi-90
$$

Utilizando a lei dos senos novamente, temos que: 


$$
\frac{r_{s}}{\sin \Psi}=\frac{d}{\sin \gamma}
$$

combinando (3.8), (3.9) e (3.10), teremos que:

$$
\cos \theta=\frac{\sin \gamma}{\sqrt{1+\left(\frac{r_{e}}{r_{s}}\right)^{2}-2 \cdot \frac{r_{e}}{r_{s}} \cdot \cos \gamma}}
$$

A qual nos permite calcular o ângulo de elevação a partir das coordenadas da estação e do satélite, do raio orbital e do raio da Terra.

Para o caso de satélites geoestacionários, tem-se que:

$$
\begin{gathered}
L_{s}=0 \\
r_{s}=42242 \mathrm{~km} \\
r_{e}=6370 \mathrm{~km}
\end{gathered}
$$

Logo o ângulo central é dado por:

$$
\cos \gamma=\cos L_{e} \cdot \cos \left(l_{s}-l_{e}\right)
$$

Sendo a distância entre a estação e o satélite dada por:

$$
d=42242 \sqrt{1,02274-0,301596 \cdot \cos \gamma}
$$

E o ângulo de elevação por:

$$
\cos \theta=\frac{\sin \gamma}{\sqrt{1,02274-0,301596 \cdot \cos \gamma}}
$$

\subsubsection{2 - CALCULO DO AZIMUTE.}

Como a estação, o centro da Terra, o satélite e o ponto subsatélite se encontram no mesmo plano, então o azimute entre a estação e o satélite é igual ao que o que existe entre a estação e o ponto subsatélite. Como a determinação do azimute depende não só da posição do ponto subsatélite, que tanto pode estar a leste como a oeste da estação, mas também do hemisfério em que ambos se encontram então o calculo deste é relativamente mais complexo que o da elevação. No entanto, essa complexidade é consideravelmente reduzida quando lidamos com satélite geoestacionários.

A obtenção das expressões que regem a determinação do azimute é feita com base no triangulo esférico com vértices $\mathrm{E}$ (estação terrena), $\mathrm{S}$ (ponto subsatélite), e G (ponto em que o meridiano da estação corta a linha do equador). Pela figura 7 podemos ver todas orientações possíveis para diferentes posicionamentos do ponto subsatélite em relação à estação terrestre. 


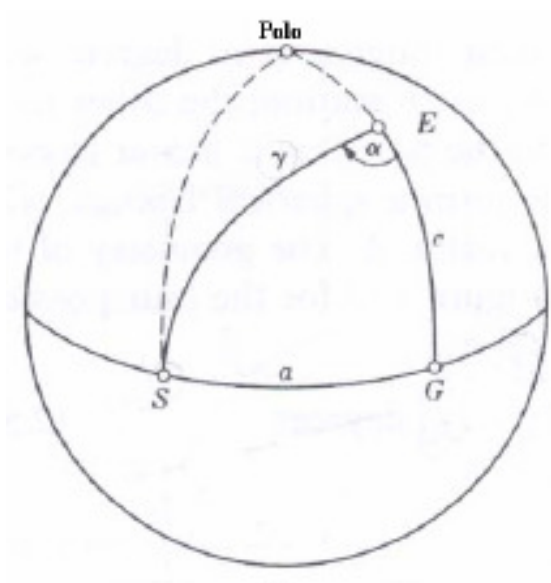

(a)

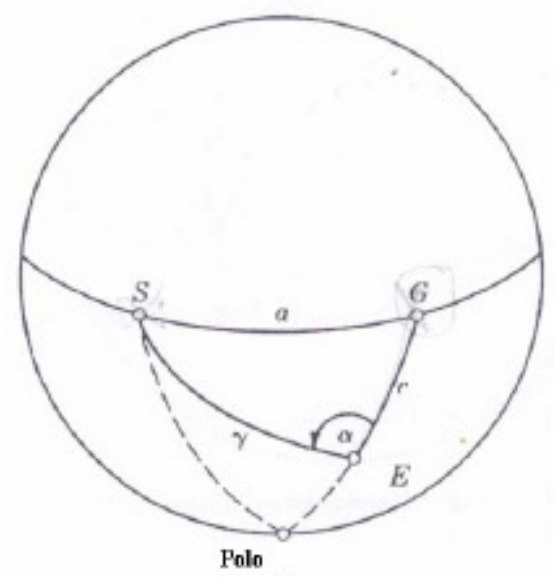

(c)

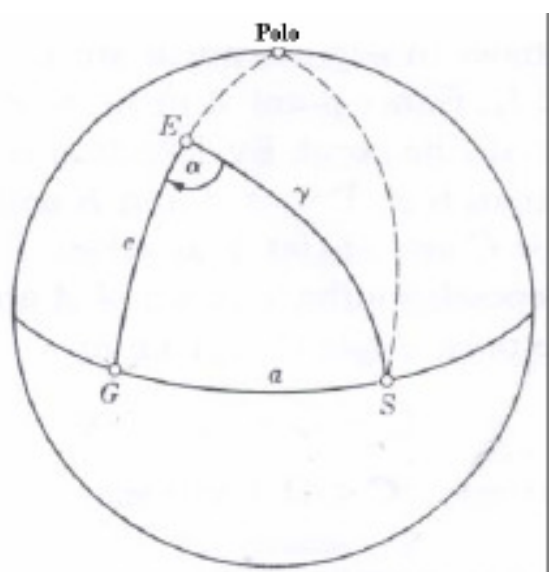

(b)

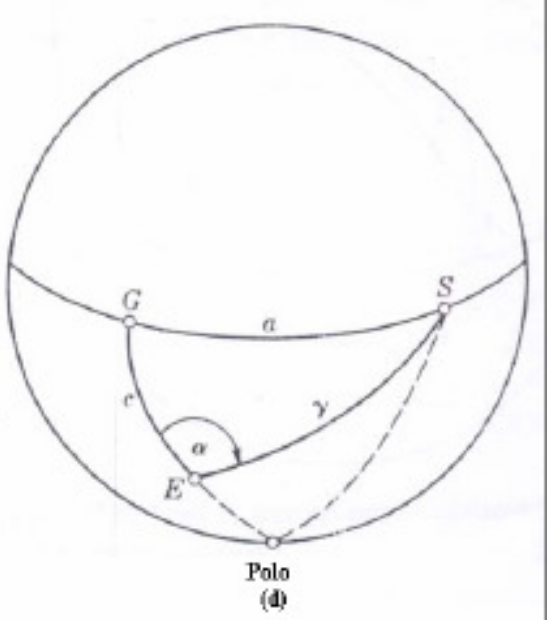

Figura 7: Trigonometria do calculo do azimute, onde $E$ é a estação, $S$ o ponto sub-satélite e $G$ o ponto de interseção da longitude da estação com a linha do equador. Fonte: Pratt, Thimoty.

Os três lados são arcos de comprimento $\gamma, a$ e $c$ sendo o primeiro o ângulo central, dado pela equação (3.7), $a$ e $c$, estão relacionados as coordenadas da estação e de ponto sub-satélite por:

$$
\begin{aligned}
& a=l_{s}-l_{e} \\
& c=\left|L_{e}-L_{s}\right|
\end{aligned}
$$

Sendo o perímetro médio do triangulo dado por:

$$
s=0,5 \cdot(a+c+\gamma)
$$

O ângulo, $\alpha$, no vértice pode ser obtido pela seguinte expressão:

$$
\tan ^{2}\left(\frac{\alpha}{2}\right)=\frac{\sin (s-\gamma) \cdot \sin (s-c)}{\sin s \cdot \sin (s-a)}
$$

Onde

$$
\alpha=2 \cdot \tan ^{-1} \sqrt{\frac{\sin (s-\gamma) \cdot \sin (s-c)}{\sin s \cdot \sin (s-a)}}
$$


Usando a figura 7, podemos relacionar o azimute com o ângulo $\alpha$, para o caso geoestacionário, usando as expressões que se encontram na tabela 2.

Tabela 2: Equações para calcular 0 azimute a partir do triangulo esférico de angulo $\alpha$ usando a figura 7 como referencia.

\begin{tabular}{cc}
\hline Situação & Equaçãa \\
\hline Ponto subsatélite a sudoeste da estação terrena (a) & $A z=180^{\circ}+\alpha$ \\
Ponto subsatélite a sudeste da estação terrena (b) & $A z=180^{\circ}-\alpha$ \\
Ponto subsatélite a noroeste da estação terrena (c) & $A z=360^{\circ}-\alpha$ \\
Ponto subsatélite a nordeste da estação terrena (d) & $A z=\alpha$ \\
\hline
\end{tabular}

Fonte: Pratt, Thimoty.

\section{2 - TEORIA BÁSICA DE TRANSMISSÃO.}

Em um sistema de telecomunicações ao invés de correntes e tensões trata-se basicamente de potência dos sinais transmitidos e recebidos, portanto o calculo da potência recebida por uma estação terrena tendo este sido originado em uma outra estação terrena transmissora é fundamental para o entendimento da comunicação por satélites e para minimização dos efeitos das fontes de ruído, atenuação e interferência existentes no sistema.

A potência pode ser obtida pelo uso da equação de densidade de fluxo ou pela equação de Friis.

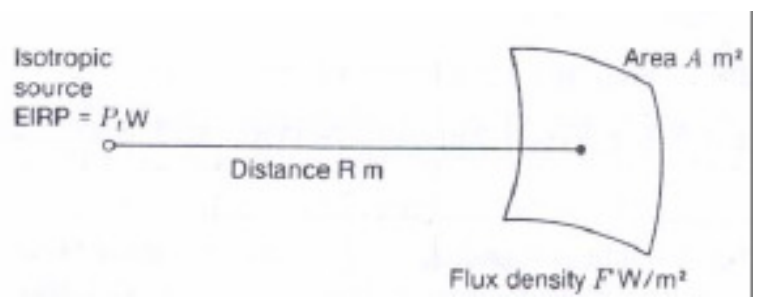

Figura 8: Densidade de fluxo produzida por uma fonte de radiação isotrópica. Fonte: Elbert, Bruce.

Consideremos uma fonte transmissora ideal isotrópica, que radia de forma uniforme em todas as direções uma potência, $P_{t}[\mathrm{~W}]$, tal como mostra a figura 8 , e que se encontra a uma distância, $R[\mathrm{~m}]$, da fonte isotrópica, a densidade de fluxo que passa pela superfície da esfera de raio, $R$, é dada por [2]:

$$
S=W=\frac{P_{t}}{4 \pi R^{2}}
$$

Como se pode ver (3.19) é para o caso ideal em que temos uma antena isotrópica que radia igualmente em todas as direções. Como na prática usam-se antenas diretivas, que 
concentram a potência a ser transmitida em uma direção, então a antena apresenta um ganho $G(\theta)$ em uma direção $\theta$, que é definido como a razão entre a potência por unidade do ângulo sólido radiado em uma dada direção e potência radiada media por unidade de ângulo sólido, ou seja:

$$
G(\theta)=\frac{P(\theta)}{P_{0} / 4 \pi}
$$

Onde:

$P(\theta)$ : é a potência radiada por unidade de ângulo sólido da antena de teste;

$P_{0}$ : é a potência total radiada pela antena de teste;

$G(\theta)$ : o ganho da antena na direção $\theta$, usualmente definida como a direção na qual a potência de radiação é máxima.

Para um transmissor com uma potência, $P_{t}$, emitida por uma antena sem perdas e com ganho, $G_{t}$, a densidade de fluxo na direção de máxima radiação da antena e dada por:

$$
S=W=\frac{P_{t} G_{t}}{4 \pi R^{2}}
$$

O produto, $P_{t . .} G_{t}$ é chamado de potência radiada efetivamente de forma isotrópica (EIRP) e ele nos da a relação entre a potência radiada e o ganho da antena em relação a uma antena isotrópica.

Caso a antena seja ideal e de área, $A\left[\mathrm{~m}^{2}\right]$, então a potência recebida é dada por:

$$
P_{r}=S A
$$

No entanto como numa antena real de área física, $A_{r}$, nem toda potência presente na expressão (3.22) é entregue a outra antena, uma vez que parte da energia incidente é refletida e outra parte é absorvida por outros componentes, então existe uma redução na eficiência da antena que é representada pela área efetiva, $A_{e}$, ou seja:

$$
A_{e}=\eta A_{r}
$$

Onde: $\eta$ - é a eficiência da antena e nela estão representadas todas as perdas existentes entre a onda incidente e porta de saída da antena, onde podemos destacar a eficiência de iluminação, bloqueio, erros de fase, efeitos de difração, polarização, perdas no casamento e de transbordamento. Para antenas parabólicas a eficiência varia de 50 a $75 \%$.

Portanto a potência recebida por uma antena real é dada por:

$$
P_{r}=\frac{P_{t} G_{t} A_{e}}{4 \pi R^{2}}
$$


A qual como podemos ver é dependente da EIRP do satélite, que por sua vez depende da freqüência, da área efetiva da antena da estação receptora e da distância entre os dois.

O ganho de uma antena, esta relacionado a sua área por:

$$
G_{r}=\frac{4 \pi A_{e}}{\lambda^{2}}
$$

Isolando $A_{e}$ e substituindo em (3.24), temos que:

$$
P_{r}=P_{t} G_{t} G_{r}\left(\frac{\lambda}{4 \pi R}\right)^{2}
$$

Que é conhecida como expressão de transmissão de Friis.

O termo $(\lambda /(4 \pi R))^{2}$ é conhecido como perda para o espaço livre, $L_{F S}$. E ela representa o espalhamento da onda eletromagnética à medida que ela se afasta da fonte transmissora Como podemos ver ela é dependente apenas da freqüência. O comportamento dessa perda pode ser observado na figura 9 .

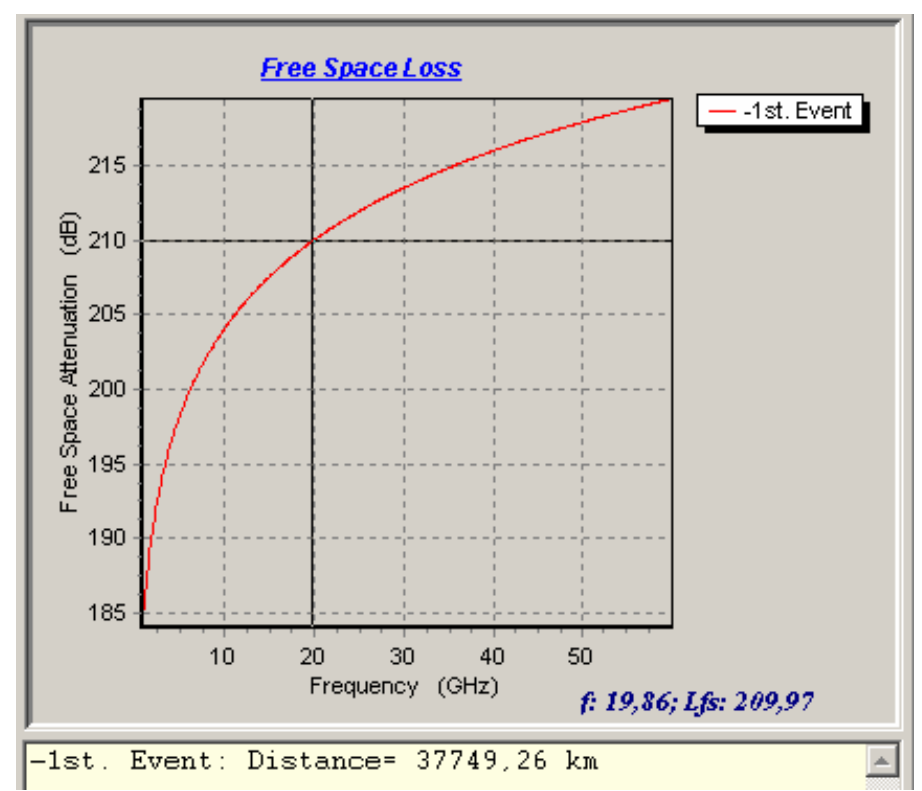

Figura 9: Resultado da análise da perda para o espaço livre para uma distancia entre a estaco terrena e o satélite de $37.749,26 \mathrm{~km}$.

Convertendo para decibéis, teremos que:

$$
P_{r}=E I R P+G_{r}-L_{F S}
$$

Onde: 


$$
\begin{aligned}
& E I R P=10 \log \left(P_{t} G_{t}\right) \\
& G_{r}=10 \log \left(\frac{4 \pi A_{e}}{\lambda^{2}}\right) \\
& L_{F S}=20 \log \left(\frac{4 \pi R}{\lambda}\right)
\end{aligned}
$$

$\mathrm{Na}$ expressão (3.27) temos representado apenas o caso ideal. No caso real precisamos levar em conta situações mais complexas onde temos presentes as perdas atmosféricas devidas a chuva, gases, cintilação e nuvens, também têm que se considerar as perdas existentes nas antenas e as perdas de apontamento. Levando todos esses fatores em conta, teremos que:

$$
P_{r}=E I R P+G_{r}-L_{F S}-L_{a}-L_{t a}-L_{r a}
$$

\section{3 - TEMPERATURA DE RUÍDO E FIGURA DE RUÍDO DO SISTEMA.}

A temperatura de ruído permite determinar quanto do ruído térmico é gerado por dispositivos ativos e passivos num sistema de recepção. Nas freqüências de microondas, todos objetos com temperatura maior que $0 \mathrm{~K}$ geram ruído elétrico na freqüência do receptor. A potência de ruído que esta disponível na saída do dispositivo e que será entregue para um dispositivo que se encontra casado à fonte depende, da densidade espectral do ruído $[\mathrm{W} / \mathrm{Hz}]$, que é considerada constante para todas as freqüências de rádio que vão até a de $300 \mathrm{GHz}$, e da banda sobre o qual o ruído é medido, ou seja:

$$
N=k T B
$$

Onde:

$k$ : é a constante de Boltzmann $=1,38.10^{-23}[\mathrm{~J} / \mathrm{K}]$;

$T$ : é a temperatura de ruído das fontes $[\mathrm{K}]$;

$B$ : banda na qual a potência de ruído é medida $[\mathrm{Hz}]$.

Como em sistemas de comunicação por satélite trabalha-se sempre com sinais muito fracos então, um dos objetivos é procurar reduzir ao máximo possível o ruído dos dispositivos de recepção, de forma a garantir a melhor relação canal ruído possível e conseqüentemente uma melhor qualidade. Este acréscimo de qualidade pode ser obtido aumentando-se a banda do receptor o suficiente para que possa permitir uma passagem sem restrições do sinal enquanto se mantém a potência de ruído o mais baixo possível. 
Para que se possa determinar a temperatura de ruído do sistema, aplica-se o modelo equivalente de um sistema linear ruidoso, figura 10, onde é representada a passagem do ruído por um dispositivo de ganho $g$.

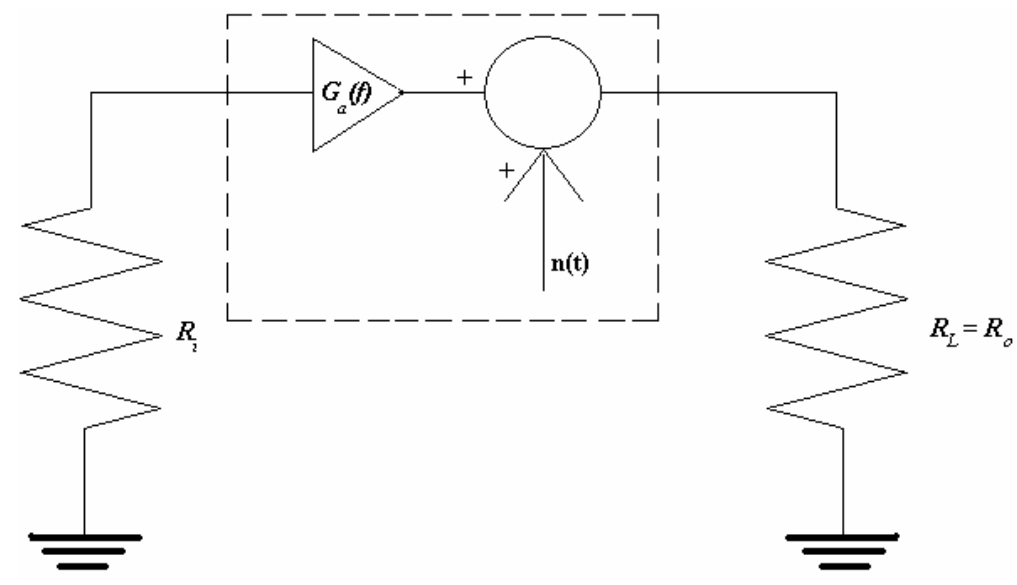

Figura 10: Modelo do sistema linear ruidoso ideal.

Considerando a figura 10, onde temos apenas um dispositivo ruidoso, tiramos que a potência de ruído na saída é dada por:

$$
N_{\text {out }}=k\left(T_{i}+T_{e}\right) g_{a} B_{T}
$$

Onde a temperatura equivalente de ruído é dada por:

$$
T_{e}=\frac{N_{o u t}-k T_{i} g_{a} B_{T}}{k g_{a} B_{T}}
$$

Cuja figura de ruído, razão entre a potência média na saída do dispositivo ruidoso com ganho, $g$, e a potência média na saída do dispositivo ideal de ganho, $g$, ou seja:

$$
F=\frac{N_{\text {out }}}{N_{a} g_{a}}=\frac{N_{a} g_{a}+P_{x}}{N_{a} g_{a}}
$$

Substituindo (3.30) em (3.33), teremos que:

$$
F=\frac{k\left(T_{0}+T_{e}\right) g_{a} B_{T}}{k T_{0} B_{T} g_{a}}=\frac{T_{0}+T_{e}}{T_{0}}
$$

Daí se tira que, a relação que existe entre a temperatura efetiva de ruído e a figura de ruído é dada por:

$$
T_{e}=T_{0}(F-1)
$$

Como um sistema de comunicação é composto por vários dispositivos em cascata, então modelando o sistema por como se fosse um único dispositivo teremos que:

$$
g_{a}(f)=g_{1}(f) g_{2}(f) g_{3}(f) \ldots g_{n}(f)
$$

Onde, a figura de ruído, é dada por:

$$
F=\frac{N_{\text {out }}}{N_{\text {ideal }}}=\frac{N_{\text {out } 1}+P_{x 2}}{N_{a} g_{1} g_{2}}=\frac{\left(P_{x 1}+g_{1} N_{a}\right) g_{2}+P_{x 2}}{N_{a} g_{1} g_{2}}
$$


Como

$$
\begin{aligned}
& P_{\mathrm{x} 1}=N_{a} g_{1}\left(F_{1}-1\right) \\
& P_{\mathrm{x} 2}=N_{a} g_{2}\left(F_{2}-1\right)
\end{aligned}
$$

Substituindo em (3.37), teremos que:

$$
\begin{aligned}
& F=\frac{\left(g_{1} N_{a}\left(F_{1}-1\right)+g_{1} N_{a}\right) g_{2}+P_{x 2}}{N_{a} g_{1} g_{2}} \\
& F=\frac{g_{1} g_{2} N_{a} F_{1}+P_{x 2}}{N_{a} g_{1} g_{2}}=F_{1}+\frac{P_{x 2}}{N_{a} g_{1} g_{2}} \\
& F=F_{1}+\frac{\left(F_{2}-1\right)}{g_{1}}
\end{aligned}
$$

Que na forma de temperatura equivalente de ruído, será:

$$
T=T_{1}+\frac{T_{2}}{g_{1}}
$$

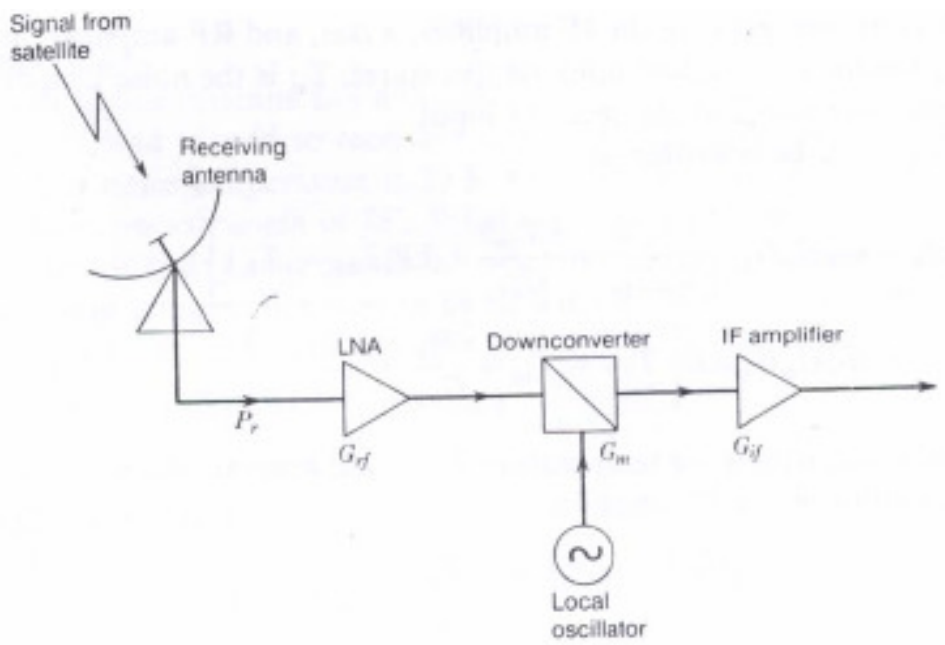

Figura 11: Esquema simplificado do receptor de uma estação terrena. Fonte: Pratt, Thimoty.

Considerando agora um sistema de recepção típico, tal como mostra a figura 11, composto por um amplificador RF, um conversor de freqüência, e implementando o seu modelo equivalente onde todos os dispositivos ruidosos serão substituídos por uma única fonte de ruído com temperatura, $T_{S}$, tem-se que a potência total de ruído será dada por:

$$
N=G_{I F} k T_{I F} B+G_{I F} G_{m} k T_{m} B+G_{I F} G_{m} G_{R F} k\left(T_{R F}+T_{i n}\right) B
$$

Que pode ser reescrita como:

$$
\begin{aligned}
& N=G_{I F} G_{m} G_{R F}\left[\frac{k T_{I F} B}{G_{m} G_{R F}}+\frac{k T_{m} B}{G_{R F}}+k\left(T_{R F}+T_{\text {in }}\right) B\right] \\
& N=G_{I F} G_{m} G_{R F} k B\left[\frac{T_{I F}}{G_{m} G_{R F}}+\frac{T_{m}}{G_{R F}}+\left(T_{R F}+T_{\text {in }}\right)\right]
\end{aligned}
$$


(3.42) mostra que uma única fonte de ruído com temperatura de ruído, $T_{S}$, pode gerar a mesma potência de ruído, ou seja:

$$
N=G_{I F} G_{m} G_{R F} k T_{S} B
$$

Portanto

$$
k T_{S} B=k B\left[\frac{T_{I F}}{G_{m} G_{R F}}+\frac{T_{m}}{G_{R F}}+\left(T_{R F}+T_{i n}\right)\right]
$$

$\mathrm{ou}$

$$
T_{S}=T_{i n}+T_{R F}+\frac{T_{m}}{G_{R F}}+\frac{T_{I F}}{G_{m} G_{R F}}
$$

De (3.45) pode-se ver facilmente que os componentes que se sucedem contribuem cada vez menos com o ruído à medida que os seus ganhos vão sendo adicionados. Pode-se notar também, que é fundamental ter no primeiro componente um dispositivo de baixo ruído, pois ele é o que mais contribui para o calculo da temperatura de ruído equivalente do sistema.

Escrevendo a equação do sistema em função da razão portadora ruído $(C / N)$ temos que:

$$
\frac{C}{N}=\frac{P_{t} G_{t} G_{r}}{k T_{s} B}\left[\frac{\lambda}{4 \pi R}\right]^{2}=\frac{P_{t} G_{t}}{k B} \cdot \frac{G_{r}}{T_{s}} \cdot\left[\frac{\lambda}{4 \pi R}\right]^{2}
$$

De (3.46) pode-se ver que $C / N$ é diretamente proporcional à razão $G_{r} / T_{S}$, também chamada de $G / T$, que é a figura de mérito, a qual também pode ser usada para especificar a qualidade de uma estação uma vez que o seu aumento implica num aumento da razão $C / N$, ou seja, aumenta o nível de potência do sinal recebido e diminui o nível de ruído que afeta o sistema.

Os valores negativos de $\mathrm{G} / \mathrm{T}$, que geralmente são observados em sistemas de comunicação por satélite, simplesmente mostram que o ganho da antena de recepção é menor do que a temperatura equivalente do sistema, ou seja:

$$
\frac{G}{T}=G_{r}-10 \log T_{S}
$$




\section{4 - ENLACE DE SUBIDA.}

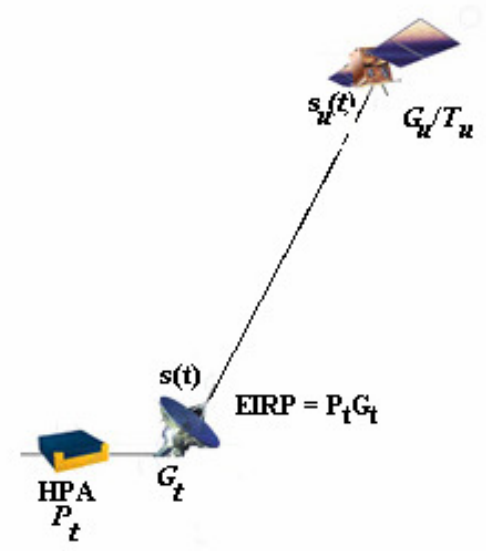

Figura 12: Enlace de subida básico.

Considerando agora um enlace de subida típico, tal como mostrado na figura 12 , onde se trabalha com uma densidade de potência especificada, e que deve ser apresentada na entrada do transponder, então teremos que a potência recebida pelo satélite será dada por: [3]

$$
p_{r s}=\frac{p_{t e u} g_{t e u} g_{r s}}{a_{u}}=\frac{e i r p_{u} g_{r s}}{a_{u}}
$$

Que em bB, será:

$$
P_{r s}=\operatorname{EIRP}_{u}+G_{r s}-A_{u}
$$

Como já foi dito, a potência de ruído, $N$, é dada por:

$$
N=k T_{S} B_{T}
$$

Onde:

$T_{S}$ : é a temperatura equivalente do sistema de recepção do satélite, então:

$$
\frac{p_{r s}}{N}=\frac{\operatorname{eirp}_{u} g_{r s}}{k T_{S} B_{T} a_{u}}
$$

Que em dB, é:

$$
\left(\frac{C}{N}\right)_{u}=E I R P_{u}+G_{r s}-A_{u}-10 \log k-10 \log T_{S}-10 \log B_{T}
$$

Como: $N=N_{0} B_{T}$, então:

$$
\left(\frac{C}{N}\right)_{u}=E I R P_{u}+G_{r s}-A_{u}-10 \log k-10 \log T_{S}
$$

Onde: $10 \log k=-228,6$.

Levando em conta a densidade de fluxo que deve ser respeitada, teremos que: 


$$
p_{r s}=W_{d s} A_{e r s}
$$

Que em dB é:

$$
P_{r s}=W_{d s}+10 \log A_{\text {ers }}
$$

Como, o ganho da antena de recepção do satélite é dado por:

$$
G_{r s}=10 \log \left(\frac{4 \pi}{\lambda_{u}^{2}}\right)+10 \log A_{\text {ers }}
$$

Então, o ganho da antena por unidade de área, será dado por:

$$
G_{r s}\left(1 m^{2}\right)\left(d B / m^{2}\right)=10 \log \left(\frac{4 \pi}{\lambda_{u}^{2}}\right)
$$

E tendo que:

$$
\left(\frac{C}{N}\right)_{u}=P_{r s}-10 \log k-10 \log T_{S}
$$

Então, substituindo (3.57) em (3.58), tem-se que:

$$
\left(\frac{C}{N}\right)_{u}=W_{d s}+10 \log A_{e r s}-10 \log k-10 \log T_{S}
$$

O que vai resultar numa relação canal ruído no enlace de subida de:

$$
\left(\frac{C}{N}\right)_{u}=W_{d s}+G_{r s}-G_{r s}\left(1 m^{2}\right)-10 \log k-10 \log T_{S}
$$

Utilizando definição de figura de mérito, tem-se que para o sistema de recepção do satélite, ela será dada por:

$$
\left(\frac{G}{T}\right)_{S}=G_{r s}-10 \log T_{S}
$$

O que resulta numa razão portadora ruído no enlace de subida de:

$$
\left(\frac{C}{N}\right)_{u}=W_{d s}+\left(\frac{G}{T}\right)_{S}-G_{r s}\left(1 m^{2}\right)-10 \log k
$$

Logo para o enlace de subida a EIRP, será:

$$
\operatorname{EIRP}_{u}=W_{d s}-G_{r s}\left(1 \mathrm{~m}^{2}\right)+A_{u}
$$

De (3.63) se tira que, para estações terrenas com antenas de diâmetro pequeno, é necessário transmitir numa potência mais alta para que se atinja a EIRP desejada. Essa redução do diâmetro das antenas na estação terrena transmissora tem a desvantagem de permitir a elevação do nível de interferência nos satélites vizinhos, uma vez que, antenas menores são menos diretivas do que as antenas maiores, ou seja, apresentam uma largura de feixe mais ampla [2]. 


\section{5 - ENLACE DE DESCIDA.}

O enlace de descida deve ser planejado tendo-se em conta os seguintes objetivos:[2]

- Garantir a continuidade da conexão para uma determinada porcentagem de tempo, sobre um determinado valor de $S / N$;

- Transportar o máximo número de canais tendo em conta o custo mínimo;

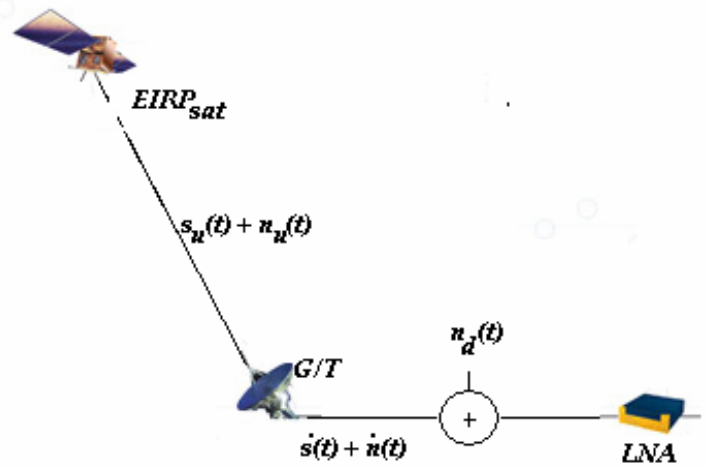

Figura 13: Enlace básico de descida.

Levando em conta a figura 13 , tem-se que por simetria para o enlace de descida, a razão portadora ruído na estação receptora será dada por: [3]

$$
\frac{p_{r e d}}{N}=\frac{e i r p_{d} g_{r e d}}{k T_{e} B_{T} a_{d}}
$$

Que em dB é:

$$
\left(\frac{C}{N}\right)_{d}=E I R P_{d}+G_{r e d}-A_{d}-10 \log k-10 \log T_{e}-10 \log B_{T}
$$

Como: $N=N_{0} B_{T}$, então se tem que para o enlace de descida, a razão $C / N$, é dada por:

$$
\left(\frac{C}{N}\right)_{d}=E I R P_{d}+G_{r e d}-A_{d}-10 \log k-10 \log T_{e}
$$

Sabendo-se que:

$$
p_{\text {red }}=W_{\text {ded }} A_{\text {ered }}
$$

Que em dB é:

$$
P_{\text {red }}=W_{\text {ded }}+10 \log A_{\text {ered }}
$$

E que:

$$
G_{\text {red }}=10 \log \left(\frac{4 \pi}{\lambda_{d}^{2}}\right)+10 \log A_{\text {ered }}
$$


Então:

$$
\left(\frac{C}{N}\right)_{d}=P_{r e d}-10 \log k-10 \log T_{e}
$$

Substituindo (3.68) em (3.70), tem-se que:

$$
\left(\frac{C}{N}\right)_{d}=W_{\text {ded }}+10 \log A_{\text {ered }}-10 \log k-10 \log T_{e}
$$

Ou ainda:

$$
\left(\frac{C}{N}\right)_{d}=W_{d e d}+G_{r e d}-G_{r e d}\left(1 m^{2}\right)-10 \log k-10 \log T_{e}
$$

Tendo em conta que: a figura de mérito para a estação receptora é dada por:

$$
\left(\frac{G}{T}\right)_{e d}=G_{r e d}-10 \log T_{e}
$$

Então se tem que no enlace de descida, a razão portadora ruído é:

$$
\left(\frac{C}{N}\right)_{d}=W_{d e d}+\left(\frac{G}{T}\right)_{e d}-G_{r e d}\left(1 m^{2}\right)-10 \log k
$$

Onde:

$$
E I R P_{d}=W_{d e d}-G_{r e d}\left(1 m^{2}\right)+A_{d}
$$

Considerando que o sistema deva funcionar com um valor de razão portadora ruído total, então modelando o enlace da figura 12 e da figura 13, pelo modelo da figura 14 , então:

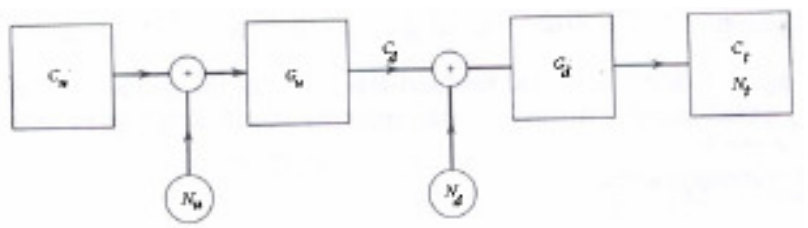

Figura 14: Modelo equivalente do ruído no enlace. Fonte: Carvalho, Paulo H.

$$
\begin{aligned}
& C_{T}=C_{u} G_{u} G_{d} \\
& N_{T}=N_{u} G_{u} G_{d}+N_{d} G_{d}
\end{aligned}
$$

O que irá resultar em:

$$
\left(\frac{N}{C}\right)_{T}=\frac{N_{u} G_{u} G_{d}}{C_{u} G_{u} G_{d}}+\frac{N_{d} G_{d}}{C_{u} G_{u} G_{d}}=\frac{N_{u}}{C_{u}}+\frac{N_{d}}{C_{u} G_{u}}=\frac{N_{u}}{C_{u}}+\frac{N_{d}}{C_{d}}
$$

Então:

$$
\left(\frac{C}{N}\right)_{T}=\frac{1}{\left(\frac{C}{N}\right)_{u}^{-1}+\left(\frac{C}{N}\right)_{d}^{-1}}
$$


Que em dB é:

$$
\left(\frac{C}{N}\right)_{T}=-10 \log \left(10^{-\frac{(C / N)_{u}}{10}}+10^{-\frac{(C / N)_{d}}{10}}\right)
$$

\section{6 - PROPAGAÇÃO E SUAS INFLUÊNCIAS NO ENLACE.}

De (3.29) desenvolvida no item 3.2, que nos indica como a potência recebida pelo receptor depende da EIRP do transmissor, do ganho da antena de recepção, das diversas perdas que ocorrem no sistema, pode-se notar que todos os seus termos são independentes do tempo com exceção da perda atmosférica $L_{a}$, que é escrita como uma soma de termos; a absorção atmosférica e a atenuação.

$\mathrm{Na}$ maioria das freqüências de interesse, a absorção atmosférica, é relativamente desprezível, sendo que a atenuação é igual a zero quando temos tempo limpo, podendo aumentar para valores elevados durante condições de propagação desfavoráveis.

Quando um satélite usa polarização ortogonal para transmitir dois canais diferentes numa mesma freqüência, o sinal acaba sendo degradado pelo efeito de despolarização, que é o fenômeno em que parte da energia que esta sendo propagada em uma onda passa para outra que está polarizada ortogonalmente.

Portanto a perda de propagação que existe em um enlace Terra-satélite é a soma de diferentes contribuições, [6] tais como:

- Atenuação por gases atmosféricos;

- Atenuação pela chuva;

- Atenuação por nuvens;

- Cintilação e efeitos de múltiplo-percurso;

- Espalhamento do feixe, e outros efeitos.

\subsection{1 - ATENUAÇÃO POR GASES ATMOSFÉRICOS.}

A altas freqüências a ondas eletromagnéticas interagem com as moléculas dos gases que compõem a atmosfera causando assim a atenuação. [2] Abaixo dos $100 \mathrm{GHz}$, temos freqüências que possuem um elevado índice de atenuação, figura 15, uma vez que nessas freqüências as moléculas de oxigênio e vapor de água que estão presentes na 
atmosfera entram em ressonância com as ondas eletromagnéticas, causando assim um elevado índice de atenuação.

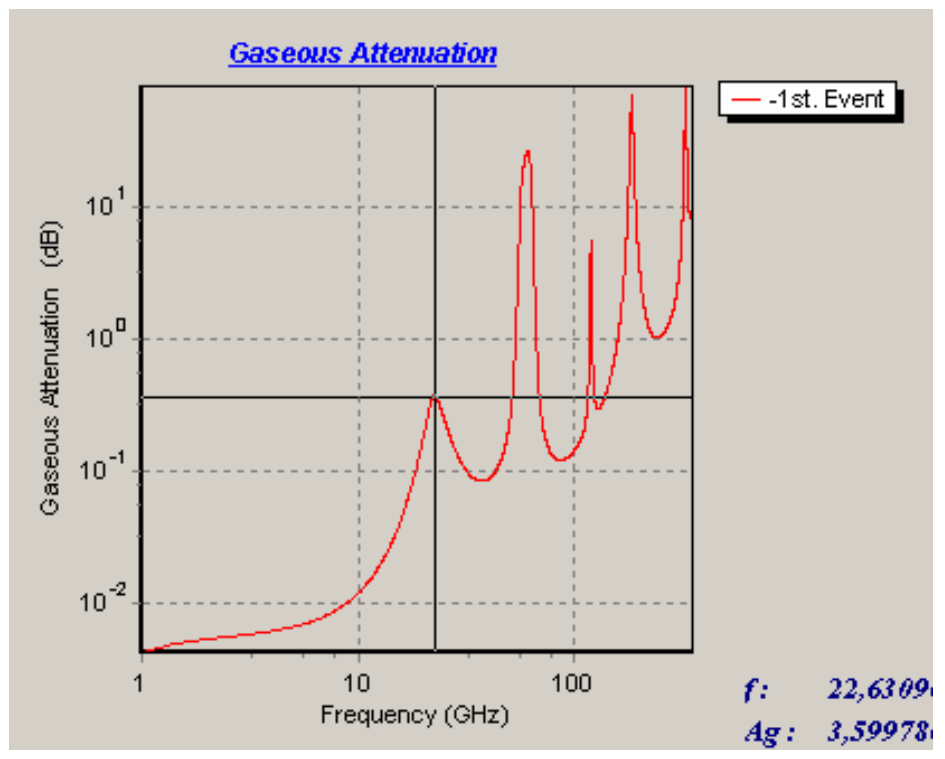

Figura 15: Atenuação existente num enlace de satélite devida aos gases atmosféricos.

Para se estimar o valor da atenuação por gases, há a necessidade de se saber antes a atenuação que temos para o caso em que temos ar seco, $\gamma_{o}(\mathrm{~dB} / \mathrm{km})$, e para quando temos ar úmido, $\gamma_{w}(\mathrm{~dB} / \mathrm{km})[7]$.

Para o ar seco, tem-se que:

Para $\mathrm{f} \leq 54 \mathrm{GHz}$

$$
\gamma_{o}=\left[\frac{7.34 r_{p}^{2} r_{t}^{3}}{f^{2}+0.36 r_{p}^{2} r_{t}^{2}}+\frac{0.3429 b \gamma_{o}^{\prime}(54)}{(54-f)^{a}+b}\right] f^{2} \times 10^{-3}
$$

Para $54 \mathrm{GHz}<\mathrm{f}<66 \mathrm{GHz}$

$$
\begin{aligned}
\gamma_{o}=\exp & \left\{\left[54^{-N} \ln \left(\gamma_{o}(54)\right)(f-57)(f-60)(f-63)(f-66) / 1944\right.\right. \\
& -57^{-N} \ln \left(\gamma_{o}(57)\right)(f-54)(f-60)(f-63)(f-66) / 486 \\
& +60^{-N} \ln \left(\gamma_{o}(60)\right)(f-54)(f-57)(f-63)(f-66) / 324 \\
& -63^{-N} \ln \left(\gamma_{o}(63)\right)(f-54)(f-57)(f-60)(f-66) / 486 \\
& \left.\left.+66^{-N} \ln \left(\gamma_{o}(66)\right)(f-54)(f-57)(f-60)(f-63) / 1944\right] f^{N}\right\}
\end{aligned}
$$

Para $66 \mathrm{GHz} \leq \mathrm{f}<120 \mathrm{GHz}$

$$
\gamma_{o}=\left[\frac{0.2296 d \gamma_{o}^{\prime}(66)}{(f-66)^{c}+d}+\frac{0.286 r_{p}^{2} r_{t}^{3.8}}{(f-118.75)^{2}+2.97 r_{p}^{2} r_{t}^{1.6}}\right] f^{2} \times 10^{-3}
$$

Para $120 \mathrm{GHz} \leq \mathrm{f} \leq 350 \mathrm{GHz}$ 


$$
\gamma_{o}=\left[3.02 \times 10^{-4} r_{p}^{2} r_{t}^{3.5}+\frac{1.5827 r_{p}^{2} r_{t}^{3}}{(f-66)^{2}}+\frac{0.286 r_{p}^{2} r_{t}^{3.8}}{(f-118.75)^{2}+2.97 r_{p}^{2} r_{t}^{1.6}}\right] f^{2} \times 10^{-3}
$$

Onde:

$$
\begin{aligned}
& \gamma_{o}^{\prime}(54)=2.128 r_{p}^{1.4954} r_{t}^{-1.6032} \exp \left[-2.5280\left(1-r_{t}\right)\right] \\
& \gamma_{o}(54)=2.136 r_{p}^{1.4975} r_{t}^{-1.5852} \exp \left[-2.5196\left(1-r_{t}\right)\right] \\
& \gamma_{o}(57)=9.984 r_{p}^{0.9313} r_{t}^{2.6732} \exp \left[0.8563\left(1-r_{t}\right)\right] \\
& \gamma_{o}(60)=15.42 r_{p}^{0.8595} r_{t}^{3.6178} \exp \left[1.1521\left(1-r_{t}\right)\right] \\
& \gamma_{o}(63)=10.63 r_{p}^{0.9298} r_{t}^{2.3284} \exp \left[0.6287\left(1-r_{t}\right)\right] \\
& \gamma_{o}(66)=1.944 r_{p}^{1.6673} r_{t}^{-3.3583} \exp \left[-4.1612\left(1-r_{t}\right)\right] \\
& \gamma_{o}^{\prime}(66)=1.935 r_{p}^{1.6657} r_{t}^{-3.3714} \exp \left[-4.1643\left(1-r_{t}\right)\right] \\
& a=\ln \left(\eta_{2} / \eta_{1}\right) / \ln 3.5 \\
& b=4^{a} / \eta_{1} \\
& \eta_{1}=6.7665 r_{p}^{-0.5050} r_{t}^{0.5106} \exp \left[1.5663\left(1-r_{t}\right)\right]-1 \\
& \eta_{2}=27.8843 r_{p}^{-0.4908} r_{t}^{0.8491} \exp \left[0.5496\left(1-r_{t}\right)\right]-1 \\
& c=\ln \left(\xi_{2} / \xi_{1}\right) / \ln 3.5 \\
& d=4^{c} / \xi_{1} \\
& \xi_{1}=6.9575 r_{p}^{-0.3461} r_{t}^{0.2535} \exp \left[1.3766\left(1-r_{t}\right)\right]-1 \\
& \xi_{2}=42.1309 r_{p}^{-0.3068} r_{t}^{1.2023} \exp \left[2.5147\left(1-r_{t}\right)\right]-1 \\
& N=0 \text { para } f \leq 60 \mathrm{GHz} \text { e } N=-15 \text { para } f>60 \mathrm{GHz}
\end{aligned}
$$

Para o ar úmido, tem-se que:

Para $f \leq 350 \mathrm{GHz}$ 


$$
\begin{aligned}
& \gamma_{w}=\left\{3.13 \times 10^{-2} r_{p} r_{t}^{2}+1.76 \times 10^{-3} \rho r_{t}^{8.5}+r_{t}^{2.5}\left[\frac{3.84 \xi_{w 1} g_{22} \exp \left(2.23\left(1-r_{t}\right)\right)}{(f-22.235)^{2}+9.42 \xi_{w 1}^{2}}\right.\right. \\
& +\frac{10.48 \xi_{w 2} \exp \left(0.7\left(1-r_{t}\right)\right)}{(f-183.31)^{2}+9.48 \xi_{w 2}^{2}}+\frac{0.078 \xi_{w 3} \exp \left(6.4385\left(1-r_{t}\right)\right)}{(f-321.226)^{2}+6.29 \xi_{w 3}^{2}} \\
& +\frac{3.76 \xi_{w 4} \exp \left(1.6\left(1-r_{t}\right)\right)}{(f-325.153)^{2}+9.22 \xi_{w 4}^{2}}+\frac{26.36 \xi_{w 5} \exp \left(1.09\left(1-r_{t}\right)\right)}{(f-380)^{2}} \\
& +\frac{17.87 \xi_{w 5} \exp \left(1.46\left(1-r_{t}\right)\right)}{(f-448)^{2}}+\frac{883.7 \xi_{w 5} g_{557} \exp \left(0.17\left(1-r_{t}\right)\right)}{(f-557)^{2}} \\
& \left.\left.+\frac{302.6 \xi_{w 5} g_{752} \exp \left(0.41\left(1-r_{t}\right)\right)}{(f-752)^{2}}\right]\right\} f^{2} \rho \times 10^{-4}
\end{aligned}
$$

Onde:

$$
\begin{aligned}
& \xi_{w 1}=0.9544 r_{p} r_{t}^{0.69}+0.0061 \rho \\
& \xi_{w 2}=0.95 r_{p} r_{t}^{0.64}+0.0067 \rho \\
& \xi_{w 3}=0.9561 r_{p} r_{t}^{0.67}+0.0059 \rho \\
& \xi_{w 4}=0.9543 r_{p} r_{t}^{0.68}+0.0061 \rho \\
& \xi_{w 5}=0.955 r_{p} r_{t}^{0.68}+0.006 \rho \\
& g_{22}=1+(f-22.235)^{2} /(f+22.235)^{2} \\
& g_{557}=1+(f-557)^{2} /(f+557)^{2} \\
& g_{752}=1+(f-752)^{2} /(f+752)^{2}
\end{aligned}
$$

Onde:

$\rho$ : é a densidade de vapor de água $\left(\mathrm{g} / \mathrm{m}^{3}\right)$.

$f$ : freqüência $(\mathrm{GHz})$

$$
\begin{aligned}
& r_{p}=p / 1013 \\
& r_{t}=288 /(273+t) \\
& p \text { :pressão atmosférica }(\mathrm{hPa}) \\
& t: \text { temperatura }\left({ }^{\circ} \mathrm{C}\right) .
\end{aligned}
$$


Como o enlace passa por diversas camadas da atmosfera que se encontram a diferentes altitudes então, define-se uma altitude especifica que para o ar seco é dada por:

$$
h_{o}=5.386-3.32734 \times 10^{-2} f+1.87185 \times 10^{-3} f^{2}-3.52087 \times 10^{-5} f^{3}+\frac{83.26}{(f-60)^{2}+1.2} \quad \mathrm{~km}
$$

Para $1 \mathrm{GHz} \leq \mathrm{f} \leq 56.7 \mathrm{GHz}$

$h o=10 \mathrm{~km}$

Para $56.7 \mathrm{GHz}<\mathrm{f}<63.3 \mathrm{GHz}$

$h_{o}=f\left\{\frac{0.039581-1.19751 \times 10^{-3} f+9.14810 \times 10^{-6} f^{2}}{1-0.028687 f+2.07858 \times 10^{-4} f^{2}}\right\}+\frac{90.6}{(f-60)^{2}} \quad \mathrm{~km}$

Para $63.3 \mathrm{GHz} \leq \mathrm{f}<98.5 \mathrm{GHz}$

$h_{o}=5.542-1.76414 \times 10^{-3} f+3.05354 \times 10^{-6} f^{2}+\frac{6.815}{(f-118.75)^{2}+0.321} \quad \mathrm{~km}$

Para $98.5 \mathrm{GHz} \leq \mathrm{f} \leq 350 \mathrm{GHz}$

Já para o vapor de água a altura equivalente é dada por:

$h_{w}=1.65\left\{1+\frac{1.61}{(f-22.23)^{2}+2.91}+\frac{3.33}{(f-183.3)^{2}+4.58}+\frac{1.90}{(f-325.1)^{2}+3.34}\right\} \quad \mathrm{km}$

Para $\mathrm{f} \leq 350 \mathrm{GHz}$

Portanto, a atenuação por gases para ângulos de elevação menores que $90^{\circ}$, é dada por:

$$
A=\frac{A_{O}+A_{w}}{\sin \varphi} \quad \mathrm{dB}
$$

onde: $A_{o}=h_{o} \gamma_{o}$ e $A_{w}=h_{w} \gamma_{w}$

De (3.113) pode-se concluir, que a atenuação por gases depende principalmente da freqüência, ângulo de elevação, altitude da estação e da densidade de vapor de água ou umidade absoluta do ambiente.

\subsection{2 - ATENUAÇÃO POR CHUVA.}

Depois da perda para o espaço livre, a atenuação por chuva, é a que mais degrada um enlace de comunicações por satélite, figura 16. Este fenômeno ocorre porque as gotas 
de água absorvem a energia das ondas de rádio, e porque uma parte da energia é desviada da trajetória de propagação. Esse grau de interação depende do tamanho das gotas, e da sua distribuição.

Um dos fatores importantes para determinação da atenuação por chuva é a taxa de precipitação, que é a taxa na qual o nível de água se eleva por unidade de tempo.

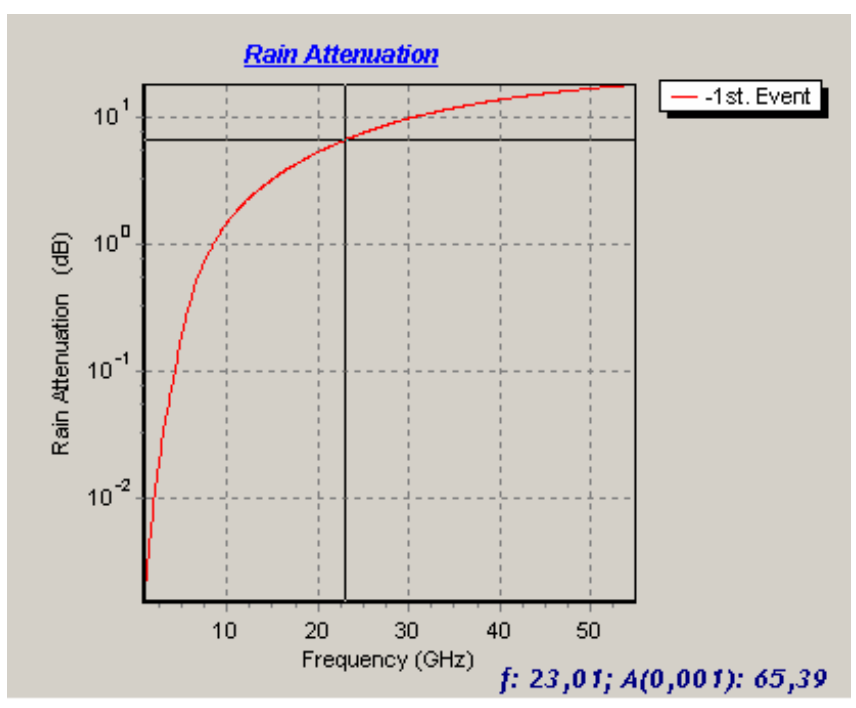

Figura 16: Atenuação que o enlace sofre devido a chuva.

O comportamento da taxa de precipitação para longos períodos é bem representado por uma distribuição de probabilidade cumulativa, figura 8.9 , a qual nos dá a porcentagem de tempo na qual a chuva irá exceder um determinado valor.

Para podermos calcular a atenuação por chuva, é necessário conhecer os seguintes parâmetros:

$R_{0,01}$ : taxa de precipitação da região para um valor excedido de $0.01 \%(\mathrm{~mm} / \mathrm{h})$

$h_{S}:$ altura acima do nível do mar $(\mathrm{km})$

$\theta$ : angulo de elevação $\left({ }^{\circ}\right)$

$\varphi$ : latitude da estação terrena $\left({ }^{\circ}\right)$

$f$ : freqüência $(\mathrm{GHz})$

$R_{e}:$ raio efetivo da Terra $(8500 \mathrm{~km})$ 


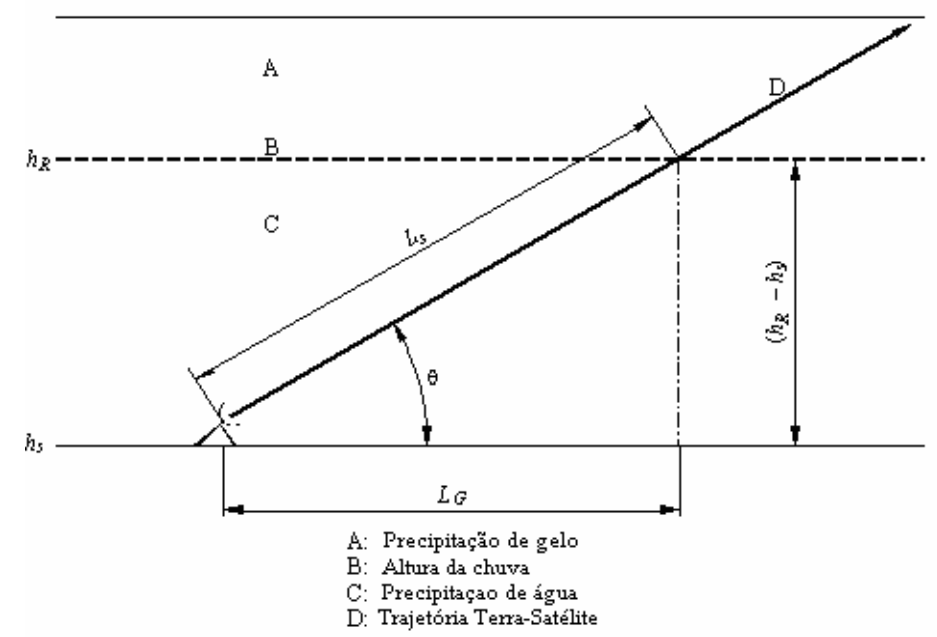

Figura 17: Representação esquemática do enlace Terra-Satélite dando os parâmetros que serão empregues no calculo da atenuação por chuva. Fonte: Rec. 618 -5.

Tendo em conta a geometria da figura 17, e considerando que à parte da chuva que irá afetar o enlace, é a que vai desde a altura da estação até a altura efetiva da chuva então, teremos que dentro dessa região a distância efetiva do enlace para um ângulo de elevação maior ou igual a $5^{\circ}$, é dada por:

$$
L_{s}=\frac{\left(h_{R}-h_{s}\right)}{\sin \theta}
$$

De onde a altura efetiva da chuva é:

$$
h_{R}=h_{o}+0,36
$$

Sendo que $h_{o}$ é a altura em que ocorre o $0{ }^{\circ} \mathrm{C}$ isotérmico da atmosfera. Este valor é obtido de dados meteorológicos.

Se $\theta<5^{\circ}$, então:

$$
L_{s}=\frac{2\left(h_{R}-h_{s}\right)}{\left(\sin ^{2} \theta+\frac{2\left(h_{R}-h_{s}\right)}{R_{e}}\right)^{1 / 2}+\sin \theta}
$$

cuja projeção horizontal é dada por:

$$
L_{G}=L_{S} \cos \theta
$$

Calculando a taxa de precipitação, para uma porcentagem de tempo excedida de $0,01 \%$, por:

$$
P_{0}=P_{R 6}\left(1-e^{-0,0117\left(\frac{M_{S}}{P_{R 6}}\right)}\right)
$$

onde $P_{R \sigma}$, e $M_{S}$ dependem da latitude e longitude da estação terrena, e seus valores são fornecidos pelo ITU em tabelas ou em gráficos. 
Depois de obtido o valor de $P_{o}$, se extraiu a taxa de precipitação de:

$$
R_{p}=\frac{-B+\sqrt{B^{2}-4 A C}}{2 A C}
$$

onde:

$$
\begin{gathered}
A=a b \\
B=a+c \ln \left(p / P_{o}\right) \\
C=\ln \left(p / P_{o}\right)
\end{gathered}
$$

Sendo que:

$$
\begin{gathered}
a=1,11 \\
b=\left(M_{C}+M_{S}\right) /\left(22932 P_{o}\right) \\
c=31,5 b
\end{gathered}
$$

Ao passar pela região chuvosa a trajetória sofre um desvio alterando o seu comprimento que será ajustado por um fator horizontal, dado por:

$$
r_{0.01}=\frac{1}{1+0.78 \sqrt{\frac{L_{G} \gamma_{R}}{f}}-0.38\left(1-\mathrm{e}^{-2 L_{G}}\right)}
$$

Para além desse ajuste existe também o ajuste vertical que é dado pelo seguinte fator vertical:

$$
?_{0.01}=\frac{1}{1+\sqrt{\sin \theta}\left(31\left(1-\mathrm{e}^{-(\theta /(1+\chi))}\right) \frac{\sqrt{L_{R} \gamma_{R}}}{f^{2}}-0.45\right)}
$$

Sendo que:

$$
\zeta=\tan ^{-1}\left(\frac{h_{R}-h_{s}}{L_{G} r_{0.01}}\right)
$$

Para $\zeta>\theta$, tem-se que a trajetória será dada por:

$$
L_{R}=\frac{L_{G} r_{0.01}}{\cos \theta}
$$

Para $\zeta<\theta$, tem-se:

$$
L_{R}=\frac{\left(h_{R}-h_{s}\right)}{\sin \theta}
$$

$\operatorname{Se}|\varphi|<36^{\circ}$, 


$$
\chi=36-|\varphi|
$$

Para outros valores de latitude,

$$
\chi=0
$$

Daí tem-se que a distancia efetiva da trajetória que se encontra na região da chuva é dada por:

$$
L_{E}=L_{R} v_{0.01}
$$

Da taxa de precipitação por chuva tira-se que a atenuação especifica é dada por:

$$
\gamma_{R}=k\left(R_{0.01}\right)^{\alpha}
$$

Onde os coeficientes $k$ e $\alpha$ são dados por:

$$
\begin{aligned}
k & =\frac{k_{H}+k_{V}+\left(k_{H}-k_{V}\right) \cos ^{2} \theta \cos (2 \tau)}{2} \\
\alpha & =\frac{k_{H} \alpha_{H}+k_{V} \alpha_{V}+\left(k_{H} \alpha_{H}-k_{V} \alpha_{V}\right) \cos ^{2} \theta \cos (2 \tau)}{2 k}
\end{aligned}
$$

Sendo que: $\tau$ é o ângulo de polarização da antena, ou seja o ângulo de polarização da onda eletromagnética, e $k_{H}, k_{V}, \alpha_{H}$, e $\alpha_{V}$ são os coeficientes horizontais e verticais que dependem da freqüência.

Finalmente tem-se que a atenuação atmosférica para $0,01 \%$ do tempo é dada por:

$$
A_{0.01}=\gamma_{R} L_{E}
$$

Quando se deseja calcular a atenuação para porcentagens diferentes então se emprega a seguinte expressão:

$$
A_{p}=A_{0.01}\left(\frac{p}{0.01}\right)^{-\left(0.655+0.033 \ln (p)-0.045 \ln \left(A_{0.01}\right)-\beta(1-p) \sin \theta\right)}
$$

onde:

Se $p \geq 1 \%$ ou $|\varphi| \geq 36^{\circ}$ :

$\beta=0$

Se $p<1 \%$ e $|\varphi|<36^{\circ}$ e $\theta \geq 25^{\circ}$ :

$\beta=-0.005(|\varphi|-36)$

Nos demais casos.

$\beta=-0.005(|\varphi|-36)+1.8-3.25 \sin \theta$ 


\subsection{3 - ATENUAÇÃO POR NUVENS.}

Para sistemas que operam acima dos $10 \mathrm{GHz}$ esse tipo de atenuação pode ser bastante severa, uma vez que o tamanho das gotículas de água que compõem as nuvens se aproximam bastante do comprimento de onda do enlace. [8] Para freqüências abaixo dos $200 \mathrm{GHz}$ à aproximação de Rayleigh é valida permitindo assim expressar a atenuação em termos da quantidade total de vapor de água presente por unidade de volume.

Portanto, a atenuação por nuvens é dada por::

$$
A_{C}=\frac{L K_{L}}{\sin \theta}
$$

onde:

$\theta$ - é o ângulo de elevação.

$L\left(\mathrm{~kg} / \mathrm{m}^{2}\right)$ - representa a quantidade total de vapor de água da nuvem, e o seu valor pode ser obtido de dados meteorológicos obtidos a partir de sondas radiométricas. Ela também pode ser obtida a partir de mapas que apresentam o valor da quantidade total de vapor de água na nuvem para um determinado valor de probabilidade excedida.

$K_{L}\left((\mathrm{~dB} / \mathrm{km}) /\left(\mathrm{g} / \mathrm{m}^{3}\right)\right)$ - é o coeficiente de atenuação específica, o qual está baseado no modelo matemático de espalhamento de Rayleigh, e que usa o modelo duplo de Debye para achar a permissividade dielétrica da água, $\varepsilon(f)$, ou seja:

$$
K_{L}=\frac{0,819 f}{\varepsilon^{\prime \prime}\left(1+\eta^{2}\right)}
$$

Sendo que a freqüência esta dada em $\mathrm{GHz}$ e que:

$$
\eta=\frac{2+\varepsilon^{\prime}}{\varepsilon^{\prime \prime}}
$$

onde a permissividade complexa da água é dada por:

$$
\begin{aligned}
& \varepsilon^{\prime \prime}=\frac{f\left(\varepsilon_{0}-\varepsilon_{1}\right)}{f_{p}\left[1+\left(f / f_{p}\right)^{2}\right]}+\frac{f\left(\varepsilon_{1}-\varepsilon_{2}\right)}{f_{S}\left[1+\left(f / f_{S}\right)^{2}\right]} \\
& \varepsilon^{\prime}=\frac{\varepsilon_{0}-\varepsilon_{1}}{1+\left(f / f_{p}\right)^{2}}+\frac{\varepsilon_{1}-\varepsilon_{2}}{1+\left(f / f_{S}\right)^{2}}+\varepsilon_{2}
\end{aligned}
$$

sendo que: 


$$
\begin{aligned}
& \varepsilon_{0}=77,6+103,3(\theta-1) \\
& \varepsilon_{1}=5,48 \\
& \varepsilon_{2}=3,51 \\
& \theta=\frac{300}{T}
\end{aligned}
$$

com $\mathrm{T}$ sendo a temperatura em graus Kelvin e as freqüências primárias e secundárias em GHz calculadas por:

$$
\begin{aligned}
& f_{p}=20,09-142(\theta-1)+294(\theta-1)^{2} \\
& f_{S}=509-1500(\theta-1)
\end{aligned}
$$

Na figura 18, tem-se o resultado da variação da atenuação por nuvens em função da freqüência.

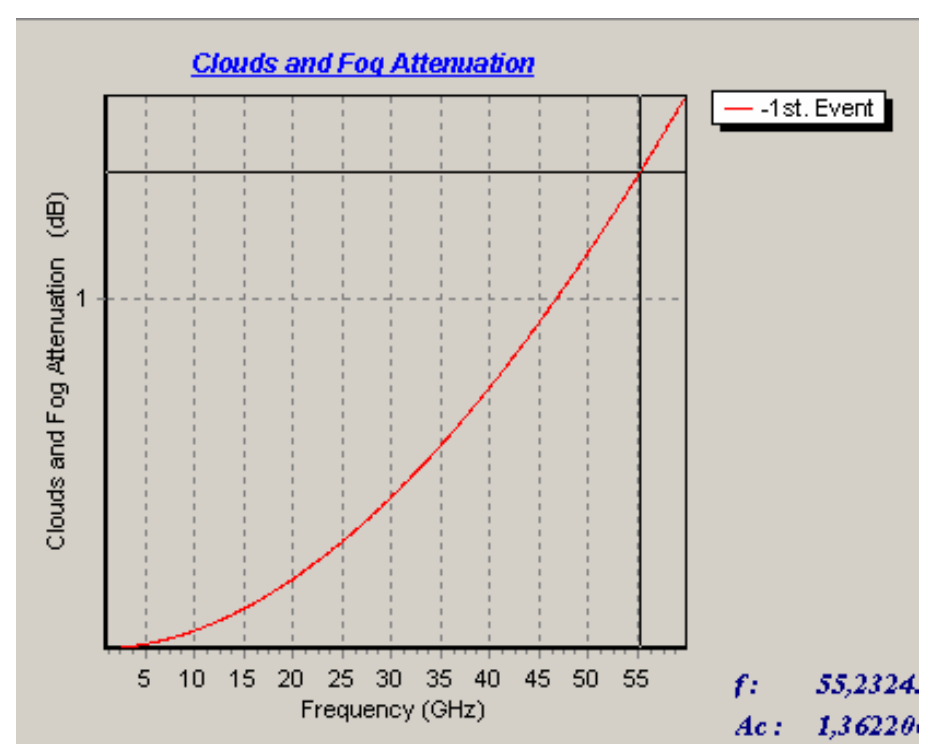

Figura 18: Atenuação por nuvens e nevoeiro.

\subsection{4 - ATENUAÇÃO POR CINTILAÇÃO ATMOSFÉRICA E MÚLTIPLO- PERCURSO.}

O múltiplo-percurso ocorre quando o sinal toma dois ou mais percursos, sendo um o caminho direto e o outro um caminho maior e resulta de uma refração. Estes sinais acabam chegando à antena receptora defasados no tempo em relação à onda que seguiu o caminho direto podendo causar tanto o cancelamento quanto a adição no sinal que chega.[1]

Como os raios são fenômenos de ondas, então as trajetórias direta e refratada podem ser combinadas usando-se o método da adição de vetores, tal como pode ser visto 
na figura 19, aonde os raios que chegam à antena se combinam para formar o sinal resultante final que será entregue ao sistema de recepção.

$\mathrm{Na}$ figura 19 (a), tem-se representado os dois casos extremos de adicionamento e de cancelamento, onde a trajetória direta é representada pelo vetor de sinal vertical de magnitude constante. Adicionado a este está o vetor de sinal refratado que pode chegar num ângulo de fase relativo qualquer, tal como mostrado pelo circulo que tem o vetor principal como centro. Nela podemos verificar que existe um aumento ou uma diminuição do nível do sinal dependendo do ângulo de chegada da onda refratada. [1] Se o sinal refratado possui o mesmo nível que o sinal direto, mas apresenta uma fase relativa de $180^{\circ}$ então ocorre o cancelamento e conseqüentemente a perda do sinal.

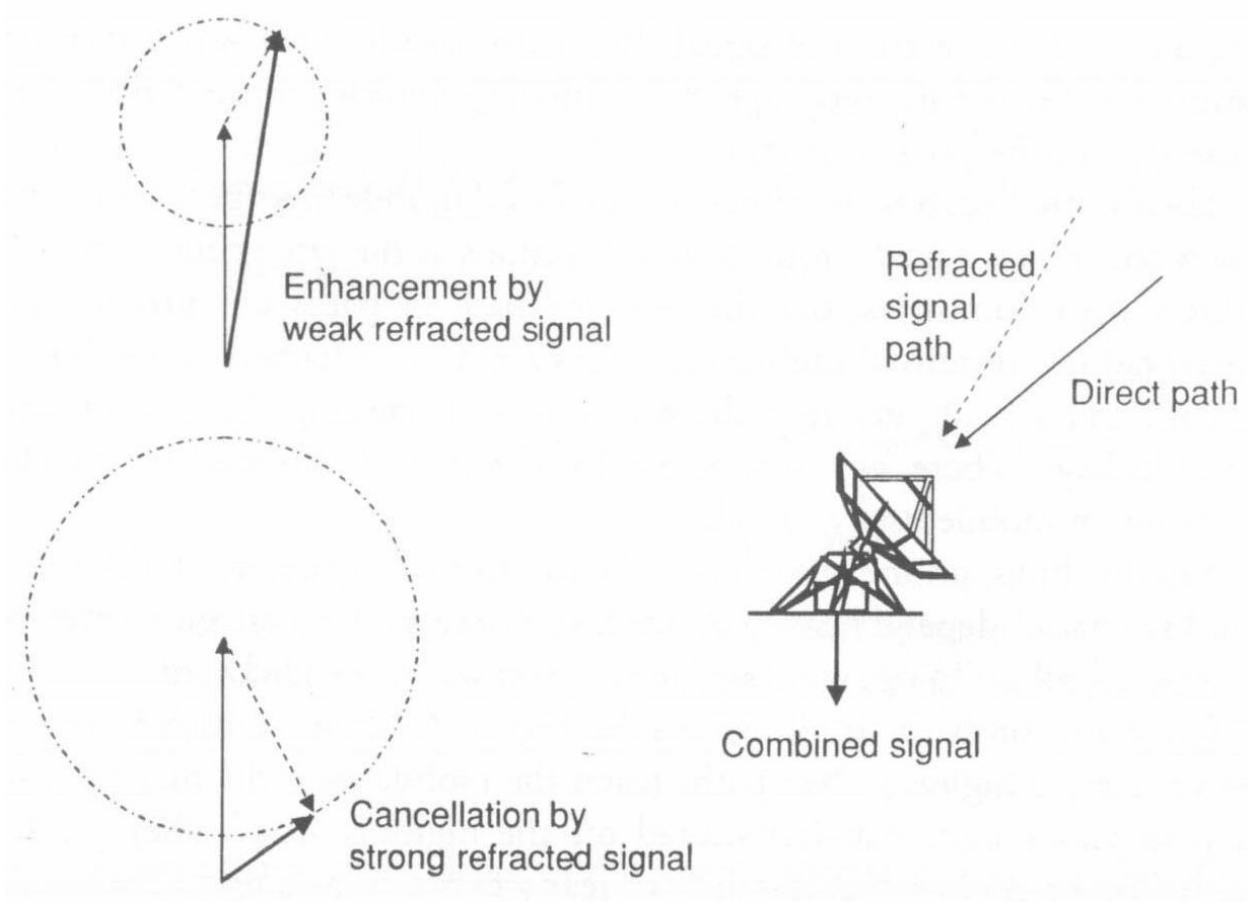

Figura 19: O múltiplo-percurso provoca o enriquecimento ou o cancelamento do sinal direto quando recebido por uma antena tal como mostrado pelos diagramas dos vetores. Fonte: Pratt, Thimoty.

A cintilação atmosférica é provocada por condições instáveis da ionosfera que ocorrem com mais intensidade em dois períodos do ano (equinócios de inverno e verão). As estações que se encontram perto do equador geomagnético são as que observam esse fenômeno com mais intensidade durante tais períodos do ano. [1]

A sua magnitude depende da magnitude, da estrutura e da variação do índice de refração, aumentando com a freqüência, com o comprimento da trajetória que passa pelo meio e diminuindo com a diminuição da largura de feixe da antena.

Para predição da distribuição cumulativa da cintilação ionosférica empregam-se os dados anuais ou mensais médios da temperatura $t\left({ }^{\circ} \mathrm{C}\right)$, umidade relativa $H$, e as condições 
climáticas especificas da região. Portanto a atenuação por cintilação e múltiplo-percurso é calculada da seguinte forma: [6]

Considerando-se os valores de temperatura média anual ou mensal, $t$, obtém-se a pressão de saturação do vapor de água, $e_{S}(\mathrm{hPa})$ pela seguinte expressão: [9]

$$
e_{S}=a e^{\left(\frac{b t}{t+c}\right)}
$$

onde:

$t$ - é a temperatura em graus Celsius;

$H$ - é a umidade relativa em porcentagem;

E os coeficientes $a, b$ e $c$, dependem do meio (água ou gelo) e são dados por:

Para água:

$$
\begin{aligned}
& a=6,1121 \\
& b=17,502 \\
& c=240,97
\end{aligned}
$$

Para o gelo:

$$
\begin{aligned}
& a=6,1115 \\
& b=22,452 \\
& c=272,55
\end{aligned}
$$

Tendo os valores da pressão de saturação do vapor de água, obtém-se o valor do índice de refração para condições de umidade, $N_{\text {wet }}$, o qual é calculado por:

$$
N_{w e t}=3,732.10^{5} \frac{e}{T^{2}}
$$

onde:

$e$ : é a pressão de vapor de água $(\mathrm{hPa})$, e é dada por:

$$
e=\frac{H e_{S}}{100}
$$

$T$ : é a temperatura absoluta em graus Kelvin.

Obtidos os valores do índice de refração para as condições de umidade, obtém-se agora o desvio padrão da amplitude do sinal, $\sigma_{r e f}$, que é dado por:

$$
\sigma_{r e f}=3,6 \cdot 10^{-3}+10^{-4} \times N_{w e t}
$$

O que irá permitir calcular o comprimento efetivo da trajetória dentro do meio por:

$$
L=\frac{2 h_{L}}{\sqrt{\sin ^{2} \theta+2,35.10^{-4}}+\sin \theta}
$$


Onde:

$h_{L}$ : é a altitude da camada de turbulência cujo valor a ser empregue deve ser de $1000 \mathrm{~m}$.

Do diâmetro geométrico da antena, $D$, estima-se agora o diâmetro efetivo desta,

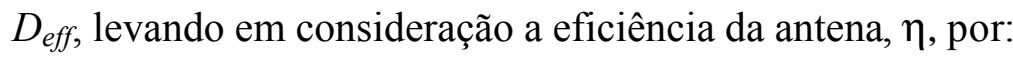

$$
D_{\text {eff }}=\sqrt{\eta} D
$$

O qual será útil para o calculo do fator de disponibilidade da antena que é:

$$
g(x)=\sqrt{3.86\left(x^{2}+1\right)^{11 / 12} \cdot \sin \left[\frac{11}{6} \arctan \frac{1}{x}\right]-7.08 x^{5 / 6}}
$$

Onde:

$$
x=1.22 D_{\text {eff }}^{2}(f / L)
$$

Com isso calcula-se o desvio padrão do sinal para a trajetória e para o período em consideração a partir de:

$$
\sigma=\sigma_{r e f} f^{7 / 12} \frac{g(x)}{(\sin \theta)^{1.2}}
$$

Considerando o fator de porcentagem para o qual a atenuação será excedida, que é obtido de:

$$
a(p)=-0,061(\log p)^{3} ? 0,072(\log p)^{2}-1,71 \log p ? 3,0
$$

De (3.139) e (3.140), tiramos que:

$$
A_{S}(p)=a(p) \sigma
$$

Cuja curva característica é mostrada na figura 20, onde podemos ver que esse tipo de atenuação possui pouco impacto sobre o sinal.

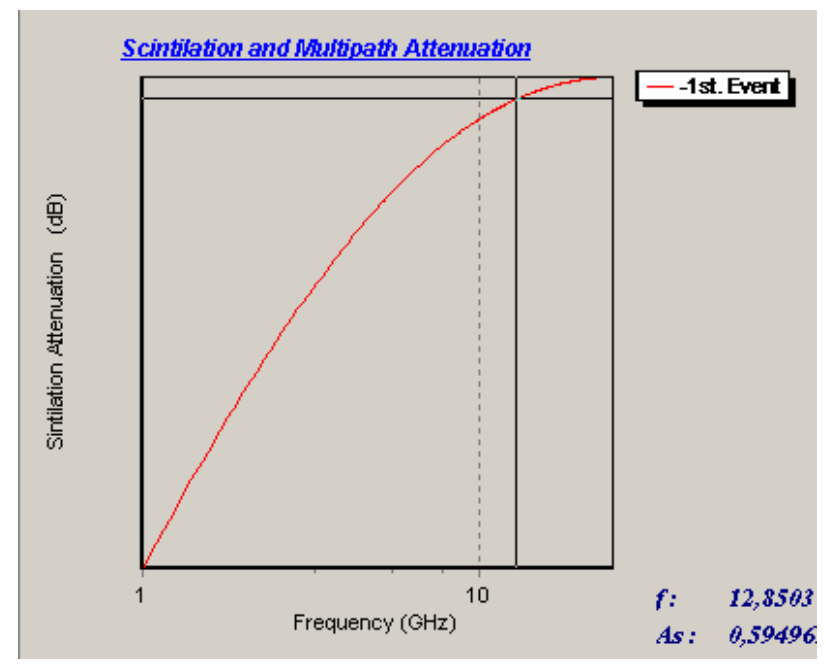

Figura 20: Atenuação por cintilação ionosférica. 


\subsection{5 - ATENUAÇÃO ATMOSFÉRICA TOTAL.}

A atenuação atmosférica total representa a combinação dos efeitos provocados pelas chuvas, gases, nuvens e cintilações. Como ela é uma função densidade de probabilidade, então ela pode ser calculada por:

$$
A_{T}(p)=A_{G}(p)+\sqrt{\left(A_{R}(p)+A_{C}(p)\right)^{2}+A_{S}^{2}(p)}
$$

Onde:

$A R(p)$ : atenuação por chuva;

$A_{C}(p)$ : atenuação por nuvens;

$A_{G}(p)$ : atenuação por gases;

$A S(p)$ : atenuação por cintilação;

Cujas formas de calcular foram desenvolvidas nos itens 3.6.1, 3.6.2, 3.6.3 e 3.6.3.

O efeito de combinação desses fatores pode ser observado na figura 21.

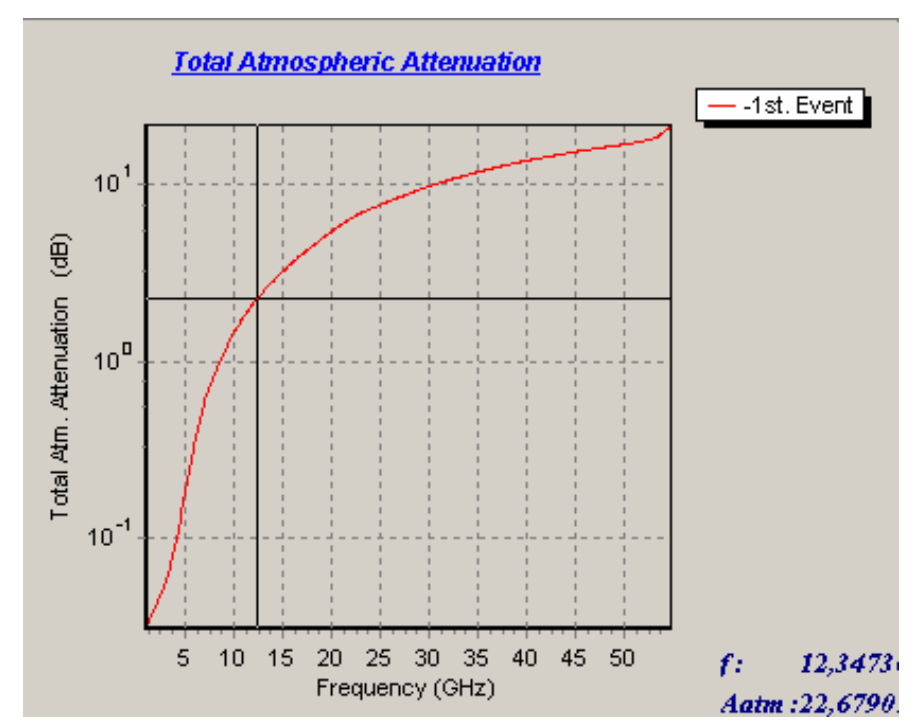

Figura 21: Atenuação atmosférica total.

\section{7 - POLARIZAÇÃo CRUZADA.}

O reuso de freqüência pelo uso da polarização ortogonal é freqüentemente usado nos novos sistemas de satélite para dobrar a sua capacidade, no entanto o isolamento entre polarizações ortogonais é sempre degradado como resultado do efeito de despolarização estática das antenas e do efeito de despolarização do meio de propagação. Esses efeitos fazem com que uma porção da energia do sinal transmitido, com uma dada polarização, 
seja transferido para o outro sinal que é transmitido numa polarização ortogonal causando o efeito de interferência por polarização cruzada.

A despolarização da frente de onda é outro efeito que pode ser provocado pela chuva, ela ocorre porque as gotas de chuva de grandes dimensões não possuem uma forma esférica, mas oblata, ou seja, achatadas nos pólos, as quais caiem com o seu eixo maior quase na horizontal. Se todas as gotas durante a chuva estivessem alinhadas e as ondas eletromagnéticas estiverem propagando com o seu vetor campo elétrico paralelo ao eixo maior das gotas (ondas polarizadas horizontalmente) iremos verificar que a atenuação que ocorre é máxima. Já quando o vetor campo elétrico é paralelo ao menor eixo das gotas (ondas polarizadas verticalmente) o que iremos verificar é que irá ocorrer a atenuação mínima. Em ambos os casos não ira ocorrer o efeito de despolarização [2].

No caso em que o ângulo de polarização se encontra entre a polarização horizontal e vertical podemos dizer que ela possui duas componentes de polarização, uma horizontal e a outra vertical, tal como podemos ver na figura 22. Esses componentes se propagam pela chuva sem que a sua polarização seja alterada, só que o componente horizontal será mais atenuado do que o componente vertical. Se em qualquer ponto da propagação se fizera recombinação dos componentes horizontal e vertical de modo a podermos reconstruir a onda, o que iremos verificar é que a polarização sofreu uma rotação na direção do eixo vertical, o que faz com que apareça o componente de polarização cruzada. $[10,11]$

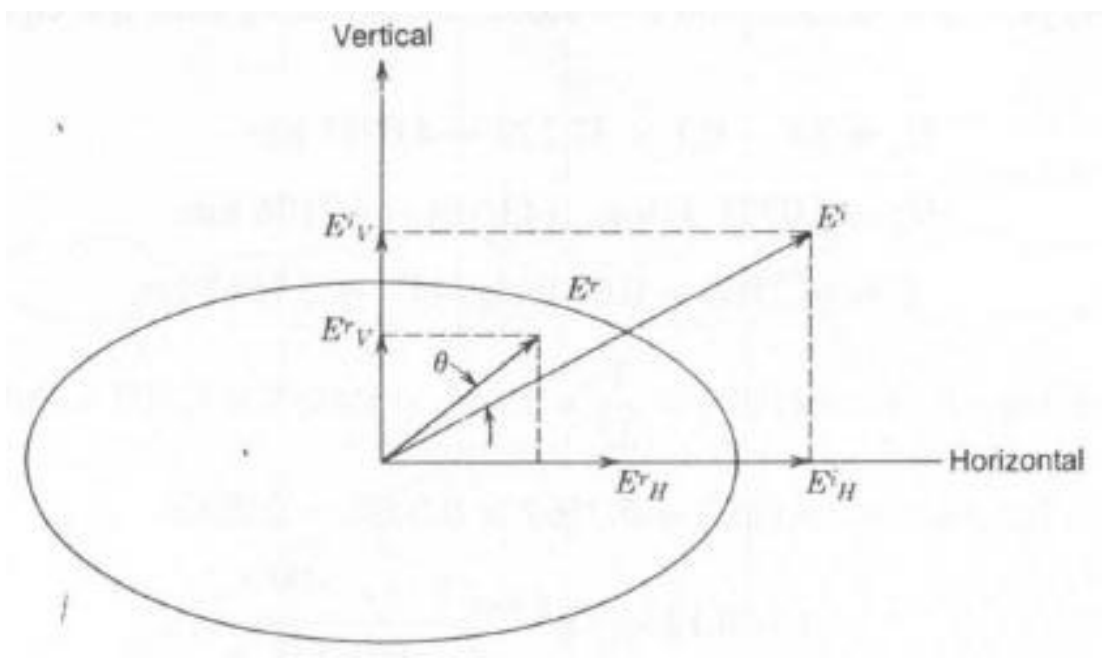

Figura 22: Explicação simplificada da despolarização por chuva. Uma onda eletromagnética com vetor campo elétrico $E^{i}$ atinge uma gota de chuva. Ele é decomposto em dois componetes; um vertical $E_{V}^{i}$ e um horizontal $E_{H}^{i}$. O componete horizontal sofre uma atenuaçao maior do que o componete vertical uma vez que atravessa mais água. Portanto quando são recombinados os componetes vertical, $E_{V}^{r}$, e horizontal, $E_{H}^{r}$, que chegam ao receptor, notamos que o campo recebido, $E^{r}$, teve uma rotaçao na polarizaçao ao longo do eixo vertical por um ângulo $\theta$. Fonte: Pratt, Thimoty. 
Para se poder estimar o efeito da despolarização por causa da chuva tem que se levar em conta os seguintes parâmetros:

$A_{p}:$ atenuação por chuva (dB) calculada no item 3.6.2;

$\tau$ : o ângulo de polarização do vetor campo elétrico da antena (sendo que para a polarização circular $\tau=45^{\circ}$.);

$f$ : freqüência $(\mathrm{GHz})$;

$\theta$ : ângulo de elevação (graus).

Para o termo dependente da freqüência, temos que para $8=\mathrm{f}=35 \mathrm{GHz}$ :

$$
C_{f}=30 \log f
$$

Para o termo dependente da atenuação por chuva temos:

$$
C_{A}=V(f) \log A_{p}
$$

Onde:

Para $8=\mathrm{f}=20 \mathrm{GHz}$

$$
V(f)=12,8 f^{0,19}
$$

E para $20=\mathrm{f}=35 \mathrm{GHz}$

$$
V(f)=22,6
$$

O termo dependente da polarização é dado por:

$$
C_{\tau}=-10 \log [1-0,484(1 \cos 4 \tau)]
$$

O termo dependente do ângulo de elevação é dado por:

$$
C_{\theta}=-40 \log (\cos \theta)
$$

O termo dependente do falso ângulo é dado por:

$$
C_{\sigma}=0,0052 \sigma^{2}
$$

Onde

$\sigma$ - é o desvio padrão efetivo da distribuição do falso ângulo e é expresso em graus.

Portanto o valor de polarização cruzada devido à chuva é dado por:

$$
X P D_{\text {rain }}=C_{f}-C_{A} ?_{\tau} ? C_{\theta} C_{\sigma}
$$

E o valor de polarização cruzada devido ao gelo é dado por:

$$
C_{\text {ice }}=X P D_{\text {rain }} \times(0,3 ? 0,1 \log p) 2
$$

Sendo que a polarização cruzada total é dada por:

$$
X P D_{p}=X P D_{\text {rain }}-C_{\text {ice }}
$$

Aplicando (3.152), obtemos a figura 23, que nos mostra que à medida que a freqüência aumenta o efeito de polarização cruzada vai diminuindo. 


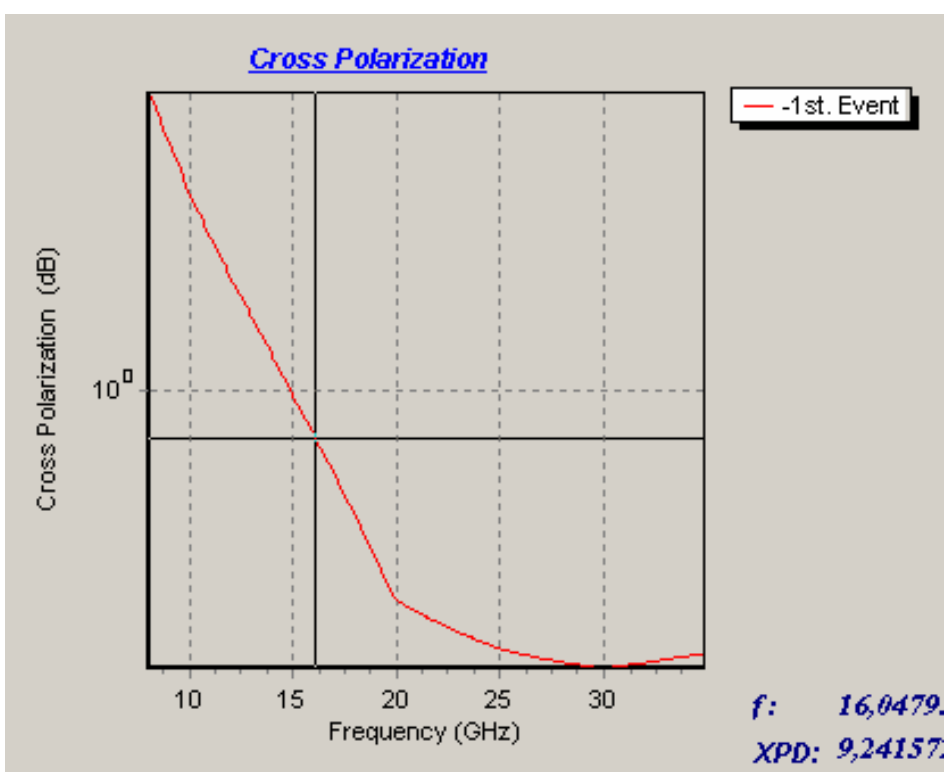

Figura 23: Efeito da polarização cruzada em função da freqüência.

\section{8 - ANÁLISE DA INTERFERÊNCIA.}

Considerando $i_{1, u}(t), i_{2, u}(t), \ldots, i_{p, u}(t)$, sinais aditivos cujas potências são dadas por $I_{1, u}, I_{2, u}, \ldots, I_{p, u}$ e que as mesmas se encontram dentro da banda de interesse do sistema no enlace de subida, teremos que a potência total interferente mais o ruído deste enlace será dada por: [3]

$$
N_{T, u}=N_{u}+\sum_{k=1}^{p} I_{k, u}
$$

Levando em consideração a ocorrência de interferência no enlace de subida então teremos que a razão portadora ruído será:

$$
\begin{aligned}
& \frac{C}{N_{T, u}}=\frac{1}{\left(\frac{C}{N_{u}}\right)^{-1}+\left(\sum_{k=1}^{p} \frac{C}{I_{k u}}\right)^{-1}} \\
& \frac{C}{N_{T, u}}=\frac{1}{\left(\frac{C}{N_{u}}\right)^{-1}+\left(\frac{C}{I}\right)^{-1}}
\end{aligned}
$$

Onde:

$$
\frac{C}{I_{u}}=\left(\left.\sum_{k=1}^{p} \frac{C}{I_{k}}\right|_{u} ^{-1}\right)^{-1}
$$


De forma análoga para o enlace de descida temos que considerando os sinais $i_{1, d}(t)$, $i_{2, d}(t), \ldots, i_{p, d}(t)$ sinais aditivos cujas potências são dadas por $I_{1, d}, I_{2, d}, \ldots, I_{p, d}$ e se encontram dentro da banda de interesse do sistema deste enlace à potência total considerando o ruído será dada por:

$$
N_{T, d}=N_{d}+\sum_{k=1}^{p} I_{k, d}
$$

Tendo em consideração a interferência na estimativa da relação canal ruído do enlace de descida, obtém-se que:

$$
\begin{aligned}
& {\frac{C}{N_{T, d}}}=\frac{1}{\left(\frac{C}{N_{d}}\right)^{-1}+\left(\sum_{k=1}^{p} \frac{C}{I_{k d}}\right)^{-1}} \\
& \frac{C}{N_{T, d}}=\frac{1}{\left(\frac{C}{N_{d}}\right)^{-1}+\left(\frac{C}{I_{d}}\right)^{-1}}
\end{aligned}
$$

Onde:

$$
\frac{C}{I_{u}}=\left(\left.\sum_{k=1}^{p} \frac{C}{I_{k}}\right|_{u} ^{-1}\right)^{-1}
$$

Conhecendo-se as interferências, a razão portadora ruído total do enlace será dada por:

$$
\begin{aligned}
& \frac{C}{N_{T}}=\frac{1}{\left(\frac{C}{N_{u}}\right)^{-1}+\left(\frac{C}{I}\right)^{-1}+\left(\frac{C}{N_{d}}\right)^{-1}+\left(\frac{C}{I}\right)_{d}^{-1}} \\
& \frac{C}{N_{T}}=\frac{1}{\left(\frac{C}{N}\right)^{-1}+\left(\frac{C}{I}\right)^{-1}}=\frac{1}{\left(\frac{C}{N_{T, u}}\right)^{-1}+\left(\frac{C}{N_{T, d}}\right)^{-1}}
\end{aligned}
$$

Onde:

$$
\frac{C}{I}=\frac{1}{\left(\frac{C}{I_{u}}\right)^{-1}+\left(\frac{C}{I_{d}}\right)^{-1}}
$$

Uma vez definida a modulação a razão $C / N$ total, considerando a interferência pode ser determinada e conseqüentemente o desempenho do sistema pode ser analisado.

Em sistemas digitais o desempenho é medido em função da $B E R$ a qual é função da razão $E_{b} / N_{0}$ e que está relacionada com a razão $C / N$ pela seguinte expressão:

$$
\frac{C}{N}=10 \log \frac{E_{b}}{N_{0}}-10 \log R_{b}
$$


O arranjo imposto à equação:

$$
\frac{C}{N_{T}}=\frac{1}{\left(\frac{C}{N}\right)^{-1}+\left(\frac{C}{I}\right)^{-1}}=\frac{1}{\left(\frac{C}{N_{T, u}}\right)^{-1}+\left(\frac{C}{N_{T, d}}\right)^{-1}}
$$

A qual mostra que a razão $C / N$ total depende do tipo de interferência que esta ocorrendo no sistema e dos sinais interferentes serem não correlatados e do tipo ruído branco aditivo gaussiano (AWGN). Caso não se verifiquem esses pontos (3.162) resultará numa visão pessimista da $B E R$, uma vez que a potência total obtida pela soma das potências dos sinais interferentes mais a correlação entre estes daria uma intensidade menor do que a predita no caso de correlação nula. 


\section{0 - PROGRAMA CLARKE.}

O programa Clarke é uma ferramenta computacional desenvolvida usando-se a linguagem de programação Delphi. Ele permite que se faça à simulação ou a analise dos diversos fatores que afetam a propagação de um sinal de radio freqüência em um enlace de comunicações por satélite, também permite projetar um enlace tendo em conta dados mundiais dos fenômenos atmosféricos que afetam a boa propagação do sinal e irão acarretar numa degradação deste na entrada das antenas receptoras do satélite e da estação terrena. Depois de efetuado o projeto e tendo se obtido os dados ele permite que se faça a otimização do enlace caso assim se desejar.

O Clarke é composto basicamente por três módulos que apresentam funções distintas e que interagem entre si. O módulo 1, é o responsável pelo banco de dados do programa. Esse banco de dados é constituído por tabelas que contêm os dados das estações terrenas, transmissora e receptora, e aos dados do satélite. Ele também é composto por tabelas cujos dados não podem ser editados pelo usuário uma vez que se tratam de dados probabilísticos de condições atmosféricas globais que foram obtidas de informações meteorológicas que vêm sendo coletadas há 15 anos pelos satélites meteorológicos europeus.

O modulo 2, é o que é composto pelas calculadoras de analise. Elas permitem que o usuário realize a análise de uma determinada situação especifica ou de um dado ponto de operação do sistema que ele possa julgar critico e ver como o fenômeno se comporta dentro da faixa de interesse. Esse módulo apresenta os resultados dos cálculos em modo gráfico e em forma de relatório simultaneamente. Ele permite também que se possam simular varias situações e que se faça uma comparação entre os resultados obtidos em analises anteriores. Todas as simulações feitas neste modulo fazem uso do modulo 1, que como se disse, contém informações que permitem o calculo de uma situação ou de um evento.

O modulo 3, é o de projeto. Ele utiliza todas as ferramentas que estão disponíveis nos outros dois módulos, só que agora é realizada uma análise qualitativa, que levará a realização do projeto. No fim da simulação ele apresenta um relatório completo sobre as condições do enlace que se está projetando. Ele permite que se faça uma otimização do resultado obtido permitindo assim que se refine mais o projeto. Nele estão contidos vários modelos de projeto uma vez que geralmente as operadoras oferecem um método para projeto de enlace de satélite que seja mais conveniente para o seu caso em específico. 


\section{1 - ENTRADA DE DADOS.}

Quando o programa é inicializado, o usuário se depara com uma tela, tal como mostra a figura 24, onde podemos ver dois campos bem distintos. O da esquerda é campo de entrada de dados de calculo, que serão utilizados nos processos de análise, enquanto que o outro é o campo de saída de resultados e relatórios. É neste segundo campo que se faz a escolha de variáveis e se definem os limites e faixas de análise.

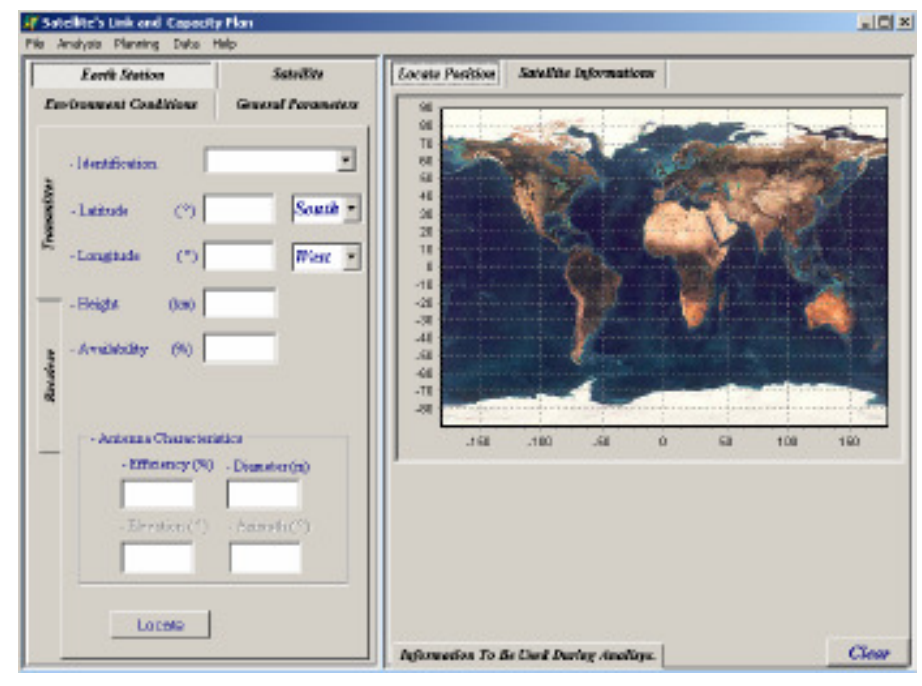

Figura 24: Tela inicial.

Nota-se que o campo de entrada de dados esta dividido obedecendo ao tipo de informação que será fornecida e a quem ela está associada. Se a informação que se quer dar é sobre o satélite, então, se deve escolher a guia do satélite para poder informar um dado valor ou então, escolher qual dos casos existentes no banco de dados serão utilizados. Aqui o procedimento é igual para cada guia.

Ele não permite alterações no banco de dados sobre as estações ou sobre os satélites. Caso se queira fazer alguma alteração ao banco ou adicionar alguma informação que esteja faltando, então acessando o menu data o usuário terá de escolher que tipo de dado irá fornecer (estação terrena ou de satélite). Este procedimento irá ativar o campo de editoração de dados, figura 25, do Clarke.

Para editar alguma informação, basta usar a barra de navegação que permite fazer a procura, adição, edição e remoção das informações que existem. No caso do usuário escolher a edição dos dados do satélite então ele poderá entrar com as imagens, figura 25, das coberturas que o operador de satélite dá sobre a $E I R P$ e a razão $G / T$ 


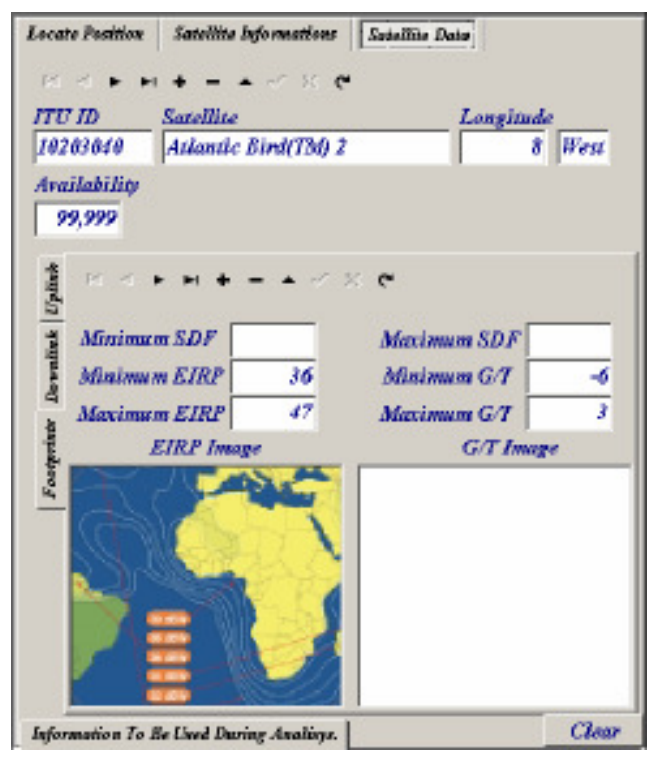

Figura 25: Campo de editoração dos dados que se encontram no banco de dados. No caso os dados que serão editados serão os dados de satélite.

Depois de inseridas as informações que serão utilizadas durante as análises, é possível verificar se as estações que se quer utilizar ou projetar estão dentro da região de visibilidade do satélite bastando para tal clicar o botão Locate, figura 26, que será traçado no globo, presente no campo à direita, às estações o satélite e os limites de visibilidade e das inclinações de $5^{\circ}$ e $10^{\circ}$ graus de elevação, caso estas estejam dentro da região de cobertura global do satélite, figura 26. Caso contrário será emitido um aviso informando quais os limites de visibilidade máxima para aquele satélite em questão. Neste calculo também é feito apontamento da antena e informados os seus valores de azimute e elevação tanto no relatório que se monta sobre as estações, figura 26 , quanto na caixa de azimute e elevação da antena no campo de entrada de dados.

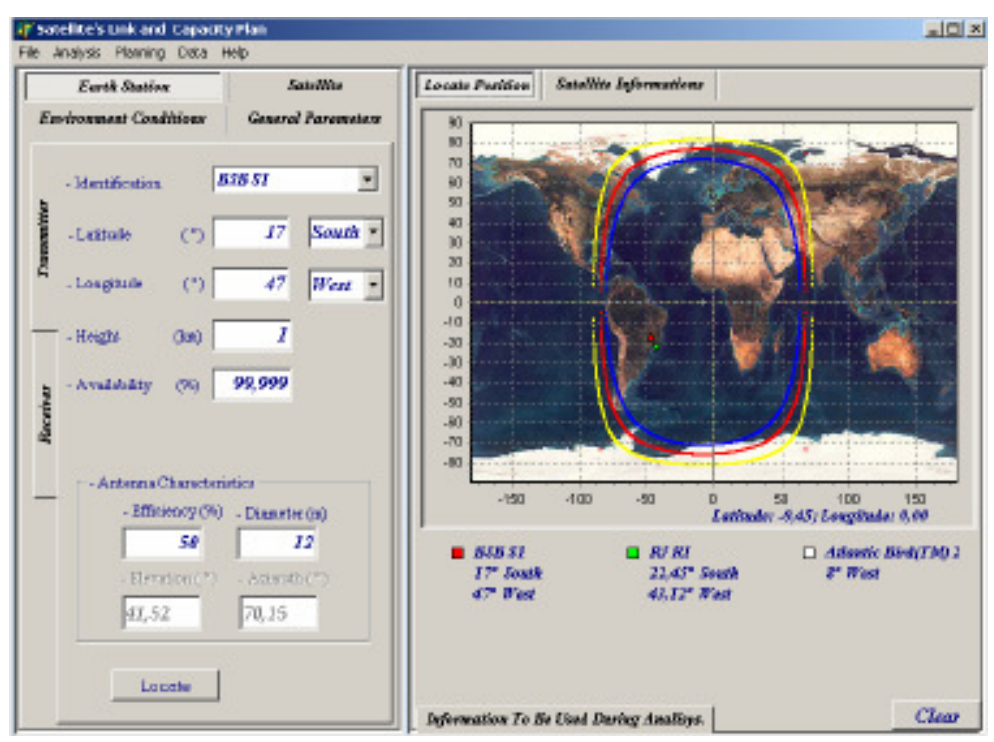

Figura 26: Visualização dos limites de visibilidade do satélite e informação dos ângulos de elevação e azimute das antenas das estações terrenas, utilizando a informação fornecida. 


\section{2 - FERRAMENTAS DE ANALISE.}

Estas só podem ser acessadas por meio do menu Analisys, figura 27, que nos dá acesso aos diferentes tipos de calculadoras: - atenuação por chuva, por nuvens e nevoeiro, por gases, atmosférica, para o espaço livre, por cintilação e por espalhamento de feixe; $C / N$ do uplink, do downlink e o total; - Incremento da temperatura de ruído; e finalmente efeito de polarização cruzada.

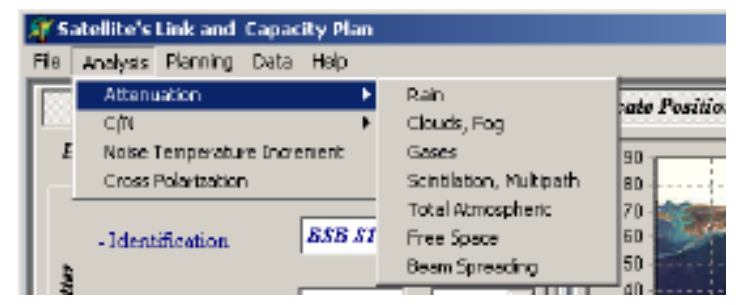

Figura 27: Menu Analysis do programa. Ele permite acessar as diferentes calculadoras existentes no programa.

Quando se escolhe uma delas abre-se no campo de saída, figura 28, um guia que permite, a escolha da variável, estação que será utilizada no calculo. Em seqüência vão sendo pedidos os parâmetros que irão ser utilizados durante o processo de análise. Depois de preenchidos todos os valores necessários ao calculo, pode-se visualizar o resultado da analise em forma gráfica e em forma de relatório, figura 29.

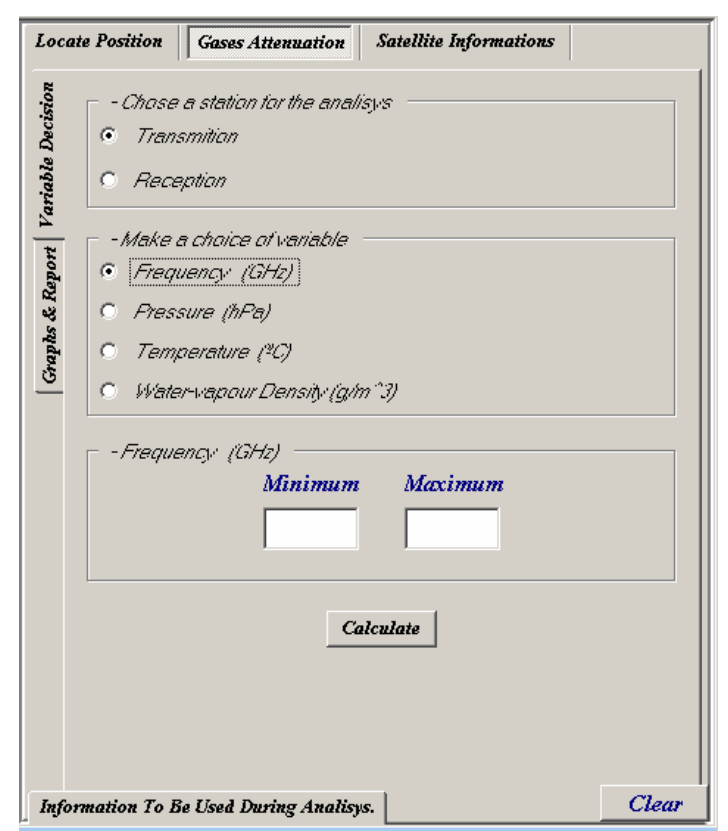

Figura 28: Aparência de um das calculadoras que permitem a análise individual de cada um dos fatores que afetam o enlace. 


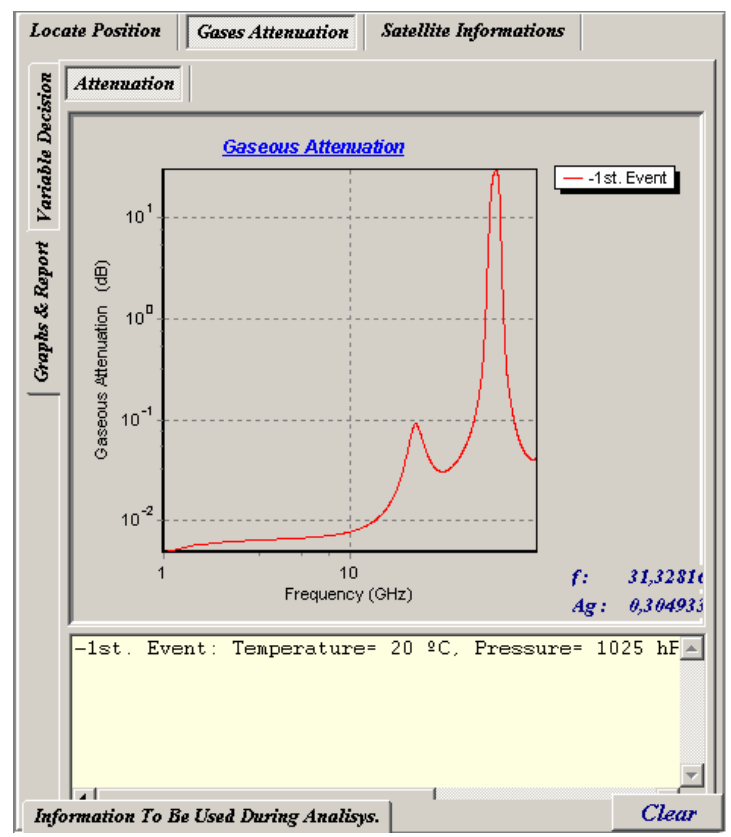

Figura 29: Tipos de saída que temos após definidos os parâmetros de análise e as faixas de variação.

Se se pedir para que seja feita mais de uma análise, então vão se armazenando os gráficos e os relatórios sobre as condições que foram utilizadas durante o processo, figura 30 .

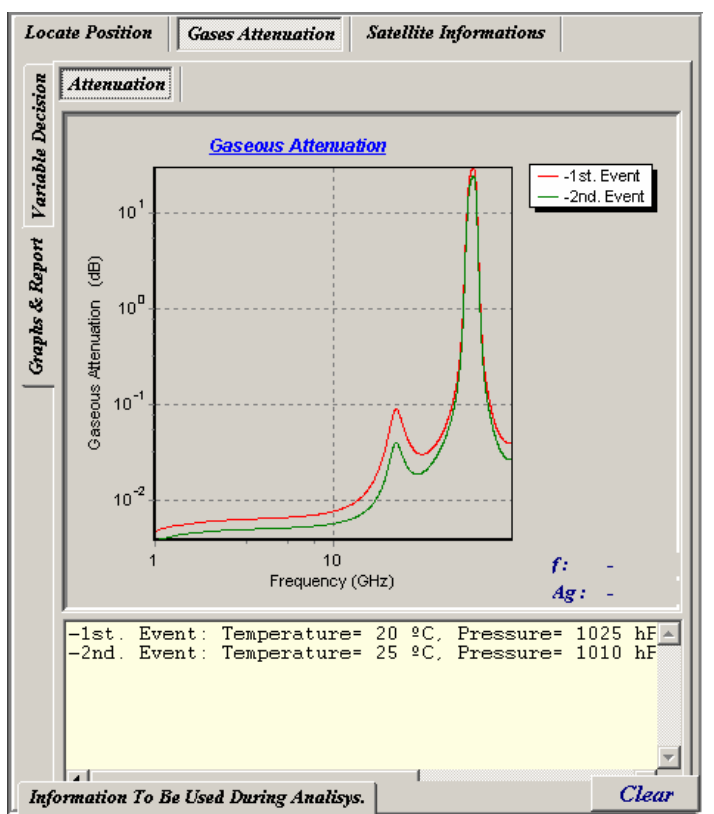

Figura 30: Saída para o caso de mais de termos mais de um evento para se fazer a análise e assim escolher o melhor caso.

Os procedimentos utilizados para que se efetuassem os cálculos foram todos descritos no capítulo 1. Portanto, cada calculadora segue o procedimento do seu tópico, descrito no capitulo 1, ou seja, para a analise da atenuação por chuva, o procedimento de calculo é o que está descrito no item 3.6.2. Já para a analise da atenuação por gases o 
procedimento de calculo é o que está descrito no item 3.6.1, para a da atenuação por nuvens e nevoeiro é o descrito no item 3.6.3, para a da atenuação por cintilação ionosférica e múltiplo-percurso é o descrito no item 3.6.4, para a da atenuação atmosférica total é o descrito no item 3.6.5, a atenuação por polarização cruzada é o descrito no item 3.7.

No caso da atenuação por espalhamento de feixe temos que tomar o cuidado de termos a estação terrestre com um ângulo de elevação abaixo dos seis graus uma vez que essa atenuação só ocorre com mais intensidade para valores de elevação abaixo dos seis graus, sendo desprezível para valores de ângulo de elevação superiores. No entanto, caso não se obedeça a esse critério será emitida uma mensagem de erro com os limites de elevação para esse tipo de calculo, figura 31.

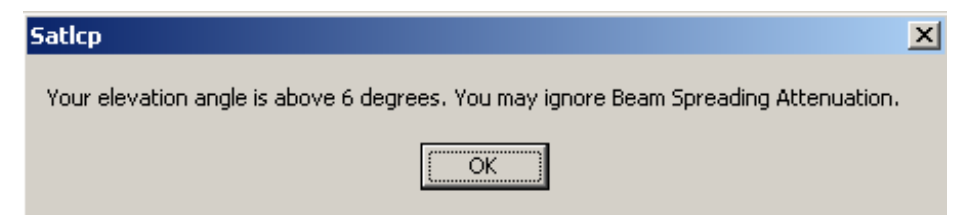

Figura 31: Caixa de dialogo informando uma situação de calculo que foi violada.

\subsection{PROJETO DE SISTEMA VIA SATÉLITE}

O projeto de um sistema via satélite depende da definição da disponibilidade total do sistema, da determinação da relação canal ruído total, que irá garantir uma BER ou qualidade do sinal deseja durante este período de disponibilidade.

Como se sabe os critérios de qualidade variam de sistema para sistema e dependem essencialmente do tipo de modulação que será utilizado durante o processo de comunicação entre o dispositivo transmissor e o receptor. O tipo de modulação utilizado é que nos permite extrair a taxa de erro de bits (BER), a qual por sua vez é essencial para a determinação da razão portadora ruído total que iremos ter presente no sistema para a técnica de modulação e para a taxa de erro de bit que escolheu. Esse valor é obtido das curvas características de cada modulação. Obtido assim o valor da razão portadora ruído total do sistema pode-se determinar agora os equipamentos que compõem o sistema e que irão permitir o estabelecimento da comunicação entre a estação transmissora e a receptora.

Portanto, para que o projeto seja bem executado e contenha o mínimo de imprecisões, há a necessidade de se definirem os seguintes parâmetros:

- Técnica de multiplexação e de modulação;

- Interferência adjacente, que pode ser minimizada empregando-se para tal antenas muito diretivas e com baixo nível de lobos laterais; 
- Interferência de sistemas terrestres, que depende da escolha adequada do local de posicionamento da estação terrena e pela escolha de freqüências diferentes daquelas utilizadas pelos sistemas de comunicação terrestres.

- Interferência por polarização cruzada, que como já se disse no item 3.7 é devida ao uso de dupla polarização em ambientes chuvosos e que apresentam uma grande oscilação da ionosfera. Essa interferência pode ser analisada usando-se a calculadora de análise de polarização cruzada, que pode ser acessada pelo menu Analysis/Cross Polarization e que irá permitir a visualização do efeito de polarização cruzada sobre uma dada faixa de freqüências (figura 23).

- Interferência por intermodulaçao, que pode ser minimizada não só pelo uso adequado de nível de back-off, como também pela definição da quantidade de portadoras que podem compartilhar o mesmo canal;

- Interferência intersimbólica, que pode ser reduzida pela escolha adequada dos filtros e dos moduladores e demoduladores do sistema;

- Interferência por canal adjacente, que pode ser minimizada pelo ajuste correto dos níveis de back-off do sistema. Esta informação normalmente é fornecida pelo operador do satélite, e é dada para as condições de tempo ideal (atmosfera sem nuvens e chuva) e pela curva característica do transponder (figura 32);

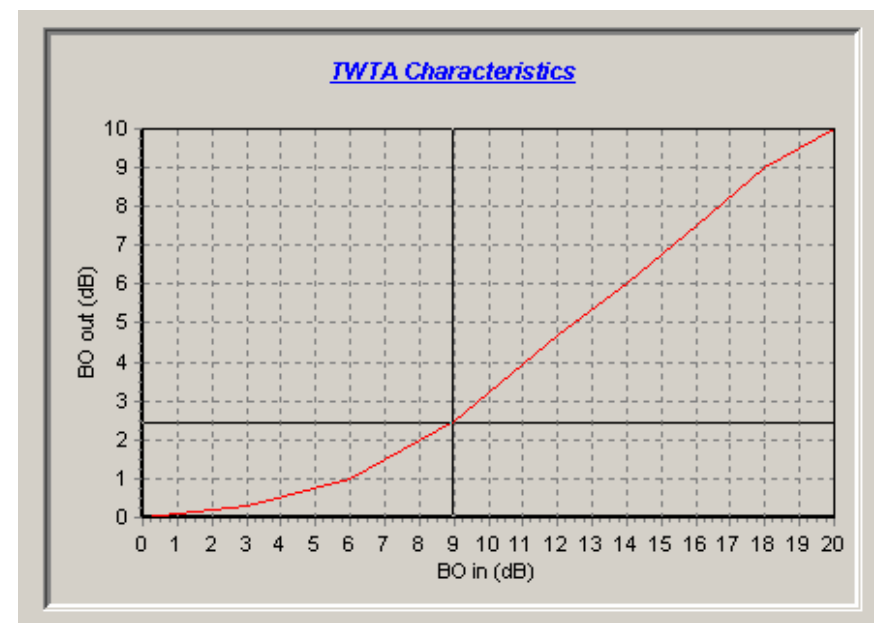

Figura 32: Curva característica do transponder.

- Atenuação atmosférica, que pela escolha adequada dos parâmetros ambientas que envolvem as estações permitem a minimização da mesma (figura 21); 
- Perdas de apontamento, que dependem das antenas e do sistema de rastreamento do satélite pelas mesmas.

O algoritmo desenvolvido para a implementação do projeto, que tem como objetivo calcular os ganhos das antenas da estação transmissora e receptora, é o seguinte:

- Dados Iniciais:

○ Dados do satélite:

- Posição: longitude do ponto subsatélite

- Sistema de recepção:

- Densidade de fluxo de potência de saturação;

- $G / T$

- Dados de back-off de saída, $B O_{O U T}$, em função do back-off de entrada, $B O_{I N}$ :

- Banco de dados para gráficos, tabelas e/ou equações

- Dados da antena de transmissão e de recepção:

○ Dimensões;

○ Tipo de polarização;

○ Polarização cruzada (tilt)

- Sistema de transmissão:

- EIRP na saturação

- Dados da Estação Terrena transmissora:

- Posição: latitude, longitude e altitude;

- $B O_{I N}$ sem chuva;

- Perdas na circuitaria;

- Dados da antena TX e RX

- Dimensões;

- Tipo de polarização;

- Polarização cruzada

- Dados da Estação Terrena receptora:

- Perdas na circuitaria

- Posição: latitude, longitude e altitude;

- Nesse projeto, pode-se dispensar este dado e fornecer como resultado um gráfico, tabela e figura de cobertura, em função da posição (latitude, longitude e altitude) na superfície terrestre.

- Dados de Interferência para o uplink e o downlink: 
- Pode ser dado um valor total;

○ Qualidade: $C / N$

Com os dados completos então se seguiu o seguinte procedimento de calculo:

Passo 1:

Determinação do $E I R P_{S A T} \operatorname{sem} B O_{I N}$

Determinação do $C / N$ (ruído térmico) total do uplink com chuva

Passo 2:

Determinação do $C / I$ total do uplink com chuva

Levar em consideração uma degradação devido à chuva no uplink que diminui a potência do sinal

Levar em consideração o $B O_{I N}$

Passo 3:

Determinação do $C / N$ total do enlace de uplink com chuva

Levando em consideração que a interferência é do tipo AWGN

Passo 4:

Determinação de $C / N$ total do sistema.

Levar em consideração a BER especificada e o tipo de sistema.

Levar em consideração a margem de ISI

Levar em consideração a vantagem por alguma técnica de correção e identificação de erros.

Passo 5:

Determinar $C / N$ total do downlink

Já levando em consideração as degradações devido à chuva e interferência.

Passo 6:

Encontrar o novo $B O_{I N}$

Levar em conta as perdas por chuva no uplink.

Com o novo $B O_{I N}$ encontrar o respectivo $B O_{O U T}$.

Passo 7:

Determinar $C / I$ do downlink sem chuva.

Levar em consideração a atenuação da parcela de $B O_{O U T}$ que degrada a saída.

Passo 8:

Determinar $C / N$ do downlink.

Passo 9: 
Determinar $G / T$ do sistema receptor da Estação Terrena.

A seguir, será apresentado um exemplo de um projeto via satélite em que se utilizará o Clarke para que se possa projetar o mesmo.

Deseja-se planejar um sistema de comunicação via satélite cujas informações disponíveis sobre o sistema são:

O enlace em questão é um enlace duplex, onde será aplicada uma modulação do tipo QPSK com taxa de transmissão de 60 Mbps com fator de rolloff de 0,2 e cuja banda a ser ocupada deverá ser de $36 \mathrm{MHz}$ (banda do transponder).

Os parâmetros que foram oferecidos pelo operador foram de que o satélite opera com um backoff de entrada ideal de $3 \mathrm{~dB}$ que corresponde a um backoff ideal de saída de 0,3 dB. Também foi fornecida, pelo operador do sistema, uma tabela da curva característica do transponder (tabela 3) que deverá ser utilizada durante a execução do projeto.

As perdas por apontamento que deverão ser consideradas são de $1,5 \mathrm{~dB}$ no enlace de subida e de 1,2 dB no enlace de descida. Determinou-se também que o sistema deverá operar com as seguintes características de interferência: $C / I$ para os sistemas adjacentes de $32 \mathrm{~dB}$ no uplink e o mesmo valor no downlink. Para os canais adjacentes os valores a serem observados serão de 29 db para o uplink e para o downlink, sendo que a margem de interferência intersimbólica da estação terrena deverá ser de $3 \mathrm{~dB}$.

Tabela 3: Característica do transponder do satélite.

\begin{tabular}{c|c}
\hline $\begin{array}{c}\text { Back-off } \\
\text { (entrada) }\end{array}$ & $\begin{array}{c}\text { Back-off } \\
\text { (saida) }\end{array}$ \\
\hline 0 & 0 \\
3 & 0,3 \\
6 & 1 \\
9 & 2,5 \\
12 & 4,7 \\
14 & 6 \\
16 & 7,5 \\
18 & 9 \\
20 & 10 \\
\hline
\end{tabular}

Para executar o projeto no Clarke, seguiu-se o seguinte procedimento:

- Inicia-se escolhendo as estações terrenas de transmissão e recepção, os locais onde serão implantadas (figura 33). Pode-se escolher entre duas estações já existentes ou então fornecer os dados sobre as novas estações; 


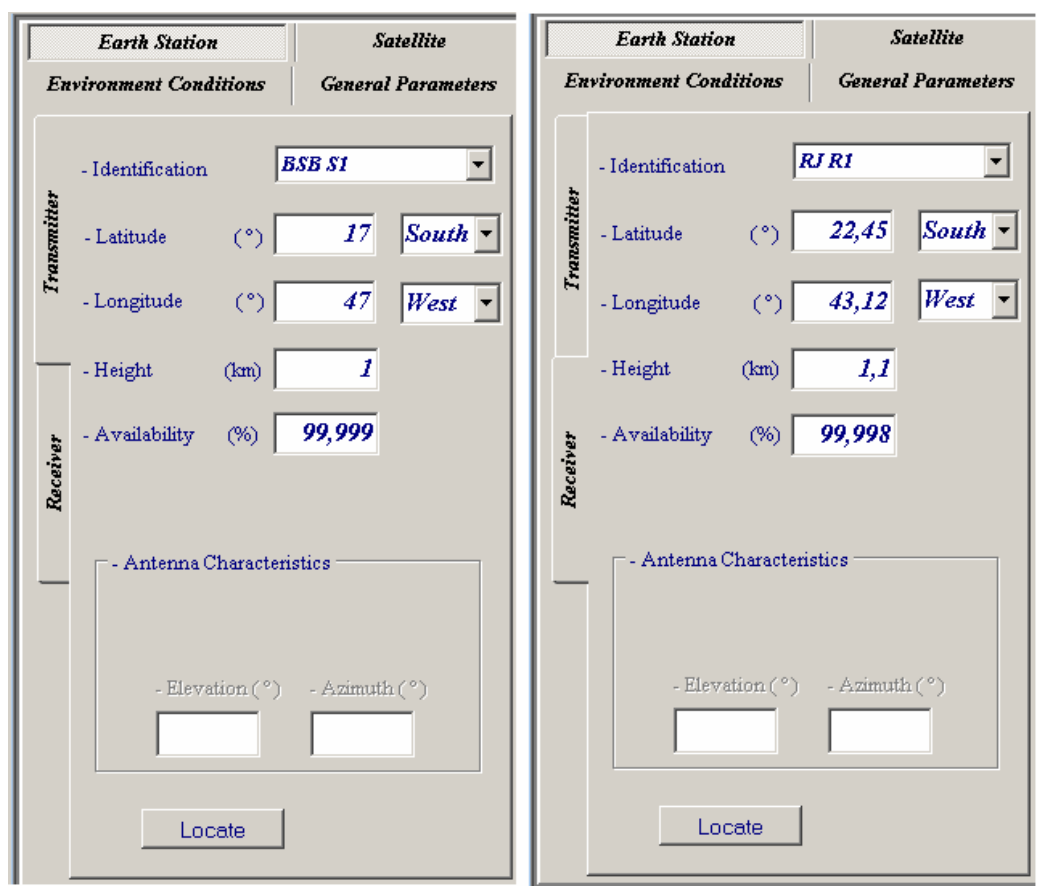

Figura 33: Entrada e/ou escolha de informações sobre as estações terrenas.

- Para que se estabeleça a comunicação entre as estações, escolhe-se ou informa-se, qual satélite será utilizado (figura 34).

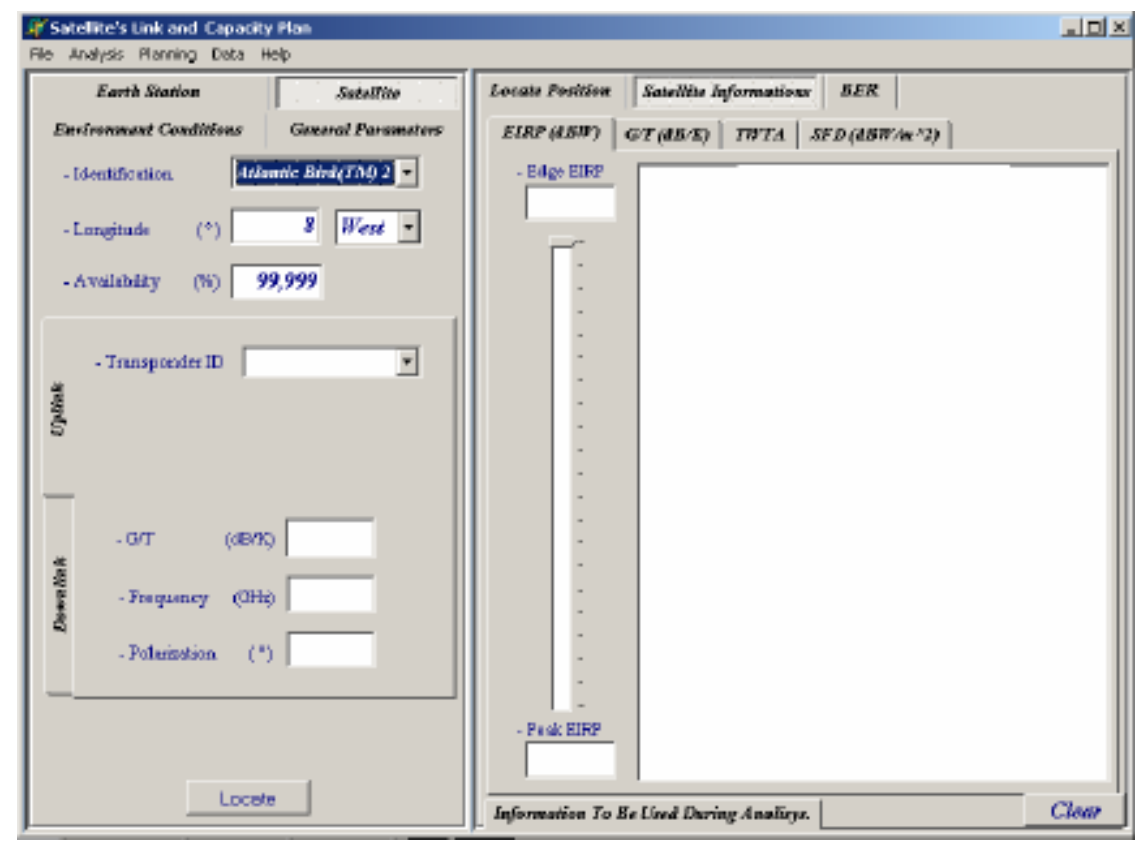

Figura 34: Escolha do satélite que será utilizado.

- Depois de fornecidos esses dados, podem-se obter os valores de elevação e azimute das antenas, e verificar se as estações se encontram dentro da região de cobertura do satélite. Para verificar se as estações estão dentro da área de visibilidade do satélite pressiona-se o botão locate, obtendo-se assim a área cobertura total do satélite, e as curvas onde a elevação das antenas é de 0,5 e 10 graus, respectivamente (figura 35); 


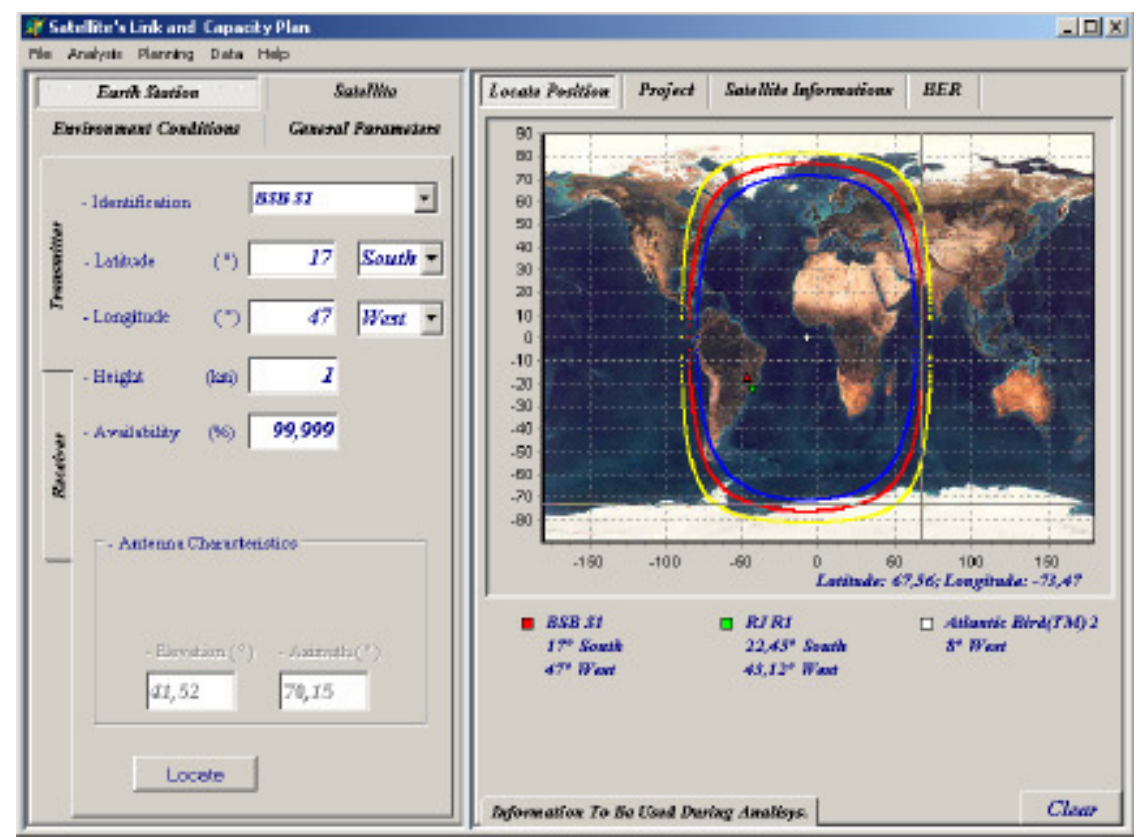

Figura 35: Localização das estações e do satélite. Verificação de visibilidade das estações. Determinação dos ângulos de elevação e azimute.

- Após se ter verificado que as estações se encontram dentro da região de visibilidade, escolhem-se os transponders que serão utilizados, e se fornecem as características de potência radiada, da figura de mérito, da densidade de fluxo de potência e da curva característica do TWTA, escolhendo-se também o ponto de back-off fornecido pelo operador (figura $36,37)$;

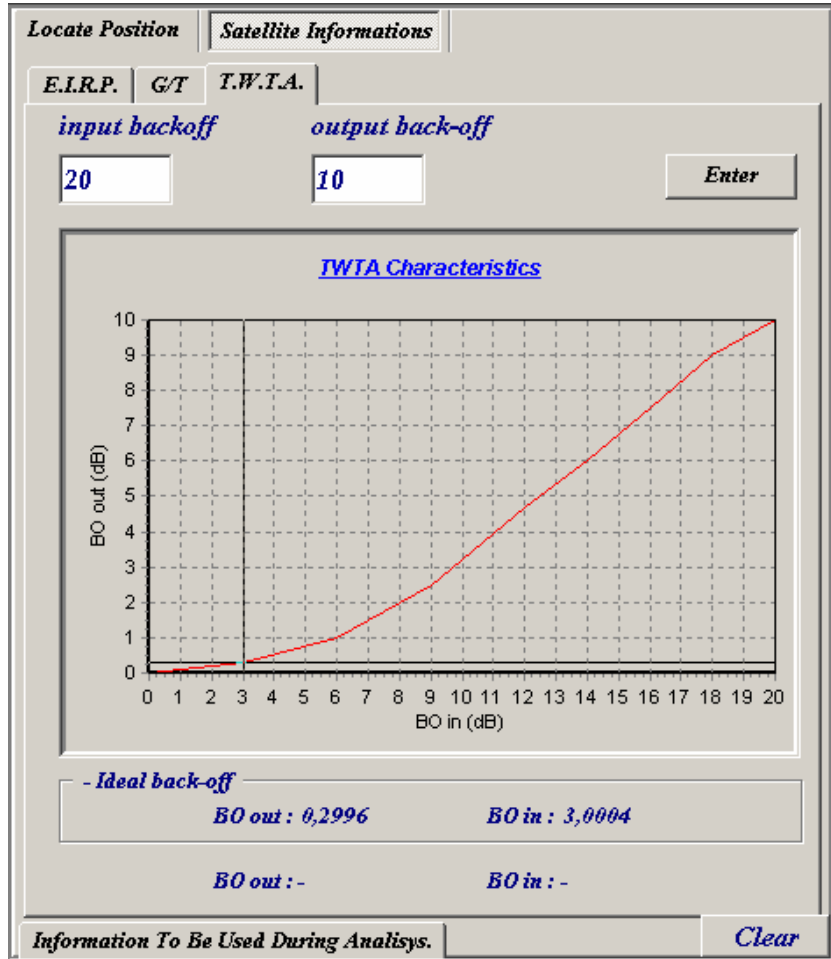

Figura 36: Curva de back-off e escolha do ponto ideal. 


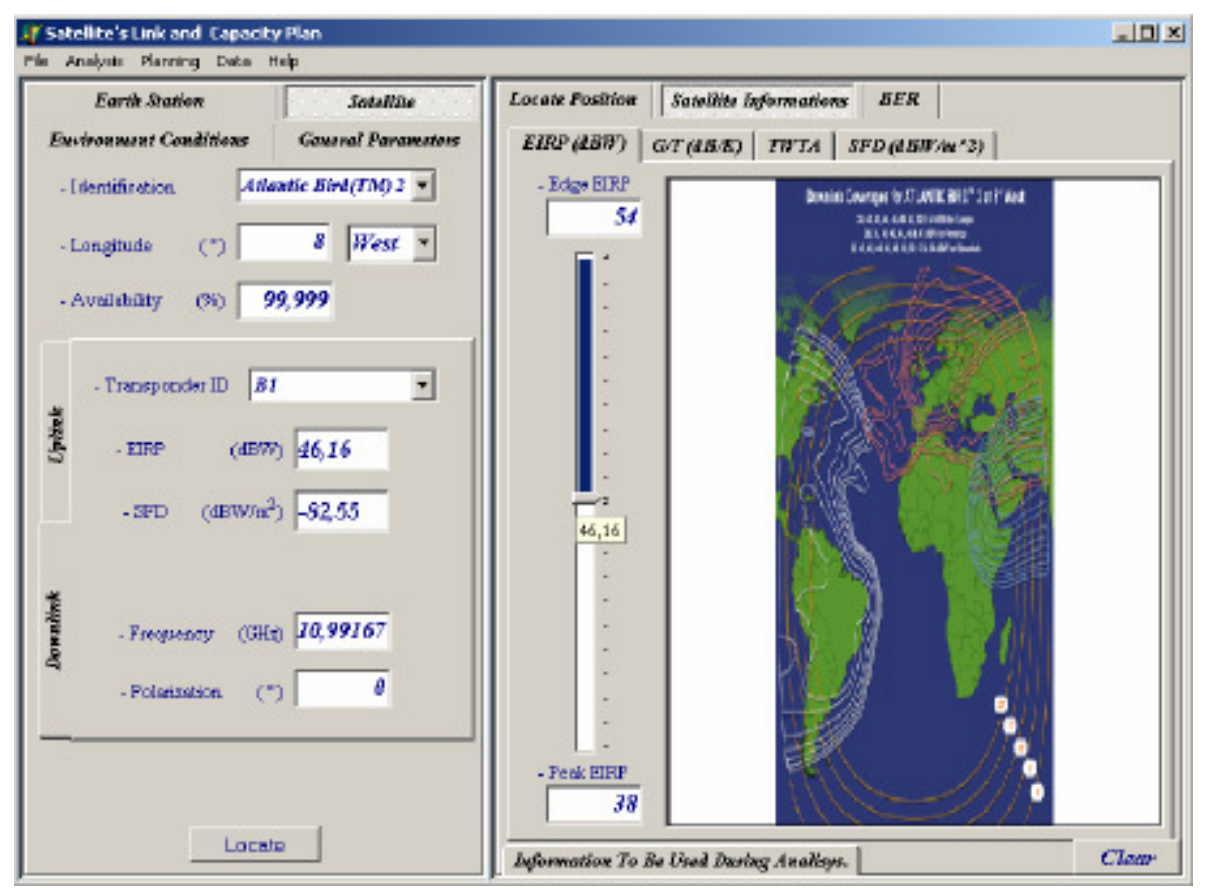

Figura 37: Escolha dos pontos de operação do transponder escolhido.

- Em seguida escolhe-se no menu em planning o tipo de projeto que se deseja realizar. O projeto existente permite que se analise o caso em que temos: chuva no enlace de subida, mas não no de descida e depois o processo inverso;

- Escolhido o tipo de projeto, em seguida se informam as condições ambientais em que as estações irão operar durante a maior parte do tempo. Observe que quando se definem as porcentagens, em que os fenômenos irão exceder um valor, à disponibilidade dos enlaces e do sistema é automaticamente determinada (figura 38);

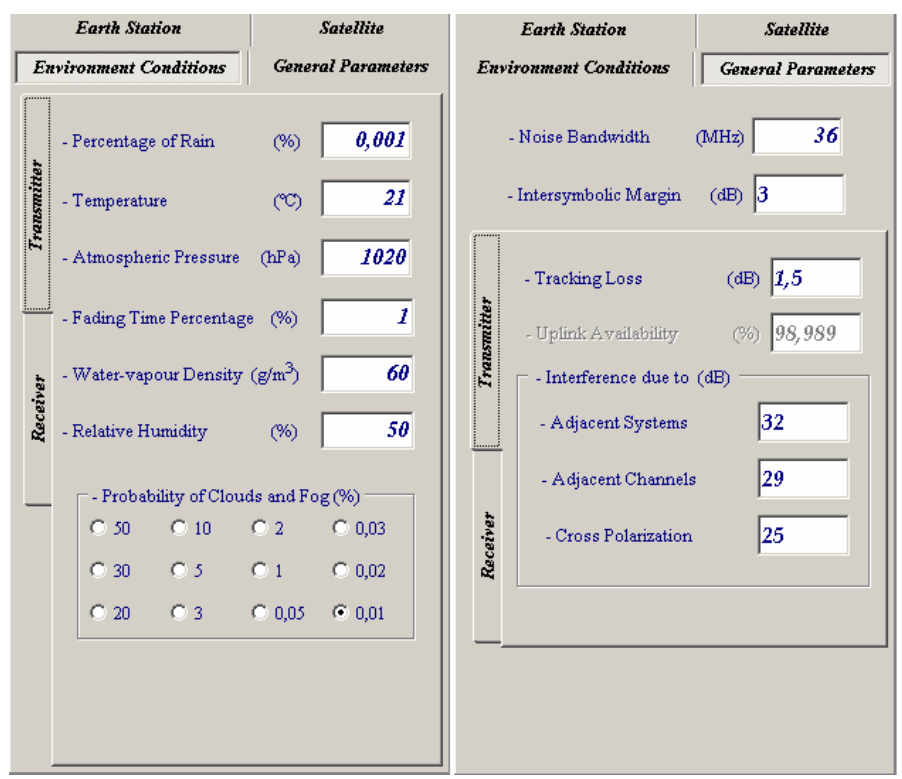

Figura 38: Escolha das porcentagens em que o fenômeno ira exceder um valor e calculo automático da disponibilidade dos enlaces de subida e descida. 
- Tendo-se as disponibilidades das estações, do satélite e dos enlaces, obtémse a disponibilidade total do sistema clicando na caixa de entrada de dados Availability. Antes de se pedir para o programa calcular os parâmetros que se desejam obter, há necessidade de informar o valor da razão portadora ruído total do sistema. Pode-se informar diretamente, ou então consultar as curvas de BER fornecidas (figura 39).

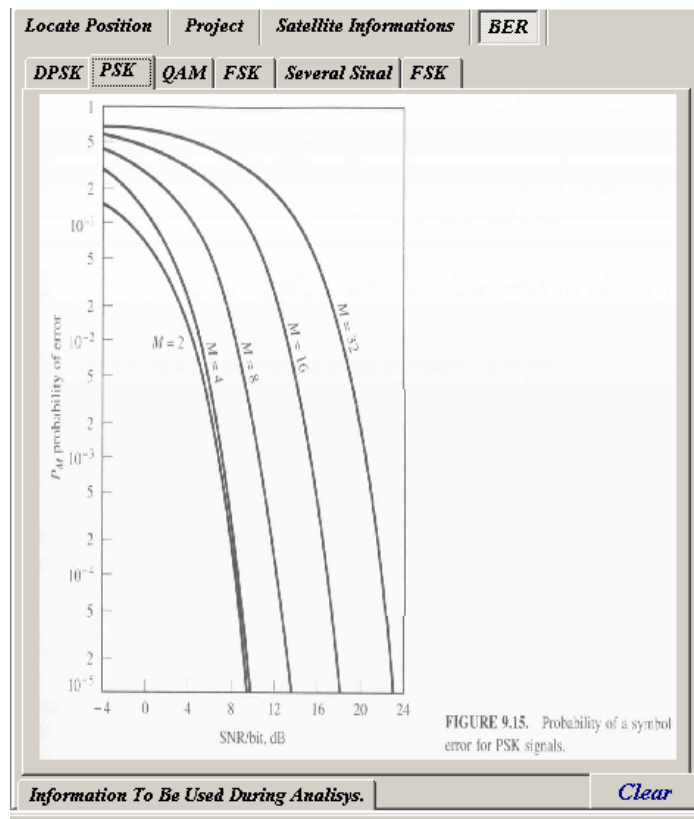

Figura 39: Curvas de BER fornecidas pelo programa para auxiliar na escolha da razão $C / N$ total do sistema.

- Depois de informado o valor da razão $\mathrm{C} / \mathrm{N}$ total do sistema, pode-se finalmente fazer o calculo dos parâmetros finais do enlace, que serão informados no relatório emitido durante o processo (figura 40);

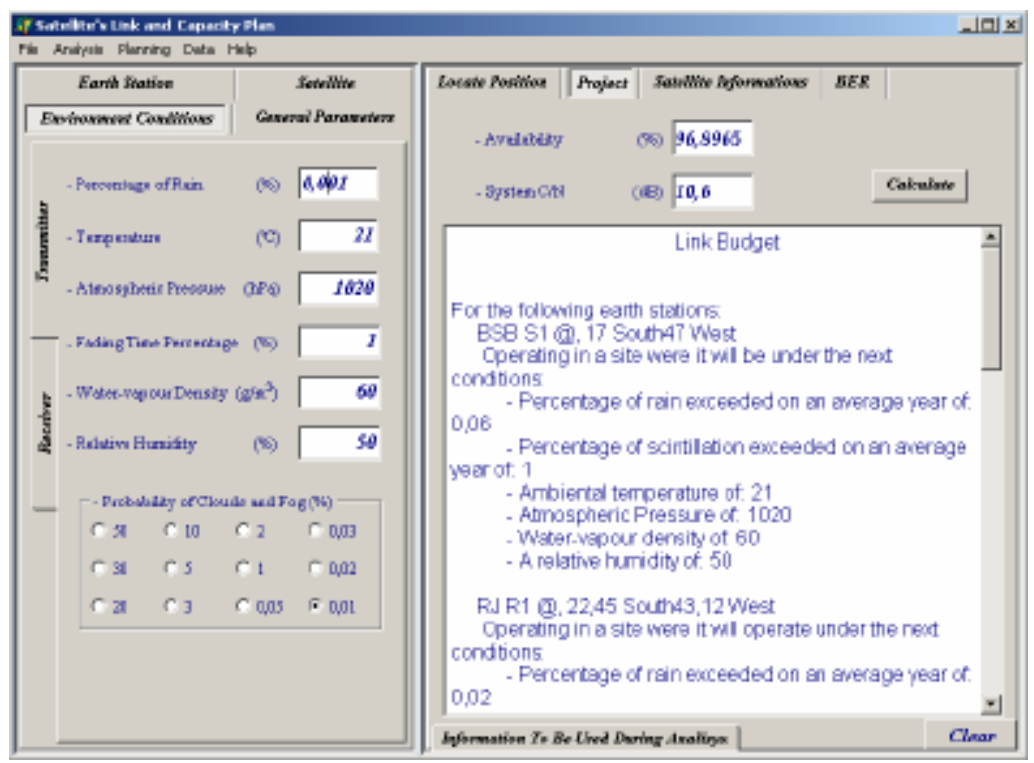

Figura 40: Etapa final do projeto em que é apresentado o relatório detalhado do que ocorreu durante o processo. 
O relatório que foi gerado para o projeto em questão é:

Link Budget

For the following earth stations:

BSB S1@, 17 South47 West

Operating in a site were it will be under the next conditions:

- Percentage of rain exceeded on an average year of: 0,02

- Percentage of scintillation exceeded on an average year of: 1

- Ambient temperature of: 21

- Atmospheric Pressure of: 1020

- Water-vapour density of: 60

- A relative humidity of: 50

RJ R1@, 22,45 South 43,12 West

Operating in a site were it will operate under the next conditions:

- Percentage of rain exceeded on an average year of: 0,1

- Percentage of scintillation exceeded on an average year of: 2

- Ambient temperature of: 33

- Atmospheric Pressure of: 1026

- Water-vapour density of: 75

- A relative humidity of: 80

Using the satellite:

Atlantic Bird(TM) $2 @, 8$ West

Witch will operate with, B1 transponder on the uplink, and with, B1 transponder on the downlink.

The referred transponders are operating with:

- G/T of: 3,1

- E.I.R.P. of: 46,2

- Flux density of: $-82,5$

- Uplink frequency of: 13,79167

- Uplink polarization of: 90

- Downlink frequency of: 10,99167 
- Downlink polarization of: 0

And obeying the following parameters:

- Noise bandwidth of: 36

- Intersimbolic margin of: 3

- $\mathrm{C} / \mathrm{N}$ total of: 8

With an uplink limited by:

- Tracking loss of: 1,5

- Interference due to adjacent systems of: 32

- Interference due to adjacent channels of: 29

- Cross polarization of: 25

With a downlink limited by:

- Tracking loss of: 1,2

- Interference due to adjacent systems of: 32

- Interference due to adjacent channels of: 29

- Cross polarization of: 25

Considering that we have rain in the uplink, then:

- EIRP of satellite saturation: 78,5051

- Attenuations due to:

- Rain, of: 12,5128

- Clouds, of: 0,2521

- Gases, of: 0,2556

- Scintillation, of: 0

- Total attenuation, of: 13,0205

- Uplink C/N of: 13,3505

- Uplink C/I of: 11,1899

- Uplink total C/N of: 9,1269

- New output back-off due to rain of: 7,1535

In a downlink withought rain, and considering the rain in the uplink, we will have:

- Downlink total C/N of:14,4102

- Downlink C/I of:20,0821

- Downlink C/N of:15,7824

- Attenuations due to: 
- Clouds, of: 0,1181

- Gases, of: 0,1537

- Scintillation, of: 0

- Total attenuation, of: 0,2718

Witch will result in a:

- G/T of:29,951

Now, considering that we do not have rain in the uplink, then:

- EIRP of satellite saturation: 78,5051

- Attenuations due to:

- Clouds, of: 0,2521

- Gases, of: 0,2556

- Scintillation, of: 0

- Total attenuation, of: 0,5077

- Uplink C/N of: 25,8633

- Uplink C/I of: 24,2105

- Uplink total C/N of: 21,9484

And we have rain in the downlink, then, we will have:

- Downlink total C/N of: 8,1786

- Downlink C/I of: 26,9372

- Downlink C/N of: 8,2368

- Attenuations due to:

- Rain, of: 2,5974

- Clouds, of: 0,1181

- Gases, of: 0,1537

- Scintillation, of: 0

- Total attenuation, of: 2,8692

Witch will result in a:

- G/(T + Delta T) of:18,1478

And in a:

- Reception effective temperature, of: 8,6864

- For a temperature variation due to rain in downlink, of: 122,8853

- Reception antenna gain of: 39,3394

- Transmition antenna gain of: 61,9347 


\subsection{CONCLUSÃO}

O objetivo geral deste trabalho foi à implementação de uma ferramenta CAD de auxílio a projetos, planejamento e otimização de enlaces de microondas via satélite usando-se como base de desenvolvimento as recomendações e normas da União Internacional de Telecomunicações - ITU e a partir daí estender para casos isolados e específicos que seriam as normas que cada país, região e operador de satélites utiliza para regulamentar e controlar o tráfico e o acesso aos satélites e no caso de falta de cobertura de um determinado ponto que se achasse necessário recorrer à vasta bibliografia que existe na área.

Os resultados que se obtiveram da implementação de tais normas são analisados de uma forma quantitativa pelo calculo da figura de ruído que se tem no final do enlace, ou seja, na estação terrena receptora, uma vez que é desta razão que se retiram os parâmetros finais da estação tais como tamanhos das antenas e os níveis de ruído que o sistema deverá ou poderá suportar e é ela quem permite o dimensionamento das antenas que serão utilizadas nas estações.

Para continuidade do trabalho sugere-se que se desenvolvam mais calculadoras que permitam encontrar o valor das diversas fontes de interferência que não foram analisadas e que como se sabe em algumas situações podem chegar a degradar o sistema bem mais do que as atenuações que o enlace sofre dos diferentes fatores ambientais que envolvem o ambiente de estudo. Há a necessidade de se implementar também um banco de dados que contenha informações sobre os diagramas de radiação, figura de ruído e densidade de fluxo de potência dos diversos satélites uma vez que o método atual de informação do valor sobre tais pontos pode ser eliminado, pois como já é informada a localização das estações é possível extrair tais valores do referido banco de dados. Faltou também à implementação das curvas que nos dão a razão sinal ruído em função de uma determinada taxa de bits e do processo de modulação empregue, sem esquecer das normas que existem sobre limites de radiação lateral que as antenas devem obedecer. Com isso espera-se obter um programa que permita auxiliar o processo de projeto de um enlace otimizando-se não só o tempo gasto em projeto como também o funcionamento das estações terrenas. 


\section{0 - REFERÊNCIAS BIBLIOGRAFICAS}

[1] Elbert, Bruce R., Introduction to Satellite Communication, Norwood, MA, Artech House, 1999, Second Edition.

[2] Pratt, Timothy, and Bostian, Charles W., Satellite Communications, New York, NY, John Wiley \& Sons, 1986.

[3] Carvalho, Paulo H., Sistemas de Comunicação Via Satélite, Apostila 02, Brasília, DF, Universidade de Brasília, 2001.

[4] S. Silver, Ed., Microwave Antenna Theory and Design, Vol. 12, MIT Radiation Lab Series, 1947.

[5] Krauss, H. L., Bostian, C. W., and Raab, F. H., Solid State Radio Engineering, John Wiley \& Sons, New York, 1981.

[6] ITU, Propagation data and prediction methods required for the design of Earthspace telecommunication systems, Recommendation ITU-R P.618-7, ITU-R, 2001.

[7] ITU, Attenuation by atmospheric gases, Recommendation ITU-R P.676-5, ITU-R, 2001.

[8] ITU, Attenuation Due to Clouds and Fog, Recommendation ITU-R P.840-3, ITU-R, 1999.

[9] ITU, The radio refractive index: its formula and refractivity data, Recommendation ITU-R P.453-8, ITU-R, 1999.

[10] Thomas, David T., Cross-Polarization Distortion in Microwave Radio Transmission Due to Rain, Radio Science, 6, 833-839 (Outubro 1971).

[11] Watson, P. A., and Arbabi, M., Rainfall Cross-Polarization at Microwave Frequencies, Proceedings of IEEE (London), 120, 413-418 (Abril 1973).

[12] http://home.domaindlx.com/cyberboot/astrosofia/satelite/artificial/index.html. 